\title{
WestVirginiaUniversity
}

THE RESEARCH REPOSITORY @ WVU

Graduate Theses, Dissertations, and Problem Reports

2019

\section{Three Essays on Urban Consumer Service Firms: Evidence from Yelp}

Josh Matti

West Virginia University, jomatti@mix.wvu.edu

Follow this and additional works at: https://researchrepository.wvu.edu/etd

Part of the Economics Commons

\section{Recommended Citation}

Matti, Josh, "Three Essays on Urban Consumer Service Firms: Evidence from Yelp" (2019). Graduate Theses, Dissertations, and Problem Reports. 3887.

https://researchrepository.wvu.edu/etd/3887

This Dissertation is protected by copyright and/or related rights. It has been brought to you by the The Research Repository @ WVU with permission from the rights-holder(s). You are free to use this Dissertation in any way that is permitted by the copyright and related rights legislation that applies to your use. For other uses you must obtain permission from the rights-holder(s) directly, unless additional rights are indicated by a Creative Commons license in the record and/ or on the work itself. This Dissertation has been accepted for inclusion in WVU Graduate Theses, Dissertations, and Problem Reports collection by an authorized administrator of The Research Repository @ WVU.

For more information, please contact researchrepository@mail.wvu.edu. 


\title{
Three Essays on Urban Consumer Service Firms: Evidence from Yelp
}

\author{
Joshua Christopher Matti \\ Dissertation submitted to the \\ Chambers College of Business and Economics \\ at West Virginia University \\ in partial fulfillment of the requirements \\ for the degree of \\ Doctor of Philosophy \\ in \\ Economics \\ Joshua Hall, Ph.D., Chair \\ Brad Humphreys, Ph.D. \\ Jane Ruseski, Ph.D. \\ Jack Dorminey, Ph.D. \\ Department of Economics \\ Morgantown, West Virginia \\ 2019
}

Keywords: spatial competition, consumer services, emotional cues, localization, Yelp

Copyright 2019 Joshua Christopher Matti 


\begin{abstract}
Three Essays on Urban Consumer Service Firms: Evidence from Yelp

Joshua Christopher Matti
\end{abstract}

This dissertation explores questions related to consumer services using Yelp data from the Phoenix area. Chapter 1 explores competition. Competition is a key feature of the market process assumed to improve market outcomes. But how strong is the relationship between competition and positive consumer experiences, and how does the relationship vary across space? This chapter explores these questions by exploiting Yelp data from thousands of restaurants in the Phoenix area. After controlling for restaurant characteristics, census tract level demographics, census tract fixed effects, and sub-industry fixed effects, the results are consistent with spatial competition positively affecting consumer experiences. Chapter 2 considers where these consumer service firms are located. The chapter analyzes the spatial concentration of a variety of consumer services firms in the Phoenix, AZ area using georeferenced Yelp data from over 29,000 establishments. Results from a K-density approach indicate substantial localization and service differentiation among localized firms. Firm concentration varies across service cost and quality; higher quality/cost establishments tend to cluster. Chapter 3 explores the influence of emotional cues on consumer behavior. Using nearly 1 million Yelp reviews from the Phoenix area, I empirically test for the presence of loss aversion and reference-dependent preferences in reviewer behavior. Consistent with loss aversion, unexpected losses lead to worse reviews while there is no effect for unexpected wins. The results also reflect reference-dependent preferences since wins and losses in games predicted to be close do not impact reviewer behavior. 


\section{Acknowledgements}

I would like to thank the people who have been influential in my development as a scholar over the years. To my advisor, Dr. Joshua Hall, thank you for the tremendous support during my time at West Virginia University. Thank you for your mentorship in learning about the economics profession, your teaching advice, and your wisdom in navigating the job market process. Your guidance has allowed me to steadily progress through the PhD program and given me confidence as I take the next steps in my career.

To my undergraduate advisor, Dr. Tom Lehman, thank you for providing me with a solid understanding of economics. The many writing and research opportunities I had while at Indiana Wesleyan University were excellent preparation for completing a $\mathrm{PhD}$ program. Your passion for economics was contagious; I hope to have the same influence on my students.

I am also grateful to those serving on my dissertation committee. To Dr. Brad Humphreys, thank you for the excellent exposure you have given me to research in urban and sports economics. I have benefitted greatly from your knowledge in these areas. To Dr. Jane Ruseski, thank you for advice on being in academia, with helpful insights on everything from serving as a discussant to managing time wisely. I am also thankful for the detailed care you have in providing feedback on papers. To Dr. Jack Dorminey, thank you for providing feedback during the proposal and defense process that ensured a broad readability of the dissertation.

To my peers joining me on this journey, thank you for making it fun. To Amir, Patrick, and Chris, thank you for providing advice and encouragement as those further along in the program. To Paul, Perry, and Yang, thank you for all the comradery, both in classes and research.

Finally, I am thankful for the emotional support of loved ones, including my parents, David and Sharon, my siblings, Laura and Michael, and my fiancé, Elise. 


\section{Contents}

Acknowledgements $\quad$ iii

List of Figures $\quad$ vi

List of Tables $\quad$ vii

1 Reaching for the Stars: Competition and Consumer Reviews 1

1.1 Introduction . . . . . . . . . . . . . . . . . . 1

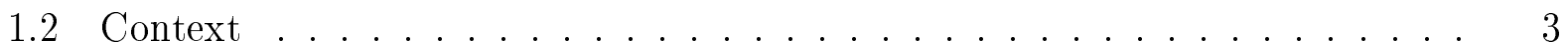

1.3 Data . . . . . . . . . . . . . . . . . . . 4

1.4 Empirical Approach . . . . . . . . . . . . . . . . . . . 8

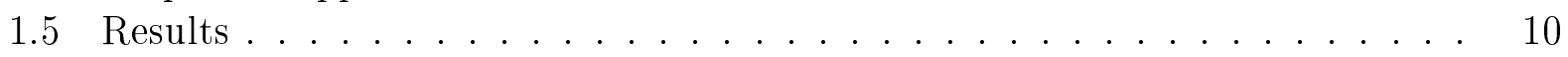

1.5.1 Competition Within 5 Miles . . . . . . . . . . . . . 10

1.5.2 Competition Within Walking and Driving Distance ........ 11

1.6 Conclusion and Future Research . . . . . . . . . . . . . . . . . . 12

2 The Spatial Distribution of Urban Consumer Service Firms: Evidence from Yelp Reviews $\quad 24$

2.1 Introduction . . . . . . . . . . . . . . . . . . . 24

2.2 Context: Theory and Evidence on Clustering . . . . . . . . . . . . 26

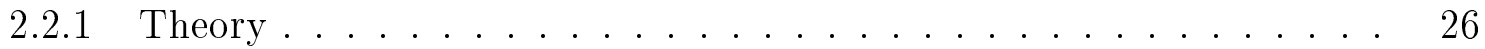

2.2 .2 Empirical Evidence . . . . . . . . . . . . . . . 29

2.3 Data . . . . . . . . . . . . . . . . . . . . . 31

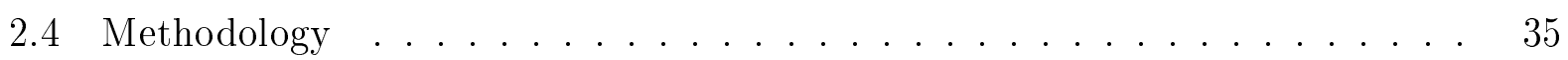

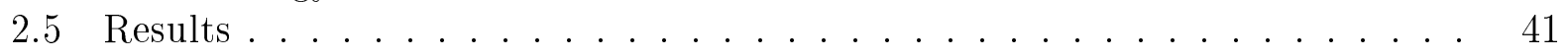

2.5.1 Results by Establishment Category . . . . . . . . . . . . 43

2.5.2 Results by Cost and Quality . . . . . . . . . . . . . 49

2.6 Conclusions . . . . . . . . . . . . . . . . . . . 53

3 Frustrated Customers: The Effect of Unexpected Emotional Cues on Yelp Reviews

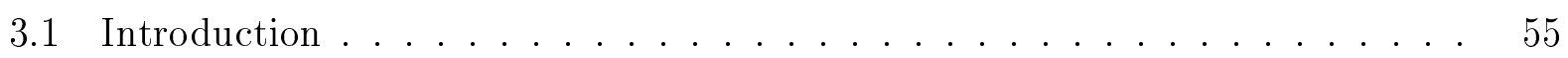

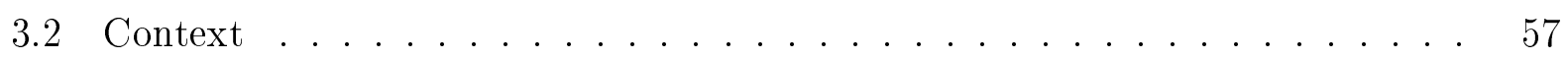

3.3 Data . . . . . . . . . . . . . . . . . . 60

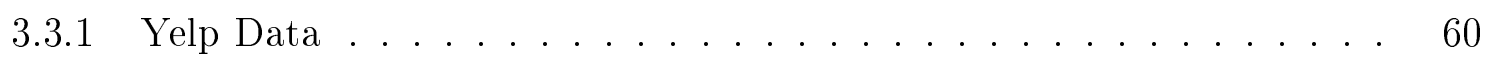


3.3 .2 Sports Data . . . . . . . . . . . . . 63

3.4 Empirical Approach . . . . . . . . . . . . . . . . . . . 64

3.5 Results . . . . . . . . . . . . . . . . . 67

3.5.1 Loss Aversion . . . . . . . . . . . . . . . . 67

3.5.2 Reference-Dependent Preferences . . . . . . . . . . . . 68

3.5.3 Robustness Check - Random Timing . . . . . . . . . . . . . 69

3.5.4 Robustness Check - Beauty \& Spas and Sports Bars . . . . . . . . . 70

3.5.5 Robustness Check - Alternative Explanations . . . . . . . . . . 72

3.6 Conclusion . . . . . . . . . . . . . . . . . . 73 


\section{List of Figures}

1.1 Standard Yelp Search . . . . . . . . . . . . . . . . . . 14

1.2 Restaurant Locations . . . . . . . . . . . . . . . . . . . . 15

1.3 Number of Categories per Restaurant . . . . . . . . . . . . . . . 16

2.1 Spatial Distribution of Consumer Services Establishments in Phoenix . . . . 33

2.2 Price (Dollar Sign) Distributions by Primary Category . . . . . . . . . . . 37

2.3 Establishment Quality (Star) Distributions by Primary Category . . . . . . . 38

2.4 K-densities for Four Illustrative Categories . . . . . . . . . . . . . . . . 42

2.5 Localization and Dispersion . . . . . . . . . . . . . . 43

2.6 Share of Localized and Dispersed Categories . . . . . . . . . . . . . 44

3.1 Spatial Distribution of Consumer Services Establishments in Phoenix . . . 83

3.2 Reviews by Day . . . . . . . . . . . . . . . . . . 84

3.3 Point Spreads vs. Realized Point Differences . . . . . . . . . . . . . . . 84

3.4 NBA Fan Bases Across the United States . . . . . . . . . . . . . . . . . . 85

3.5 Differences in Means . . . . . . . . . . . . . . . . . 85 


\section{List of Tables}

1.1 Ten Most Common Restaurant Categories . . . . . . . . . . . . . . 17

1.2 Descriptive Statistics for Chain Restaurants . . . . . . . . . . . . . . . . 18

1.3 Descriptive Statistics for Independent Restaurants . . . . . . . . . . . . . . 19

1.4 Estimated Effect of Competition on Chain Restaurants . . . . . . . . . . . 20

1.5 Estimated Effect of Competition on Independent Restaurants . . . . . . . . 21

1.6 Estimated Effects of Competition on Chain Restaurants - Driving vs. Walking 22

1.7 Estimated Effect of Competition on Independent Restaurants - Driving vs.

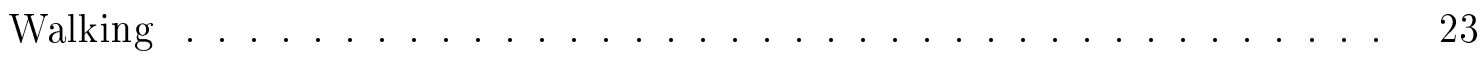

2.1 Yelp Consumer Service Categories . . . . . . . . . . . . . . . . . . 36

2.2 Most Highly Localized Subcategories . . . . . . . . . . . . . . . 46

2.3 Most Highly Dispersed Subcategories . . . . . . . . . . . . . . . . 48

2.4 Location Patterns by Category and Cost . . . . . . . . . . . . . . . . 50

2.5 Location Patterns by Subcategory and Cost . . . . . . . . . . . . . 51

2.6 Location Patterns by Quality Rating . . . . . . . . . . . . . . 52

3.1 Yelp Consumer Service Categories . . . . . . . . . . . . . . . 76

3.2 Descriptive Statistics for Reviews . . . . . . . . . . . . . . 77

3.3 Descriptive Statistics for Suns Games . . . . . . . . . . . . . . . 77

3.4 Effects of Unexpected Wins and Losses on Reviews . . . . . . . . . . . 78

3.5 Effects of Unexpected Wins and Losses on Reviews (Logit Model) . . . . . . 79

3.6 The Effects of Wins and Losses on Reviews in Games Expected to be Close 80

3.7 Robustness Check - Random Timing . . . . . . . . . . . . . . . . 81

3.8 Robustness Check - Beauty \& Spas and Sports Bars . . . . . . . . . . . 82 


\section{Chapter 1}

\section{Reaching for the Stars: Competition and Consumer Reviews}

\subsection{Introduction}

Competition is a central aspect of the market process. Competition between firms is assumed to be a disciplining force causing firms to better serve their customers. But to what extent is competition associated with better experiences for consumers and how does the effect vary across space? Relatively little empirical work outside of health markets ${ }^{1}$ has explored the effect of spatial competition on the consumer experience.

Recent empirical papers focused on spatial competition include Liao and Chuang (2004), Matsa (2011), Gravelle et al. (2016), and Pennerstorfer (2017). Closest to this study, Liao and Chuang (2004) find that across 25 chain restaurants in the Midwest, greater local competition is associated with higher service quality and customer satisfaction. In the supermarket industry, Matsa (2011) finds that store quality, as proxied by low levels of inventory shortfalls, increases with greater local competition. More recently, building upon the price and quality spatial competition model of Brekke et al. (2010), Gravelle et al. (2016) and Pennerstorfer (2017) empirically explore the simultaneous effect of spatial competition on prices and quality. Gravelle et al. (2016) finds that among general practitioners in Australia, having more distant competitors is associated with higher prices and lower quality, as proxied

\footnotetext{
${ }^{1}$ See Gaynor and Town (2011) for a thorough review of the health industry competition literature.
} 
by consultation duration. Exploiting a unique data set on Austrian camp sites, Pennerstorfer (2017) establishes a positive impact of spatial competition on camp site quality and a negative impact on price (conditional on quality).

This paper adds to the small but growing literature in two key ways. First, it uses online review data from Yelp instead of proxies for quality. Reviews convey customers' overall satisfaction while proxies for quality are merely correlated with the outcome variables of interest. Liao and Chuang (2004) use survey review data; however, they are limited to 25 chain restaurants while the Yelp data exploited in this paper contains thousands of restaurants of different types. While Gravelle et al. (2016) and Pennerstorfer (2017) examine the effect of spatial competition on prices and quality, with Yelp review data this paper examines whether competition is associated with businesses finding the combination of prices and quality most satisfying to their customers. Thus, this paper establishes the relationship between spatial competition and the overall consumer experience, which is ultimately most important to consumers. The second contribution comes from studying different sub-groups of the restaurant industry. Previous research examines the effect of spatial competition in a single industry. By exploiting information on types and prices of restaurants, this paper establishes the spatial competition effects for sub-industries, where competition is likely more fierce.

This paper contributes to the literature by exploiting Yelp data from 6482 restaurants in the greater Phoenix area. With geo-referenced microdata, the number of competitors within five miles is calculated. Using the Yelp data, competition is defined by overall, sameprice, and same-type restaurants nearby. Given differences between chain and independent restaurants, competition is further segmented across these two types of establishments. After controlling for restaurant characteristics, census tract level demographics, census tract fixed effects, and sub-industry fixed effects, the results suggest that spatial competition is associated with better customer experiences for independent restaurants. However, the associated is not present for overall and same-price independent restaurant competition nor for chain restaurants.

To explore spatial heterogeneity in the relationship, I calculate competition for walking distance (0-1mi) and driving distance (1-5mi). For chain restaurants, regardless of the dis- 
tance, there is no relationship between competition and ratings. For independent restaurants, only same-category competition between 1-5mi is associated with higher ratings. These results are relevant for cities designing policies to attract residents by offering high-quality consumer amenities. The different relationship between competition and ratings for chain and independent restaurants is also relevant for considering how managerial incentives relate to competition and restaurant performance.

\subsection{Context}

Several spatial competition models following Salop (1979) explore the effects of competition on price and quality. ${ }^{2}$ Although both Economides (1993) and Gravelle (1999) predict that competition reduces prices, they find different effects with quality. Economides (1993) finds that competition reduces quality while Gravelle (1999) finds no effect. In a more general model, Brekke et al. (2010) do not unambiguously determine the effects of competition on price and quality. However, they are able to classify conditions under which competition decreases price and increases quality, noting that the scope for a positive impact on quality is larger than in previous models. Most recently, Pennerstorfer (2017) develops a model where the effect of competition on quality is dependent upon cost substitutability between output and quality.

Overall, the theoretical literature modeling the effects of competition on prices and quality finds that competition decreases prices while the effect on quality is less clear. This paper relates to the theoretical literature by empirically testing whether the overall effect of competition is associated with better consumer experiences.

Much of the previous empirical research exploring the effect of competition on consumer experiences has focused on industries with limited competition and substantial regulation. For example, Mazzeo (2003) studies the airline industry and finds that after controlling for weather and congestion, a flight operating on a monopoly route arrives 1.35 minutes later than a flight on a competitive route. In their survey of competition in health care markets, Gaynor and Town (2011) document that in markets where price is fixed, such as Medicare,

\footnotetext{
${ }^{2}$ For a recent review of the literature see Biscaia and Mota (2013).
} 
competition always increases quality. However, in markets where price is not fixed, the results are mixed. In contrast to the majority of previous studies, this article examines the highly competitive restaurant industry.

In a comprehensive study of restaurant failure, Parsa et al. (2005) find that over onequarter of restaurants fail in their first year and over one-half fail within three years. They identify poor location choice and negative consumer perception of value as primary elements of failure. Recent empirical work supports the finding that consumer perception of value has a substantial impact on the success or failure of restaurants.

Luca (2016) and Anderson and Magruder (2012) both implement a regression discontinuity (RD) design to establish causal effects of Yelp reviews on restaurant outcomes. Since Yelp aggregates reviews for a business and rounds to the nearest half star, an RD design is appropriate for comparing restaurants slightly below and above the rounding threshold. Luca (2016) shows that a one star increase causes a 9\% increase in revenue. Anderson and Magruder (2012) use restaurant reservation data and find that a half star increase causes a restaurant to sell out $49 \%$ more often.

Within the competitive restaurant industry, small differences in consumer satisfaction can have considerable effects on restaurant outcomes. Given the impact of Yelp reviews on restaurant performance, increased spatial competition is likely to be associated with higher Yelp reviews as lower-rated restaurants either improve their customers' experiences or are driven out of the market by higher-rated restaurants.

\subsection{Data}

Yelp is an online review multinational corporation founded in 2004 that has over 100 million unique monthly visitors. ${ }^{3}$ Rather than paid expert reviews, Yelp provides a platform for user generated reviews. Although a variety of businesses ranging from auto mechanics to yoga studios have Yelp reviews, restaurants are the most common. Figure 1.1 displays a standard Yelp search for restaurants in the Phoenix area. The search function allows for filtering by several variables including price, distance, and category of restaurant. Table 1.1

\footnotetext{
${ }^{3}$ This amount is from March 15 to April 13, 2017 on quantcast.com.
} 
lists the ten most common categories for Yelp restaurants in the Phoenix area. In total there are 102 unique categories of restaurants in the Phoenix area. In addition to being distributed across different categories, Yelp restaurants are also distributed across space. Figure 1.2 displays the location of Yelp restaurants, with the greatest concentration of restaurants around the Phoenix city center and other city centers such as Glendale, Scottsdale, and Tempe.

In addition to the Yelp data, which was obtained via the Yelp dataset challenge, I also collected demographic data at the census tract level from the 2015 American Community Survey 5-year estimates. Table 1.2 displays chain restaurant descriptive statistics for the demographic variables and the essential restaurant variables of stars, review count, price, and the different classifications for number of competitors. ${ }^{4}$ On average each chain restaurant has roughly 36 other restaurants within a mile and nearly 429 between one and five miles.

Table 1.3 displays the same information but for independent restaurants. On average each independent restaurant has roughly 43 other restaurants within a mile and nearly 496 between one and five miles. Additionally, the average number of stars for independent restaurants is roughly 3.7 while chain restaurants have an average star rating around 3 .

Although having thousands of establishments with precise latitude and longitude information means a considerably larger sample than previous spatial competition studies in the literature such as Liao and Chuang (2004), there are potential concerns with using Yelp review data. Luca (2015) frames potential issues by comparison to traditional surveys such as the Census and National Longitudinal Survey of Youth. While traditional surveys contain national, representative sampling, Yelp users voluntarily provide reviews and no effort is made to create a representative sample of the population.

Given the unique way Yelp generates reviews, self-selection is a reasonable concern. For example, reviews would exhibit a U-shaped distribution if only the most extreme experiences elicit a review. Diners with extreme negative experiences, such as finding glass in their food, or extreme positive experiences, such as finding a new favorite restaurant, may be more

\footnotetext{
${ }^{4}$ Census tracts are small geographic areas designed by the Census to generally contain around 4000 inhabitants. The minimum population of zero comes from one census tract, the tract located in the Phoenix airport.
} 
likely to leave a review than a moderately satisfied diner. Evidence for self-selection with Amazon reviews is documented by $\mathrm{Hu}$ et al. (2009), who find a J-shaped distribution for product reviews. However, Dai et al. (2018) document that Yelp reviews are unimodal and not J-shaped.

One explanation for why Yelp is not biased by extreme reviews is its incentive system for reviewers. Yelp awards a variety of online badges to reviewers and welcomes the highest quality reviewers into its "Elite Squad". Additionally, individual reviews can by rated as "cool", "funny", or "useful" by other Yelp users. Since behavioral incentive schemes such as badges influence people's participation in providing user generated content (Anderson et al., 2013), Yelp is able to effectively incentivize moderately satisfied diners to leave a review.

A second concern with using Yelp review data is fraud. As shown by Luca (2016) and Anderson and Magruder (2012), small differences in a restaurant's rating substantially affects restaurant outcomes. Thus, restaurant owners have an incentive to create favorable fake reviews. Ott et al. (2012) generate fake reviews and then use a computer learning approach to classify roughly $4 \%$ of Yelp reviews as fake. However, both Luca (2016) and Anderson and Magruder (2012) find no evidence of fake reviews, even in cases where a fraudulent review would generate the highest benefit by boosting a restaurant over a half-star threshold.

One explanation for the lack of fake published Yelp reviews is that Yelp has an incentive to combat fraud as Yelp's popularity is based upon the reliability of its reviews. As described in Luca and Zervas (2016), Yelp flags roughly 16\% of reviews as suspicious and drops them from businesses' official Yelp ratings. Additionally, Yelp periodically engages in sting operations by prominently displaying a banner to warn potential consumers on the Yelp pages of businesses with known fake reviews.

A third concern is data coverage. If the restaurants in the data set comprise only a small percentage of all restaurants in Phoenix, then the estimates of the effect of competition on ratings could be biased by excluding the competitive effects of non-Yelp restaurants. However, compared to other user generated online review sites such as Zomato and expert review sites such as Zagat, Yelp has considerably more restaurants reviewed. For example, roughly $5 \%$ of the sample of Los Angeles restaurants used in Jin and Leslie (2009) have a Zagat rating. 
In urban areas Yelp actually contains more restaurants than traditional reports, such as the County Business Patterns (CBP), since Yelp contains smaller establishments not included by the Census Bureau (Glaeser et al., 2017). Based upon the data from the Yelp dataset challenge, a restaurant in the Phoenix area is very likely to have a Yelp rating. Across zip codes in the Yelp dataset containing at least 1 Yelp rated restaurant establishment, the CBP reports 5746 establishments across the NAICS codes of 'Mobile Food Services', 'Full-Service Restaurants', 'Limited-Service Restaurants', and 'Cafeterias, Grill Buffets, and Buffets'. The Yelp data contain over 6000 restaurant establishments. Consistent with Glaeser et al. (2017), the Yelp data in the Phoenix area actually have better coverage of restaurants than the CBP.

A final data concern is what information Yelp reviews convey. Unlike with food experts' reviews in Michelin Guides, where a rating is given specifically for quality, the Yelp rating system is unidimensional. Using both unidimensional and multidimensional reviews data from the same digital cameras, Li and Hitt (2010) demonstrate that unidimensional reviews reflect value. Rather than a measure of quality, unidimensional ratings reflect customer satisfaction. In the context of online restaurant reviews, Pantelidis (2010) finds that food, service, and atmosphere are the largest factors shaping customer satisfaction. In this paper, Yelp ratings are treated as reflecting customer satisfaction. Yelp reviews reflect the overall consumer experience, from the taste of the food to the attractiveness of the atmosphere.

Although Yelp data provide a unique opportunity for studying the effects of spatial competition across thousands of businesses, there are reasonable concerns with the data. However, as discussed in detail above, the data in this paper hold up well to the potential problems. Ultimately, what matters is that online Yelp reviews accurately reflect customer satisfaction. Although not specific to Yelp, Gao et al. (2015) assess whether online ratings accurately reflect population perceptions of quality. They find a strong positive relationship between online ratings for physician quality and standard offline ratings drawn from a representative sample of patients. 


\subsection{Empirical Approach}

Using the Yelp and demographic data, I evaluate the effect of spatial competition by estimating an equation of the following form: ${ }^{5}$

$$
\text { stars }_{i c t}=\alpha+\beta \text { competitor }_{i c}+\delta \text { characteristics }{ }_{i c}+\gamma \text { control }_{t}+\mu_{t}+\sigma_{c}+\varepsilon_{i c t}
$$

where star $_{i c t}$ is the number of stars between one and five for restaurant $i$ in category of restaurant $c$ within census tract $t$ while characteristics $_{i c}$ accounts for restaurant-level variables likely related to ratings. Since the location choice of restaurants is not exogenous, controls $s_{t}$ contains tract level demographic variables to control for factors that could influence different rated restaurants to locate in different areas. Additionally, the census tract fixed effect $\mu_{t}$ captures other unobserved variables across locations related to both the number and ratings of restaurants. The category fixed effect $\sigma_{c}$ controls for unobserved differences in ratings across different types of restaurants. Lastly, competitor $s_{i c}$ contains the competition variables.

Since not only location but also type and price of restaurant are primary variables influencing consumers' restaurant choice (Auty, 1992), the competition variables account for category and price of restaurant. For example, with pure category competition, the competition variable is the sum of restaurants of the same categories within five miles. ${ }^{6}$ As shown in Figure 1.3, restaurants often have more than one Yelp category. For example, McDonald's is within both "Fast Food" and "Burgers". ${ }^{7}$ Thus, McDonald's competitors include the sum of nearby "Burgers" and "Fast Food" restaurants. ${ }^{8}$

With competition along price dimensions, I utilize the Yelp $\$, \$ \$, \$ \$$, and $\$ \$ \$ \$$ classification. ${ }^{9}$ Among restaurants with price information, only 157 are in the $\$ \$ \$$ and $\$ \$ \$ \$$ price

\footnotetext{
${ }^{5} \mathrm{I}$ also estimate ordered logit and tobit models. The results are similar and available upon request.

${ }^{6}$ The five-mile threshold is selected because as shown in Figure 1.1, five miles includes 'driving', 'biking', 'walking', and 'within 4 blocks' distances. It reflects the relevant range over which Yelp users search for restaurants.

${ }^{7}$ For restaurants like McDonald's with more than one Yelp category, the category fixed effect $\sigma_{c}$ will include multiple categories. For example, with McDonald's the dummy variable is 1 for "Fast Food" and "Burger" but 0 for all other categories.

${ }^{8}$ If two restaurants have the same categories multiple times, they are treated as competing along multiple dimensions. For example, since Burger King is also a fast food burger restaurant, it is counted as competing against McDonald's both as a burger restaurant and as a fast food restaurant. This construction allows restaurant competition to be weighted by the degree of similarity between restaurants.

${ }^{9}$ According to Yelp, the price range is the approximate cost per person for a meal consisting of one drink,
} 
ranges. Thus, the number of competitors in the same price range is determined only for $\$$ and $\$ \$$ restaurants. For example, among $\$$ restaurants, same price competition is defined as the number of $\$$ restaurants within five miles.

In comparison to restaurants as a whole, restaurants serving similar cuisine and restaurants with similar prices are likely stronger competitors. However, the strongest competitors are likely those with both similar cuisines and prices. For example, two high-end Chinese restaurants are likely closer competitors than a high-end Chinese restaurant and an inexpensive Chinese take-out restaurant. Thus, I define same category and same price competition as the number of restaurants within five miles with both the same category and price.

One common measure of competition not considered in the analysis is the HerfindahlHirschman Index (HHI), where competition is defined by relative market shares. Calculating HHI with Yelp data is not straightforward because restaurant revenues are not reported. One alternative would be to use number of reviews as a proxy for revenues. However, this requires the assumption that the number of reviews left for an establishment is directly correlated with revenue. The more straightforward approach used in this paper is to define competition by the number of nearby competitors. Recent papers defining competition by the number of nearby competitors include Pennerstorfer (2017) with campsites and Firgo and Kügler (2018) with ski resorts.

In addition to estimating the effect of competition by food type and price, I also test for differing effects among chain and independent restaurants. ${ }^{10}$ The ratings of chain restaurants may be less affected by competition as chains offer consistent prices, quality, menus, and decor across all their locations. However, independent restaurants may be more responsive to competition as prices, quality, menus, and decor are adjusted more easily than with chain restaurants. Additionally, the principle-agent problem may leave chain restaurant managers with little incentive to adjust to competition. Although franchising mitigates the principleagent problem in full-service restaurants, the principle-agent problem remains a problem for limited-service restaurants (Sveum and Sykuta, 2017). Given the different management

tax, and tip where $\$=$ under $\$ 10, \$ \$=\$ 11-\$ 30, \$ \$ \$=\$ 31-\$ 60$, and $\$ \$ \$ \$=$ above $\$ 61$.

${ }^{10}$ Yelp does not contain information about whether a restaurant is independent or part of a chain. Thus, I classify restaurants based upon the Technomic Chain Restaurant Report. The name of each Yelp-rated restaurant is cross-referenced to a list of the names of the 250 highest-revenue restaurant chains. 
incentives of independent and chain restaurants, the relationship between competition and ratings is expected to be strongest for independent restaurants.

\subsection{Results}

\subsubsection{Competition Within 5 Miles}

Table 1.4 displays the results for chain restaurants. The first column includes the number of chain and independent restaurants of all prices and categories within 5 miles. General restaurant competition is not related to the star ratings of chain restaurants. The second column includes restaurants that are likely to be closer competitors. Rather than restaurants as a whole, competitors are defined only as restaurants at the same price level. This is important because diners deciding where to eat are likely not choosing between a cheap fast food restaurant and an expensive steakhouse. However, same price competition is not significant.

Another way diners differentiate between restaurants and along which restaurants may face stiffer competition is by category of restaurant. For example, a diner craving Chinese food will choose only among Chinese restaurants. However, column 3 shows that same category competition is not significant. Column 4 shows that even with the strongest definition of competitors, same category and same price, the number of competitors is not related to a chain restaurant's Yelp rating.

Regardless of type of competition, there is no effect of competition on the ratings of chain restaurants. The standardization of menus and services with chain restaurants is a likely reason for why chain restaurants' ratings are not sensitive to competition. Consistency across restaurants is central to brand loyalty as every input into each restaurant, including recipes, serving utensils, and ingredients, comes from a centralized distribution network (The Daily Meal, 2015). While chain restaurants have few margins along which to adjust to competition, independent restaurants are not constrained by standardized decor, ingredients, and menus.

Consistent with the ability of independent restaurants to adjust when faced with competition, the results with independent restaurants reveal that some types of competition 
are associated with higher ratings. Table 1.5 shows that for independent restaurants same category and same category/price competition is positively related to ratings. ${ }^{11}$ However, competition from restaurants as a whole and from same price restaurants is not significant.

\subsubsection{Competition Within Walking and Driving Distance}

In addition to competition between 0 to 5 miles, I also consider how the association between competition and ratings varies across this distance. Closer competitors may influence ratings more than more distant competitors. Splitting up the number of competitors by distance follows Pennerstorfer (2017) who examines rival campsites within 2 miles and between 2 and 4 miles. The thresholds of 1 mile and 5 miles are chosen in this paper because, as shown in Figure 1.1, Yelp defines walking distance as 1 mile and driving distance as 5 miles.

Table 1.6 displays the results for chain restaurants. Regardless of distance, there is no association between any type of competition and the star ratings of chain restaurants. For both walking distance and driving distance, same price, same category, same category and price, and overall restaurant competition is not related to the rating of a chain restaurant. There is no evidence that the presence of nearby competitors affects chain restaurants.

Unlike with chain restaurants, the results with independent restaurants reveal that some types of competition are associated with higher ratings. Table 1.7 shows that for independent restaurants same category and same category/price competition between 1-5mi is positively related to ratings. However, competition from restaurants as a whole and from same price restaurants is not significant. Additionally, competition within a mile is never significant.

For independent restaurants, competition from 1-5 miles is positive and statistically significant while competition within one mile is not. One explanation for competition within walking distance not having a stronger association with ratings is the sprawl of the Phoenix

\footnotetext{
${ }^{11}$ Agglomeration is an alternative explanation for why more nearby competitors is associated with higher ratings. Agglomeration factors such as knowledge spillovers, labor-market pooling, and input sharing (Rosenthal and Strange, 2001) that increase productivity may lead to higher ratings. However, if higher productivity through agglomeration benefits is why ratings are higher for establishments with more nearby competitors, then it is unclear why the relationship is not present for chain restaurants or for certain types of competition for independent restaurants. Competition, rather than agglomeration makes better sense of the results. The positive relationship between nearby competitors and ratings is only for establishments most able to adjust to competition (independent restaurants) and for stronger forms of competition (same category and same price).
} 
area. Among similar-sized cities, the urban landscape of the Phoenix-Mesa-Glendale area is more sprawling (Smart Growth America, 2014). ${ }^{12}$ Consistent with a more sprawling landscape, Phoenix is less walkable than cities with a similar population (Walk Score, 2016). Since consumers have difficulty traveling in the Phoenix area on foot, competition of restaurants within walking distance is less intense.

The results indicate that greater spatial competition is associated with better experiences for consumers. However, the effect is not present for competitors within walking distance and among chain restaurants. Competition among chain restaurants and within a mile is not associated with better Yelp reviews.

\subsection{Conclusion and Future Research}

Previous research has explored the effect of spatial competition using proxies for quality. This paper exploits Yelp data from thousands of restaurants in the Phoenix area to assess the relationship between spatial competition and customers' satisfaction with their restaurant experiences. After controlling for restaurant characteristics, census tract level demographics, census tract fixed effects, and sub-industry fixed effects, the results are consistent with increased spatial competition leading to better consumer experiences. However, the effect is only present for independent restaurants. Consistent with the sprawling layout of the Phoenix area, the effect of competition is only for restaurants within driving distance.

The results in this paper have at least two policy implications relevant for urban areas seeking to attract new residents drawn to the amenities of consumer cities. With the rise of the consumer city (Glaeser et al., 2001; Glaeser and Gottlieb, 2006), people are drawn to cities for their diverse and dense array of amenities. In cities people migrate to areas with attractive amenities (Zheng, 2016), including restaurants (Beckers and Boschman, 2017). Restaurants are an important amenity, and residents not only value the quantity of restaurants but also the ratings of restaurants (Kuang, 2017). Since competition is positively associated with restaurant ratings, urban areas seeking to become attractive consumer cities should

\footnotetext{
${ }^{12}$ The sprawling structure of Phoenix has even drawn the attention of the satirical news organization The Onion with an article entitled "New Study Finds Most of Earth's Landmass Will be Phoenix Suburb By 2050" (The Onion, 2016).
} 
be careful of restrictions to competition among restaurants. Restrictions, such as complex or expensive permits, disproportionately affect independent restaurants, where the positive effect of competition on ratings is observed.

The second policy implication relates to walk-ability. Phoenix restaurants are easily accessible by car but not by foot. The effects of competition on ratings are present for driving distance but not walking distance. Improved walk-ability would not only allow consumers to access restaurants more easily but over time could lead to better restaurants through increased competition.

The results in this paper also have important implications for restaurant management. Competition is associated with higher ratings for independent restaurants but not for chain restaurants. A plausible explanation for this finding is a greater incentive for management in independent restaurants to adjust to competition. Subsequent research should continue to explore how differences in management affect the relationship between competition and ratings. For example, is more competition associated with better ratings for franchised chain restaurants as it is for independent restaurants?

In addition to studying management incentives, additional research should use Yelp data to explore restaurant survival. For example, how are the Yelp reviews of restaurants related to restaurant survival when a competitor opens nearby? Do higher-rated Yelp restaurants decrease the popularity and survival prospects of lower-rated restaurants? Subsequent research in this vein can contribute to the literature by addressing classic topics in new and more nuanced ways.

\section{Tables and Figures}


Figure 1.1: Standard Yelp Search

\begin{tabular}{|c|c|c|c|c|c|c|}
\hline yelp & Find Restaurants & & Near Phoc & $A Z 850$ & & Sign Up \\
\hline If Restaurants & Y Nightlife & ※ Home Services & Write a Review & Events & Talk & $\log \ln$ \\
\hline
\end{tabular}

Restaurants Phoenix, AZ 85004

Businesses > Restaurants > Breakfast \& Brunch

\begin{tabular}{|c|c|c|c|c|c|c|c|c|c|}
\hline$\$$ & $\$ \$$ & $\$ \$ \$$ & $\$ \$ \$ \$$ & (b) Open Now & Good for Groups & Full Bar & Outdoor Seating & $\because$ All Filters & \\
\hline \multicolumn{3}{|c|}{ Sort By } & \multicolumn{2}{|c|}{ Cities } & Distance & \multicolumn{2}{|c|}{ Price } & Features & Category \\
\hline \multirow{5}{*}{\multicolumn{3}{|c|}{$\begin{array}{l}\text { Best Match } \\
\text { Highest Rated } \\
\text { Most Reviewed }\end{array}$}} & \multirow{5}{*}{\multicolumn{2}{|c|}{$\square$ Phoenix }} & Bird's-eye View & \multicolumn{2}{|c|}{$\downarrow \$$} & $\square$ () Open Now 9:57 AM & Breakfast \& Brunch \\
\hline & & & & & Driving (5 mi.) & \multicolumn{2}{|c|}{$\checkmark \$ \$$} & $\square$ Take-out & $\square$ Sandwiches \\
\hline & & & & & Biking (2 mi.) & \multirow{2}{*}{\multicolumn{2}{|c|}{$\begin{array}{l}1 \$ \$ \\
\$ \$ \$ \$\end{array}$}} & $\square$ Outdoor Seating & $\square$ Cafes \\
\hline & & & & & \multirow{2}{*}{ Within 4 blocks } & & & $\square$ Good for Groups & $\square$ American (Traditional) \\
\hline & & & & & & & More Features & More Categories \\
\hline
\end{tabular}

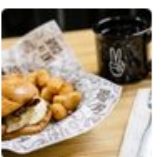

1. Even Stevens Sandwiches

t女t 76 reviews

\$. Sandwiches, Breakfast \& Brunch, Salad
21 W Van Buren St Phoenix, AZ 85003

(602) 258-4833

Even Stevens is a good place to grab a quick bite without breaking the bank in Downtown Phoenix.

1. I've tried the corned beef sandwich, New Morissey burrito (vegan), Jackfruit torta,... read more

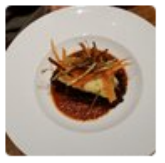

2. Province Urban Kitchen \& Bar

tht 191 reviews

$333 \mathrm{~N}$ Central Ave Phoenix, AZ 85004

\$\$ - Lounges, Breakfast \& Brunch, Burgers

(602) 429-3600

Located in the Westin Hotel in downtown Phoenix. Convenient complimentary/free valet parking with validation in the restaurant. Nice setting. Very friendly staff. Great service. A... read more

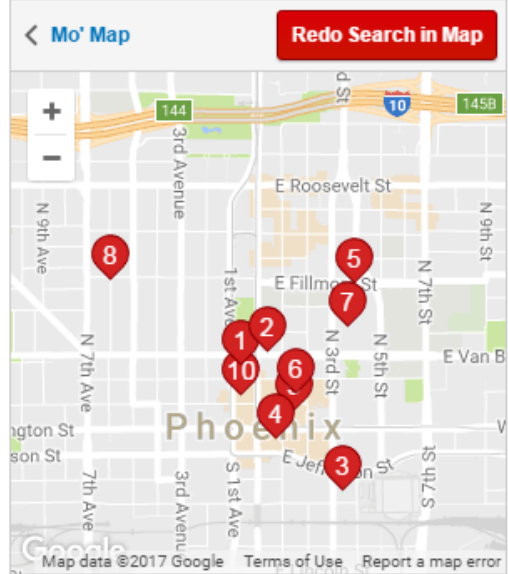


Figure 1.2: Restaurant Locations

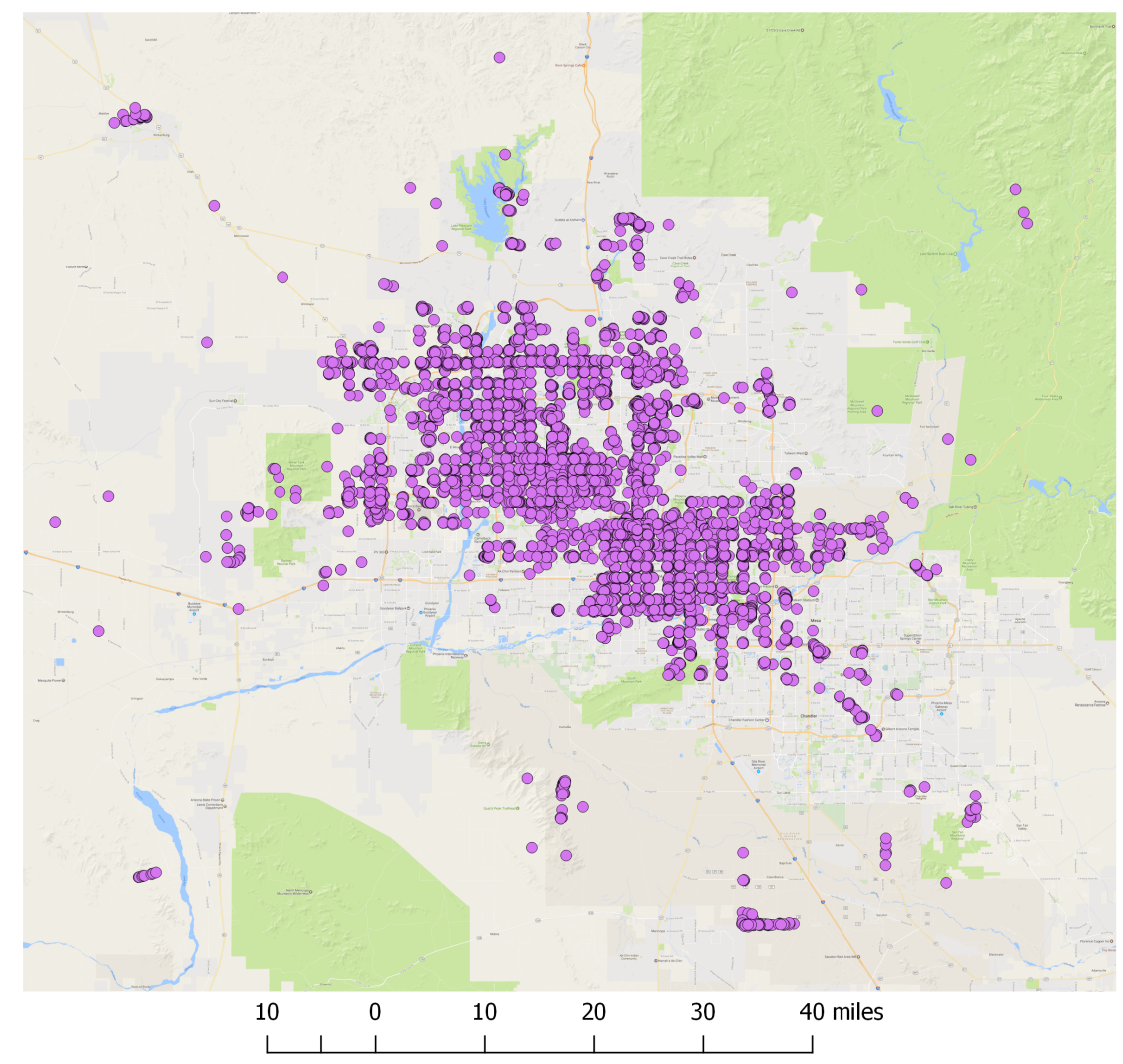


Figure 1.3: Number of Categories per Restaurant

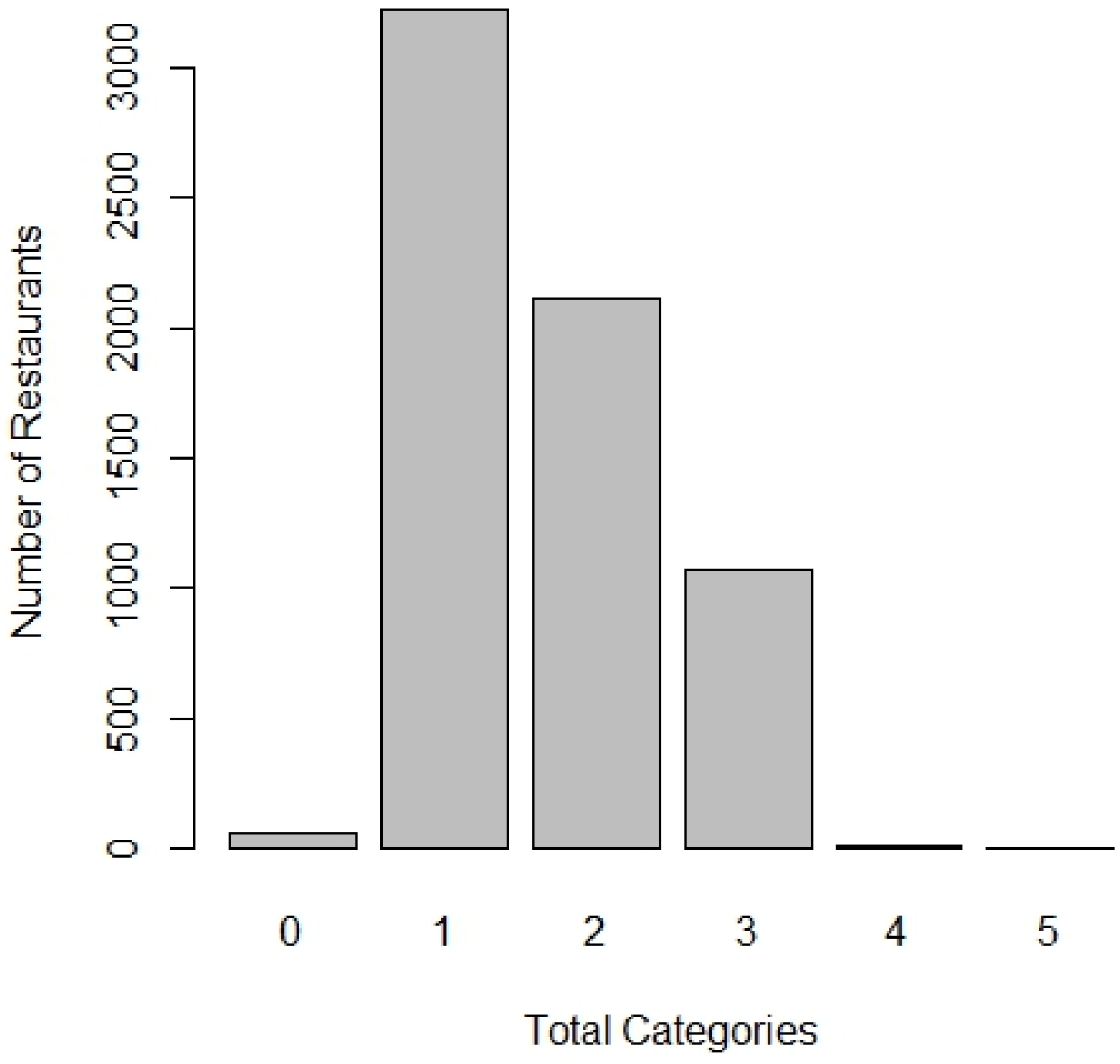


Table 1.1: Ten Most Common Restaurant Categories

\begin{tabular}{lc}
\hline Category & Observations \\
\hline Fast Food & 1205 \\
Mexican & 1049 \\
Pizza & 843 \\
Sandwiches & 842 \\
American (Traditional) & 748 \\
Burgers & 636 \\
Breakfast \& Brunch & 468 \\
American (New) & 461 \\
Italian & 457 \\
Chinese & 429 \\
\hline
\end{tabular}


Table 1.2: Descriptive Statistics for Chain Restaurants

\begin{tabular}{|c|c|c|c|c|}
\hline Statistic & Mean & St. Dev. & Min & Max \\
\hline Stars & 2.945 & 0.770 & 1 & 5 \\
\hline Restaurants (0-1mi) & 35.771 & 28.788 & 0 & 190 \\
\hline Restaurants (1-5mi) & 428.443 & 253.558 & 0 & 1,076 \\
\hline Same Price (0-1mi) & 18.610 & 15.031 & 0 & 115 \\
\hline Same Price (1-5mi) & 222.895 & 140.220 & 0 & 589 \\
\hline Same Category(0-1mi) & 7.230 & 6.506 & 0 & 52 \\
\hline Same Category (1-5mi) & 88.566 & 67.878 & 0 & 335 \\
\hline Same Category/Price (0-1mi) & 4.956 & 4.950 & 0 & 38 \\
\hline Same Category/Price (1-5mi) & 61.506 & 54.457 & 0 & 271 \\
\hline Review Count & 39.334 & 61.275 & 3 & 826 \\
\hline Price & 1.298 & 0.493 & 1 & 4 \\
\hline Population (thousands) & 4.869 & 1.925 & 0 & 17.987 \\
\hline Female $\%$ & 0.502 & 0.064 & 0 & 0.623 \\
\hline Median Age & 36.695 & 9.458 & 19.600 & 76.900 \\
\hline White \% & 0.789 & 0.136 & 0 & 0.998 \\
\hline Black \% & 0.047 & 0.046 & 0 & 0.346 \\
\hline Asian \% & 0.047 & 0.050 & 0 & 0.408 \\
\hline Hispanic/Latino \% & 0.252 & 0.199 & 0 & 0.951 \\
\hline Bachelor's Degree or Higher & 0.328 & 0.165 & 0 & 0.753 \\
\hline Per Capita Income (thousands) & 29.473 & 13.288 & 0 & 100.698 \\
\hline
\end{tabular}

Note: The full sample includes 2484 chain restaurants across 647 census tracts. 
Table 1.3: Descriptive Statistics for Independent Restaurants

\begin{tabular}{|c|c|c|c|c|}
\hline Statistic & Mean & St. Dev. & Min & Max \\
\hline Stars & 3.704 & 0.652 & 1 & 5 \\
\hline Restaurants (0-1mi) & 42.935 & 42.800 & 0 & 193 \\
\hline Restaurants (1-5mi) & 495.364 & 269.823 & 0 & 1,153 \\
\hline Same Price $(0-1 \mathrm{mi})$ & 22.165 & 23.480 & 0 & 116 \\
\hline Same Price (1-5mi) & 239.373 & 139.382 & 0 & 587 \\
\hline Same Category(0-1mi) & 5.462 & 7.980 & 0 & 71 \\
\hline Same Category (1-5mi) & 57.201 & 55.945 & 0 & 428 \\
\hline Same Category/Price (0-1mi) & 3.110 & 4.999 & 0 & 51 \\
\hline Same Category/Price (1-5mi) & 31.787 & 33.962 & 0 & 237 \\
\hline Review Count & 113.405 & 154.003 & 3 & 1,743 \\
\hline Price & 1.566 & 0.575 & 1 & 4 \\
\hline Population (thousands) & 4.367 & 1.916 & 0 & 17.987 \\
\hline Female $\%$ & 0.487 & 0.088 & 0 & 0.623 \\
\hline Median Age & 37.628 & 10.473 & 19.600 & 77.000 \\
\hline White \% & 0.786 & 0.156 & 0 & 1.000 \\
\hline Black \% & 0.047 & 0.048 & 0 & 0.383 \\
\hline Asian \% & 0.041 & 0.045 & 0 & 0.408 \\
\hline Hispanic/Latino \% & 0.260 & 0.215 & 0 & 0.957 \\
\hline Bachelor's Degree or Higher & 0.336 & 0.189 & 0 & 0.807 \\
\hline Per Capita Income (thousands) & 30.224 & 16.556 & 0 & 116.567 \\
\hline
\end{tabular}

Note: The full sample includes 3998 independent restaurants across 763 census tracts. 
Table 1.4: Estimated Effect of Competition on Chain Restaurants

\begin{tabular}{|c|c|c|c|c|}
\hline & \multicolumn{4}{|c|}{ Stars } \\
\hline & (1) & $(2)$ & $(3)$ & $(4)$ \\
\hline \multirow[t]{2}{*}{ Restaurants (0-5mi) } & 0.0002 & & & \\
\hline & $(0.001)$ & & & \\
\hline \multirow[t]{2}{*}{ Same Price (0-5mi) } & & 0.0002 & & \\
\hline & & $(0.0005)$ & & \\
\hline \multirow[t]{2}{*}{ Same Category (0-5mi) } & & & -0.0003 & \\
\hline & & & $(0.001)$ & \\
\hline \multirow[t]{2}{*}{ Same Category/Price (0-5mi) } & & & & 0.0003 \\
\hline & & & & $(0.001)$ \\
\hline \multirow[t]{2}{*}{ Review Count } & $0.003^{* * *}$ & $0.003^{* * *}$ & $0.003^{* * *}$ & $0.003^{* * *}$ \\
\hline & $(0.0004)$ & $(0.0004)$ & $(0.0004)$ & $(0.0004)$ \\
\hline \multirow[t]{2}{*}{ Price } & -0.015 & -0.014 & -0.015 & -0.020 \\
\hline & $(0.049)$ & $(0.059)$ & $(0.048)$ & $(0.057)$ \\
\hline Observations & 2,484 & 2,454 & 2,484 & 2,454 \\
\hline Adjusted $\mathrm{R}^{2}$ & 0.262 & 0.258 & 0.262 & 0.258 \\
\hline Demographic Controls & $\mathrm{X}$ & $\mathrm{X}$ & $\mathrm{X}$ & $\mathrm{X}$ \\
\hline Category FE & $\mathrm{X}$ & $\mathrm{X}$ & $\mathrm{X}$ & $\mathrm{X}$ \\
\hline Census Tract FE & $\mathrm{X}$ & $\mathrm{X}$ & $\mathrm{X}$ & $\mathrm{X}$ \\
\hline
\end{tabular}

Note:

${ }^{*} \mathrm{p}<0.1 ;{ }^{* *} \mathrm{p}<0.05 ;{ }^{* * *} \mathrm{p}<0.01$

Constant included but not reported

SEs clustered at census tract level 
Table 1.5: Estimated Effect of Competition on Independent Restaurants

\begin{tabular}{|c|c|c|c|c|}
\hline & \multicolumn{4}{|c|}{ Stars } \\
\hline & (1) & $(2)$ & $(3)$ & $(4)$ \\
\hline Restaurants (0-5mi) & $\begin{array}{l}-0.0001 \\
(0.0003)\end{array}$ & & & \\
\hline Same Price $(0-5 \mathrm{mi})$ & & $\begin{array}{c}0.0002 \\
(0.0003)\end{array}$ & & \\
\hline Same Category (0-5mi) & & & $\begin{array}{c}0.001^{* *} \\
(0.0005)\end{array}$ & \\
\hline Same Category/Price (0-5mi) & & & & $\begin{array}{c}0.002^{* * *} \\
(0.001)\end{array}$ \\
\hline Review Count & $\begin{array}{l}0.001^{* * *} \\
(0.0001)\end{array}$ & $\begin{array}{l}0.001^{* * *} \\
(0.0001)\end{array}$ & $\begin{array}{l}0.001^{* * *} \\
(0.0001)\end{array}$ & $\begin{array}{l}0.001^{* * *} \\
(0.0001)\end{array}$ \\
\hline Price & $\begin{array}{c}-0.069^{* *} \\
(0.029)\end{array}$ & $\begin{array}{c}-0.118^{* * *} \\
(0.035)\end{array}$ & $\begin{array}{c}-0.069^{* *} \\
(0.029)\end{array}$ & $\begin{array}{c}-0.107^{* * *} \\
(0.028)\end{array}$ \\
\hline Observations & 3,998 & 3,872 & 3,998 & 3,872 \\
\hline Adjusted $\mathrm{R}^{2}$ & 0.156 & 0.164 & 0.158 & 0.169 \\
\hline Demographic Controls & $\mathrm{X}$ & $\mathrm{X}$ & $\mathrm{X}$ & $\mathrm{X}$ \\
\hline Category FE & $\mathrm{X}$ & $\mathrm{X}$ & $\mathrm{X}$ & $\mathrm{X}$ \\
\hline Census Tract FE & $\mathrm{X}$ & $\mathrm{X}$ & $\mathrm{X}$ & $\mathrm{X}$ \\
\hline
\end{tabular}

Note:

${ }^{*} \mathrm{p}<0.1 ;{ }^{* *} \mathrm{p}<0.05 ;{ }^{* * *} \mathrm{p}<0.01$ Constant included but not reported SEs clustered at census tract level 
Table 1.6: Estimated Effects of Competition on Chain Restaurants - Driving vs. Walking

Stars

(1)

(2)

(3)

$\begin{array}{lc}\text { Restaurants (0-1mi) } & 0.001 \\ & (0.002) \\ \text { Restaurants (1-5mi) } & 0.0002 \\ & (0.001)\end{array}$

Same Price (0-1mi)

$-0.001$

$(0.002)$

Same Price (1-5mi)

0.0002

$(0.0005)$

Same Category (0-1mi)

0.001

(0.004)

Same Category (1-5mi)

$-0.0003$

(0.001)

Same Category/Price (0-1mi)

0.002

Same Category/Price (1-5mi)

0.0002

$(0.001)$

Review Count

$0.003^{* * *}$

$0.003^{* * *}$

$0.003^{* * *}$

$0.003^{* * *}$

(0.0004)

(0.0004)

$(0.0004)$

(0.0004)

Price

$\begin{array}{llll}-0.015 & -0.013 & -0.015 & -0.020\end{array}$

$(0.049)$

$(0.059)$

$(0.048)$

$(0.057)$

Observations

2,484

2,454

2,484

2,454

Adjusted $\mathrm{R}^{2}$

0.262

0.258

0.262

0.258

Demographic Controls

$\mathrm{X} \quad \mathrm{X}$

$\mathrm{X}$

$\mathrm{X}$

Category FE

$\mathrm{X} \quad \mathrm{X}$

$\mathrm{X}$

$\mathrm{X}$

Census Tract FE

$\mathrm{X}$

$\mathrm{X}$

$\mathrm{X}$

$\mathrm{X}$

Note:

${ }^{*} \mathrm{p}<0.1 ;{ }^{* *} \mathrm{p}<0.05 ;{ }^{* * *} \mathrm{p}<0.01$

Constant included but not reported

SEs clustered at census tract level 
Table 1.7: Estimated Effect of Competition on Independent Restaurants - Driving vs. Walking

Stars

(1)

$-0.001$

$(0.001)$

Restaurants (1-5mi)

$-0.0001$

$(0.0003)$

Same Price (0-1mi)

Same Price (1-5mi)

(2)

(3)

(4)

$\begin{array}{lc}\text { Restaurants (0-1mi) } & -0.001 \\ & (0.001) \\ \text { Restaurants (1-5mi) } & -0.0001 \\ & (0.0003)\end{array}$

$\begin{array}{cc}-0.001 \\ \text { Same Price (1-5mi) } & (0.001) \\ & 0.0002 \\ & (0.0003)\end{array}$

Same Category(0-1mi)

0.0002

(0.002)

Same Category (1-5mi)

$0.001^{* *}$

(0.001)

Same Category/Price (0-1mi)

Same Category/Price (1-5mi)

Review Count

$0.001^{* * *} \quad 0.001^{* * *} \quad 0.001^{* * *} \quad 0.001^{* * *}$

Price

(0.0001)

(0.0001)

(0.0001)

(0.0001)

-

$-0.068^{* *}$

$-0.112^{* * *}$

$-0.069^{* *}$

$-0.106^{* * *}$

(0.029)

(0.036)

(0.029)

(0.028)

Observations

3,998

3,872

3,998

3,872

Adjusted $\mathrm{R}^{2}$

0.156

0.165

0.158

0.169

Demographic Controls

Category FE

$\mathrm{X}$

$\mathrm{X}$

$\mathrm{X}$

$\mathrm{X}$

Census Tract FE

$\mathrm{X}$

$\mathrm{X}$

$\mathrm{X}$

$\mathrm{X}$

$\mathrm{X}$

$\mathrm{X}$

$\mathrm{X}$

Note:

${ }^{*} \mathrm{p}<0.1 ;{ }^{* *} \mathrm{p}<0.05 ;{ }^{* * *} \mathrm{p}<0.01$

Constant included but not reported

SEs clustered at census tract level 


\section{Chapter 2}

\section{The Spatial Distribution of Urban Consumer Service Firms: Evidence from Yelp Reviews}

\subsection{Introduction}

Over the last 30 years cities evolved from centers of production to centers of consumption (Glaeser et al., 2001; Glaeser and Gottlieb, 2006). Modern cities attract residents by providing a rich variety of consumer amenities like restaurants, bars, concerts and cultural activities, and other services in relatively small, dense areas. The importance of consumer amenities in cities raises a number of important questions about the distribution of firms across urban areas. Are consumer service firms localized or dispersed within a city? Important consumer search costs exist, and dispersion of service firms in a city may provide lower amenity value than localization.

Little is known about the extent of localization or dispersion of urban consumer service firms. Existing models of consumer service agglomeration predict that firm heterogeneity affects the tendency of consumer service firms to localize (Fischer and Harrington, 1996; Netz and Taylor, 2002; Konishi, 2005; Takahashi, 2013). Understanding spatial location patterns in consumer service firms is important given the rise of consumer cities. Recently developed spatial econometric tools for analyzing the concentration of firms have primarily been applied 
to firms in manufacturing and business-services industries, not to urban consumer service firms.

Three recent papers analyze locational decisions of consumer service firms using point pattern analyses in the vein of Duranton and Overman (2005). ${ }^{1}$ Mixed evidence on clustering exists in this literature. Nakajima et al. (2012) find that service industry firms, including consumer services such as restaurants and accommodation, medical and health care services, and education, are more clustered than firms in manufacturing sectors at close distances. Zhou and Clapp (2015) find greater dispersion of anchor department stores among new entrants than among existing anchor stores. Billings and Johnson (2016) analyze co-localization of firms in a specific urban area and find evidence of clustering among legal services and data processing firms and dispersion among firms in the accommodations sector. They find that knowledge spillovers, access to transportation, and proximity to consumers explain colocalization across a variety of industries including the consumer services industries in retail trade, arts entertainment and recreation, and accommodation and food services.

This paper contributes to this growing literature by using the K-density function to assess spatial distribution of consumer service firms across a range of consumer service categories in a single urban area. While prior research considers localization by industry type, we also consider localization by cost and quality. Since firms cluster or disperse for multiple reasons and concentration varies across industries, a more complete analysis of the spatial distribution of consumer service providers reveals patterns shaping the landscape of the modern world's increasingly consumer-driven cities.

We use Yelp review data for over 29,000 businesses in the greater Phoenix area to calculate K-densities of localization and dispersion at distances up to 30 kilometers. The results reveal that concentration varies across establishment categories, establishment cost and quality, and distances. Establishments in 4 of 15 subcategories in the Yelp food category, 11 of 32 subcategories in the restaurants category, and 19 of 43 subcategories in the shopping category

\footnotetext{
${ }^{1}$ The Duranton and Overman (2005) kernel density function improves on traditional measures of spatial concentration like the Gini Index or Ellison and Glaeser (1997) indices that rely on pre-defined areas such as counties. By using only Euclidean distances between firms, it overcomes the Modifiable Areal Unit Problem (MAUP) of measures of concentration being sensitive to the selection of the areal units (Marcon and Puech, 2009).
} 
cluster. Despite differences across categories and distances, a general pattern of localization at smaller distances emerges with service differentiation explaining much of the tendency to cluster.

The results also reveal clustering among high quality and high cost consumer service establishments, supporting the predictions in the model developed by Fischer and Harrington (1996). Few previous studies analyze the spatial distribution of establishments by quality and cost, despite the fact that quality and cost are important factors in the provision of consumer services. The variation in densities at different distances underscores the importance of using a point pattern analysis to describe densities for the entire distribution of distances rather than traditional approaches that rely on a single level of aggregation.

\subsection{Context: Theory and Evidence on Clustering}

A substantial theoretical and empirical literature addresses the tendency of consumer service firms to cluster. This literature appears in both urban economics and industrial organization. The theoretical literature is extensive, and different assumptions can generate predictions along the entire spectrum from extreme clustering to extreme dispersion (Netz and Taylor, 2002). The empirical literature tends to focus on specific industries like retail gasoline or arts and culture firms.

\subsubsection{Theory}

Much of the theoretical literature on firm clustering focuses on manufacturing with an emphasis on external scale economies and location decisions made by firms. Consumer service firms differ from manufacturing firms in several ways. Consumer service providers cater to households, not other businesses, generally cannot store their output, and cannot take advantage of scale economies to the extent that manufacturing firms can. Most models of agglomeration focus on manufacturing, not consumer service providers. However, several models address the tendency of consumer service firms to localize. ${ }^{2}$

\footnotetext{
${ }^{2}$ Incentives for consumer service firms to localize from the perspective of consumers can be motivated by the trip-chaining model of consumer shopping developed by Anas (2007).
} 
In general, consumer service providers face offsetting incentives to locate near to one another or to spatially differentiate (Netz and Taylor, 2002). All consumer service providers want to locate near large concentrations of consumers, for example in urban areas. Locating close to competitors allows spatially clustered competitors to share a common pool of customers that increases with the number of clustering firms, a market size effect that encourages clustering. However, locating close to competitors increases price competition among firms, a market share effect which tends to push firms apart. While price competition tends to spatially differentiate firms, competing firms can still cluster and enjoy market size benefits if they can sufficiently differentiate their services by quality. These quality differentiated services tend to be expensive (Schuetz and Green, 2014). Consumer uncertainty about tastes or product quality also enhances clustering (Konishi, 2005; Takahashi, 2013).

The model developed by Fischer and Harrington (1996) motivates the spatial analysis of consumer goods and service providing firms by emphasizing the importance of consumer search and product characteristics. This model includes costly search by consumers and entry by firms that make pricing decisions and sell similar, but differentiated products in either a localized geographic cluster or a dispersed periphery where firms are spread uniformly over space. The inclusion of consumer search and product differentiation makes the model applicable to many consumer services firms like art galleries, jewelery stores or car dealers.

Firms are distinguished by the specific variety they sell, which is drawn from a set of possible varieties. Consider a general category of consumer service firms like restaurants. These firms sell meals, and a large set of possible meal varieties exists. Each restaurant sells a specific variety of meal that is identified by a specific consumer willingness to pay for that variety. The degree of heterogeneity of services provided by firms in this model is reflected by the difference between the largest consumer willingness to pay for a specific variety and the smallest consumer willingness to pay. In the case of restaurants, this interval represents the difference in cost between a lavish meal in a fine dining establishment and the cost of a meal from a food truck or fast food establishment.

Consumers differ in their preference for varieties of goods services, reflected by their willingness to pay, and in their search costs. Search costs on the periphery are higher than search costs in a cluster, and once in a cluster consumers can search all firms located there 
costlessly.

This model makes specific predictions about the effect of product heterogeneity, and specific characteristics of the services provided, on the likelihood that firms cluster and the equilibrium prices in clusters and the periphery. In particular, the model predicts that the likelihood that firms cluster increases with heterogeneity in services provided by firms and with the size of the consumer expenditure on the service. In both cases, heterogeneity in services provided and heterogeneity in the cost of the service affect the tendency of firms to locate in close proximity to one another.

Humphreys and Zhou (2015) take a different approach to modelling the tendency of consumer service providing firms to localize, emphasizing the importance of monopolistic competition, product variety, travel to consumption centers, and local price effects along the lines of the model developed by Dixit and Stiglitz (1977) in localization decisions. In this model firms are differentiated by their fixed costs of production and the marginal utility generated from consuming the service produced. The model predicts that firms will enter and produce a service at a consumption center where other firms localize depending on the ratio of the firm's fixed cost of production to the marginal utility generated by the service. The model also contains an equilibrium outcome where firms do not localize at a consumption center and instead locate in dispersed spots.

The model developed by Humphreys and Zhou (2015) predicts that some firms will localize in specific consumption centers in a city, and co-locate with other consumer service producing firms if their fixed costs of production are low enough, and/or the marginal utility of consumption of the service produced is high enough. Other firms, with larger fixed costs and/or lower marginal utility will not localize. The mechanism for local agglomeration in this model is the effect of firm entry on the local price level coupled with consumer demand for service variety.

A number of models provide specific predictions about localization of consumer service producing firms. These firms may choose to locate near each other under some conditions, forming localized clusters, or alternatively they may choose to locate far from competing firms, generating a pattern of dispersion. Localization generates agglomeration benefits from increased concentration of consumers in local clusters of service providing firms, but 
also leads to increased price competition. The ability of firms to differentiate their services along non-price margins like quality tends to offset price competition, leading to clustering. This product differentiation appears to be a key factor in determining clustering of consumer service firms (Picone et al., 2009).

\subsubsection{Empirical Evidence}

Empirical analysis of the distribution of consumer service firms is not a new research area. An early empirical paper, Smith (1985), uses nearest neighbor analysis to describe the distribution of urban restaurants and finds fast food and regular restaurants more clustered than pizza parlors and doughnut shops. Fischer and Harrington (1996) analyze the geographic distribution of a range of consumer services such as auto dealers, clinics, and supermarkets. They find shoe stores the most localized and movie theaters the least localized. Recent empirical research has not only described patterns of clustering but also sought to identify specific factors driving the spatial distribution of firms.

Netz and Taylor (2002) find that gasoline stations in Los Angeles are dispersed and become more dispersed with increased competition. A one standard deviation increase in the number of gas stations within one mile increases spatial dispersion by $23 \%$. Picone et al. (2009) find that establishments selling alcohol on premises ("onsite"), like bars and restaurants, are more localized than establishments selling alcohol "offsite" like liquor stores, in five US cities. They attribute this pattern to greater service differentiation by onsite establishments. Schuetz and Green (2014) find that, at the census-tract level, Manhattan art galleries are localized with the pattern of localization stable over time. In these studies, the extent of localization can be explained by agglomeration economies, population density, and household income. While all these studies analyze the distribution of consumer services establishments, none use the point pattern analysis popularized by Duranton and Overman (2005).

Although not the first to use point pattern analysis at different geographic scales ${ }^{3}$, Duranton and Overman (2005) has been the most influential. In their analysis of UK manu-

\footnotetext{
${ }^{3}$ For example, Barff (1987) with manufacturing firms in Cincinnati, Ohio and Marcon and Puech (2003) with manufacturing firms in France.
} 
facturing firms, they find that $52 \%$ of industries are localized with localization occurring at closer distances. They also argue that any good test for spatial concentration must satisfy five criteria: (i) comparability across industries; (ii) controls for the overall agglomeration of manufacturing; (iii) controls for industrial concentration; and (iv) unbiasedness with respect to scale and aggregation. In addition, a good test should also (v) give an indication of the significance of the results. (p. 1079)

Subsequent research on spatial concentration using tests satisfying all five criteria tend to follow Duranton and Overman (2005) by analyzing nationwide manufacturing concentration. Duranton and Overman (2008) find that co-localization of vertically-linked manufacturing industries in the UK occurs at larger distances (around $150 \mathrm{~km}$ ) but not at smaller distances. Behrens and Bougna (2015) find that roughly half of Canadian manufacturing firms are localized, although the extent of localization has declined over the last decade. In addition to describing the distribution of manufacturing industries, there is at least one study using a continuous point pattern approach to test for what causes localization.

Ellison et al. (2010) determine that the co-localization of manufacturing industries in the United States can be explained by labor market pooling, knowledge spillovers, and a tendency to locate near customers or suppliers. While manufacturing has been the focus, Barlet et al. (2013) also analyze business-oriented services in France, finding that services cluster at short distances (less than $4 \mathrm{~km}$ ). While all these studies use point pattern analyses, they focus on the countrywide distribution of manufacturing or business services while this paper focuses on consumer services within an urban area.

Billings and Johnson (2016) develop a novel measure of co-location, analyze co-location decisions, and assess the importance of different sources of agglomeration across a wide variety of establishments in a single urban area, Denver Colorado. The focus on a single urban area motivates this analysis. They find relatively small rates of co-localization, between $3.3 \%$ and $5.4 \%$, between pairs of four-digit NAICS code industries within two-digit NAICS code industries in consumer services (Art, entertainment, and recreation and Accommodation and food services). They also identify natural advantage, and to a lesser extent consumption externalities, as important factors explaining observed co-location.

Given our focus on the greater Phoenix metropolitan area, studies assessing the distri- 
bution of firms in this area are also relevant. Four studies using point pattern analyses of Phoenix establishments exist; only two focus on consumer services and none account for the overall concentration of industry in the area. O hUallacháin and Leslie (2007) find that all 11 of the producer services studied are clustered at all levels between 0-20 miles. Ó hUallacháin and Leslie (2009) find that all 9 of the manufacturing industries are clustered with transportation networks shaping the patterns of localization.

Leslie and Ó hUallacháin (2006) use nearest neighbor analysis and location quotients to describe the clustering of 10 industries including the consumer services industries of retail, health care and social assistance, and entertainment and accommodation. While all industries are localized in all areas of Phoenix, the localization of each industry varies across the CBD and various suburban sub-centers. Most recently, Ó hUallacháin and Leslie (2013) find varying levels of localization and co-localization across retail. However, their analysis focuses on retail instead of all consumer services, uses data from 2004, and does not account for overall retail concentration.

The previous empirical literature on localization focuses on specific industries and finds evidence of both localization and dispersion, depending on characteristics of the firms, products, and services. In consumer service industries, localization can generally be attributed to the ability of firms to differentiate the services provided.

\subsection{Data}

Although continuous point pattern measures of concentration have been used in economics for over a decade, empirical studies remain rare. One reason for this is data availability. The K-density approach requires both data on large numbers of establishments that can be grouped and precisely defined establishment locations. Many public data sources do not meet these requirements. The data made available through the Yelp Dataset Challenge fulfill these requirements. These data sets contain information on thousands of establishments and a wide variety of establishment characteristics including summary information about cost and service quality, and the exact latitude and longitude for nearly 86,000 rated establishments across 10 cities in 4 countries. 
Using Yelp data to analyze localization of urban businesses requires that these data accurately reflect the actual number and location of establishments. Glaeser et al. (2017) assess the reliability of Yelp data by comparing establishments covered in Yelp to County Business Patterns (CBP) data across the United States. Glaeser et al. (2017) conclude that establishment coverage in Yelp data is similar to CBP data in retail, leisure and hospitality industries in dense urban areas at the ZIP code level. In some sectors, for example restaurants, Yelp data may contain firms with small numbers of employees that are not included in CBP data.

To assess the Yelp coverage of food, restaurant, and shopping establishments in Phoenix, we compare the Yelp data to 2015 CBP data at the zip code level. CBP classifies establishments by the North American Industry Classification System (NAICS). Following Glaeser et al. (2017), we define NAICS restaurant codes as Full-Service Restaurants (NAICS 722511), Limited-Service Restaurants (722513), Cafeterias, Grill Buffets, and Buffets (722514), and Snack and Nonalcoholic Beverage Bars (722515).

In Phoenix zip codes containing at least one Yelp 'Restaurant' establishment, the CBP data contain 6,259 restaurants based on establishment counts from those four NAICS codes. The Yelp data contain 6,263 restaurants, slightly more than the CBP count. The comparable numbers for CBP 'Food' and 'Shopping' establishments in Phoenix are 2,536 and 5,125. ${ }^{4}$ The Yelp data contain 2,661 food establishments and 4,437 shopping establishments. The Yelp data in all three categories accurately reflect CBP establishment counts.

The Phoenix metro area, which includes several suburbs such as Chandler, Mesa, and Scottsdale, has Yelp data containing information on 31,074 total establishments, the largest number of establishments in any of the Yelp Challenge data sets. In order to restrict the analysis to Phoenix and its closest suburbs, we drop observations for the 1909 establishments located farthest away from the city center. The remaining 29,165 establishments are all located within the rectangular area shown in Figure 3.1 . This area is $74 \mathrm{~km}$ from east to

\footnotetext{
${ }^{4}$ NAICS codes mapped in to the Yelp 'Food' category include Mobile Food Services (722330), Snack and Nonalcoholic Beverage Bars (722515), Caterers (722320), Gasoline Stations with Convenience Stores (447110), and NAICS sub-sector 445 (Food and Beverage Stores). NAICS codes mapped into the Yelp 'Shopping' category include Furniture and Home Furnishings Stores (442), Electronics and Appliance Stores (443), Building Material and Garden Equipment and Supplies Dealers (444), Clothing and Clothing Accessories Stores (448), Sporting Goods, Hobby, Musical Instrument, and Book Stores (451), and Miscellaneous Store Retailers (453).
} 
west and $62 \mathrm{~km}$ from north to south, and contains the majority of the greater Phoenix metropolitan area. The density of establishments in the sample generally follows the local population density, with the number of establishments decreasing with distance from the city center.

Figure 2.1: Spatial Distribution of Consumer Services Establishments in Phoenix

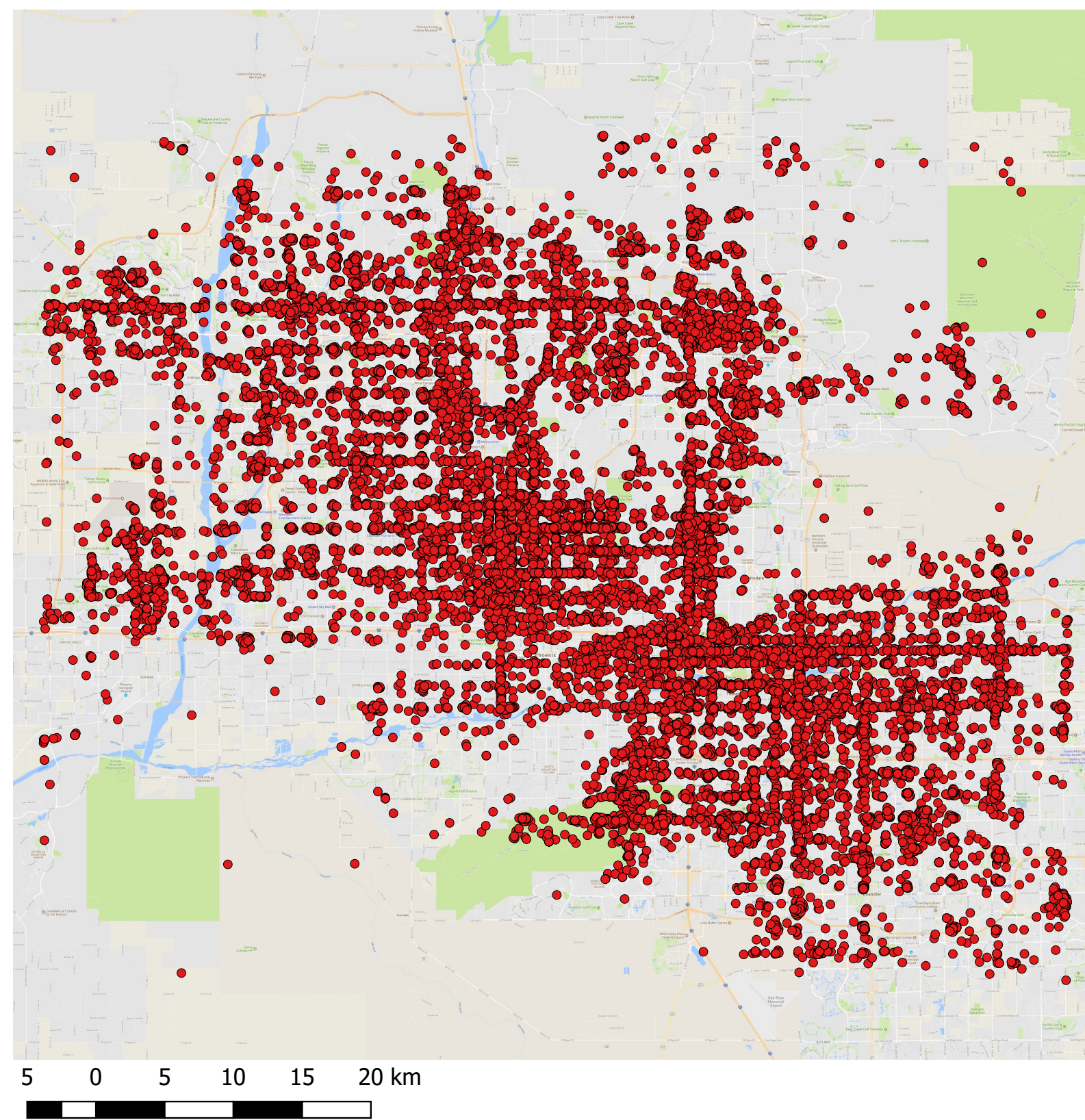

Each Yelp establishment is associated with specific descriptors for the services provided. 
These descriptors take the form of category and sub-category types describing the goods and services provided by each establishment as well as other establishment characteristics. These descriptors are designed to improve users' ability to search for, and become informed about, specific establishments. Establishments are grouped into nearly 1000 categories, subcategories, and sub-sub-categories. Establishments typically possess one primary category and multiple subcategories. For example, the popular Subway sandwich shop is classified in the category Restaurant and further identified by two sub-categories: Fast Food and Sandwiches. However, some establishments possess multiple primary categories. For example, restaurants featuring live music at night may be classified in the Restaurants and Nightlife primary categories.

The Yelp data also contain information on two additional important characteristics of consumer services not found in other data sources: average transaction cost, reflected in a number of dollar signs associated with each establishment and service quality, reflected in a star rating system. Yelp transaction cost information is determined by average cost as reflected in the number of dollar signs associated with each establishment. In the Yelp cost descriptors, one dollar sign $(\$)$ refers to an average transaction cost per person under $\$ 10$. Two dollar signs $(\$ \$)$ refers to an average transaction cost between $\$ 11$ and $\$ 30$. Three dollar signs $(\$ \$ \$)$ refers to an average transaction cost between $\$ 31$ and $\$ 60$ and four dollar signs $(\$ \$ \$)$ refers to an average transaction cost over $\$ 61$.

Yelp information on establishment quality come from customer reviews. Customers provide a written review of their experience and a rating of between 1 star (worst) and 5 stars (best) of their experience at the establishment. Yelp publishes the average number of stars each establishment receives in their customer reviews in half-star increments. The number of underlying reviews can vary substantially from a handful to hundreds of customer reviews.

Table 2.1 shows primary categories, the number of establishments in each primary category in the Phoenix area, and a representative sample of the sub-categories from the 16 primary categories defining the consumer services industry in the Phoenix Yelp data. The total sample from the Phoenix area contains 34,566 establishments and 16 primary categories. Again, some establishments fall under multiple primary categories. Our analysis focuses on establishments in three primary categories: food, restaurants, and shopping. We 
focus on food, restaurants, and shopping because these categories reflect the most common consumer activities. We further restrict the analysis to food, restaurants, and shopping subcategories with 50 or more establishments, resulting in 15 food subcategories, 32 restaurant subcategories, and 43 shopping subcategories.

Additionally, price information will be used to analyze establishment localization by service cost. We do not know of any other paper analyzing localization of consumer service firms by price. Not all Yelp-rated establishments have price information in the data set. For example, only $13.63 \%$ of establishments in the health \& medical, $7.46 \%$ in the automotive, and $7.40 \%$ in the home services primary category contain price information. Price information in the primary categories analyzed here is widespread. $90.71 \%$ of establishments in shopping, $96.55 \%$ in restaurants, and $97.07 \%$ in food establishment primary categories have price information.

Figure 2.2 shows the distribution of the Yelp cost descriptors for consumer services as a whole, as well as the food, restaurants, and shopping primary categories. Within consumer services, most establishments have either one or two dollar signs, indicating that the average transaction at these establishments would be under $\$ 30$. A majority of establishments in the food and restaurant primary categories have one dollar sign; a majority of establishments in the shopping primary category have two dollar signs.

Figure 2.3 shows the distribution of establishment quality measures, in terms of the average number of stars each establishment gets in customer reviews. The distribution of star ratings skews right overall; the modal consumer services firm gets 5 stars, on average and very few consumer service establishments get below 2.5 stars, on average. This probably reflects exits by low quality businesses. Establishment quality measures in the food, restaurants, and shopping primary categories also skew right, although there are relatively few five star establishments in the food and restaurants primary categories.

\subsection{Methodology}

We follow Duranton and Overman's (2005) three-step process for describing the spatial distribution of establishments. First, we estimate a kernel density function of the distribu- 
Table 2.1: Yelp Consumer Service Categories

\begin{tabular}{|c|c|c|}
\hline Primary Category & $\mathrm{N}$ & Sample Subcategories \\
\hline Active Life & 1,234 & $\begin{array}{l}\text { Fitness \& Instruction, Golf, Laser Tag, Parks, Swimming } \\
\text { Pools }\end{array}$ \\
\hline $\begin{array}{l}\text { Arts \& Entertain- } \\
\text { ment }\end{array}$ & 528 & $\begin{array}{l}\text { Art Galleries, Cinema, Museums, Opera \& Ballet, Per- } \\
\text { forming Arts }\end{array}$ \\
\hline Automotive & 2,332 & $\begin{array}{l}\text { Body Shops, Car Dealers, Car Wash, Gas \& Service Sta- } \\
\text { tions, Parking }\end{array}$ \\
\hline Beauty \& Spas & 3,061 & Barbers, Day Spas, Hair Salons, Piercing, Tanning \\
\hline $\begin{array}{l}\text { Event Planning \& } \\
\text { Services }\end{array}$ & 982 & $\begin{array}{l}\text { Caterers, Party Supplies, Photographers, Wedding Plan- } \\
\text { ning, Valet Services }\end{array}$ \\
\hline Financial Services & 528 & $\begin{array}{l}\text { Banks \& Credit Unions, Financial Advising, Insurance, } \\
\text { Investing, Tax Services }\end{array}$ \\
\hline Food & 2,661 & Bakeries, Breweries, Coffee \& Tea, Desserts, Grocery \\
\hline Health \& Medical & 3,104 & $\begin{array}{l}\text { Counseling \& Mental Health, Dentists, Doctors, Medical } \\
\text { Centers, Pharmacy }\end{array}$ \\
\hline Home Services & 3,164 & $\begin{array}{l}\text { Carpeting, Electricians, Home Cleaning, Plumbing, Tree } \\
\text { Services }\end{array}$ \\
\hline Hotels \& Travel & 753 & $\begin{array}{l}\text { Airports, Car Rental, Hotels, Tours, Transportation, } \\
\text { Child Care \& Day Care, Community Service/Non-Profit, }\end{array}$ \\
\hline Local Services & 1,907 & $\begin{array}{l}\text { IT Services \& Computer Repair, Pest Control, Self Stor- } \\
\text { age }\end{array}$ \\
\hline Nightlife & 993 & Bars, Comedy Clubs, Dance Clubs, Karaoke, Pool Halls \\
\hline Pets & 746 & $\begin{array}{l}\text { Animal Shelters, Pet Adoption, Pet Services, Pet Stores, } \\
\text { Veterinarians, }\end{array}$ \\
\hline $\begin{array}{l}\text { Professional Ser- } \\
\text { vices }\end{array}$ & 554 & $\begin{array}{l}\text { Accountants, Architects, Lawyers, Marketing, Web De- } \\
\text { sign }\end{array}$ \\
\hline Real Estate & 830 & $\begin{array}{l}\text { Apartments, Mobile Home Dealers, Mortgage Brokers, } \\
\text { Property Management, Real Estate Agents }\end{array}$ \\
\hline Restaurants & 6,259 & $\begin{array}{l}\text { American (Traditional), Fast Food, Chinese, Italian, } \\
\text { Seafood }\end{array}$ \\
\hline Shopping & 4,437 & $\begin{array}{l}\text { Arts \& Crafts, Department Stores, Electronics, Fashion, } \\
\text { Sporting Goods }\end{array}$ \\
\hline
\end{tabular}


Figure 2.2: Price (Dollar Sign) Distributions by Primary Category
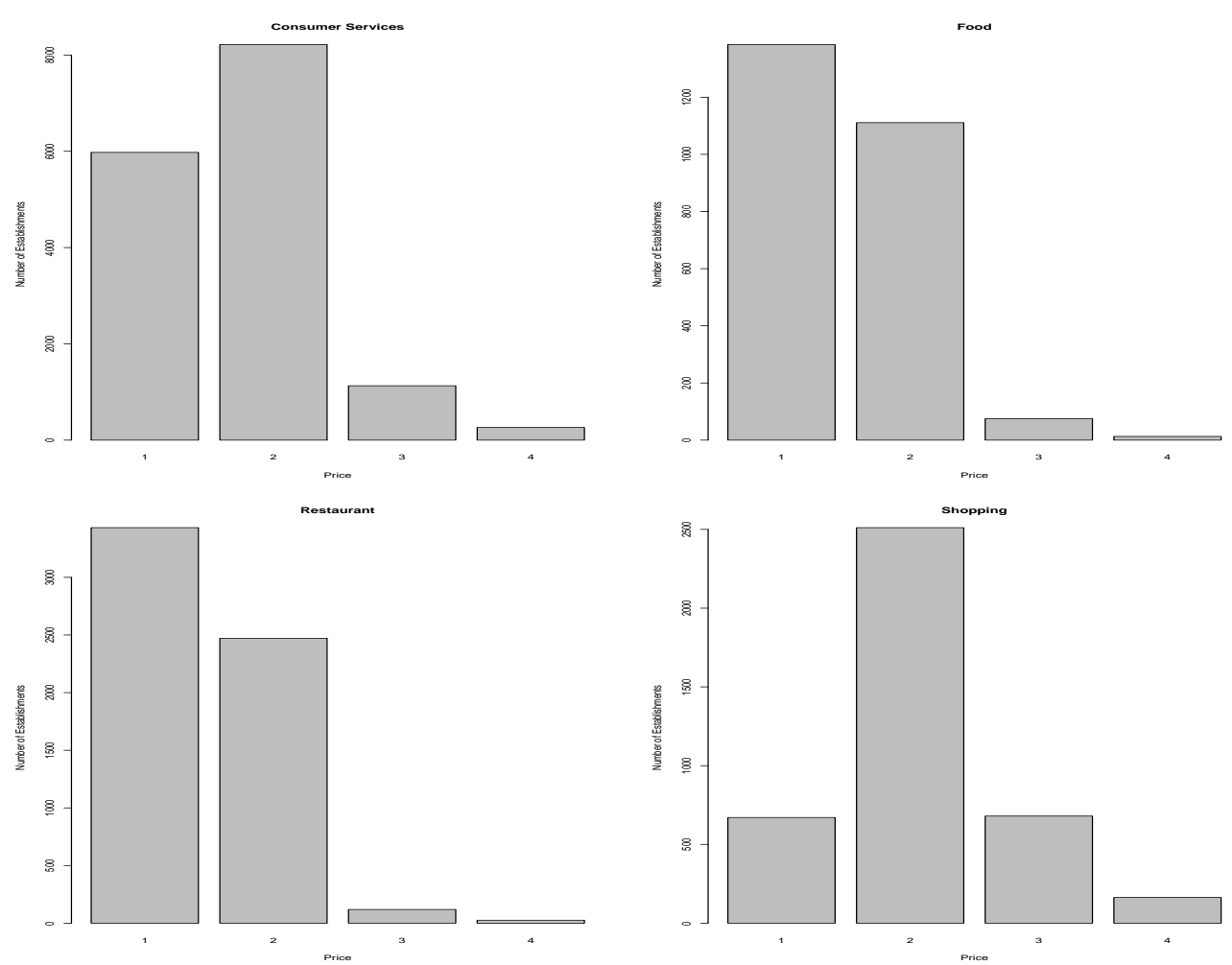
Figure 2.3: Establishment Quality (Star) Distributions by Primary Category
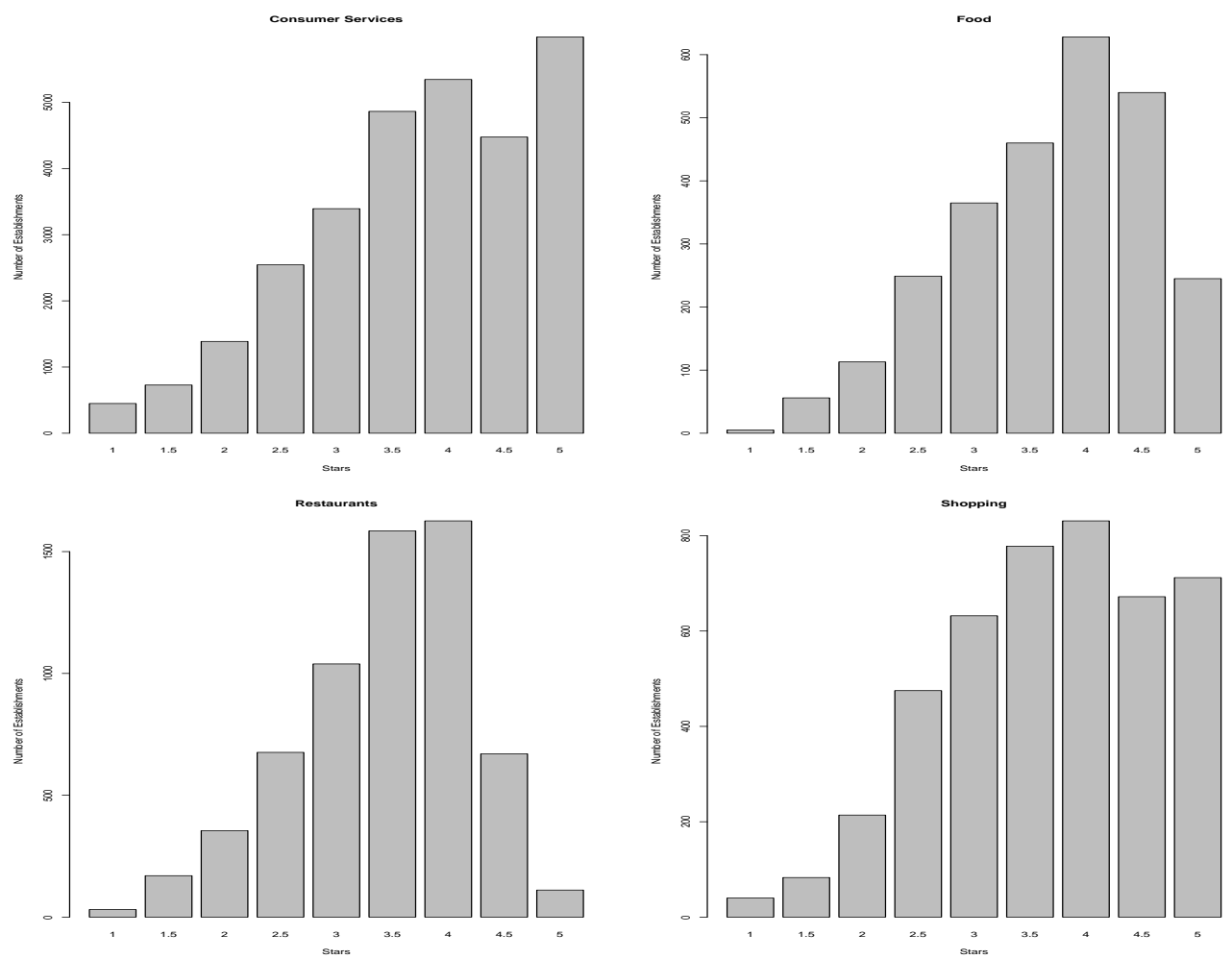
tion of all pairwise distances of establishments within the same consumer services category. Second, in order to assess the statistical significance of localization or dispersion in these firms, we construct counterfactuals where establishments in the particular industry under consideration are randomly distributed across sites occupied by firms in the consumer services industry as a whole. Third, based on the counterfactuals, confidence intervals are constructed and measures of localization and dispersion calculated based on these confidence intervals.

To estimate kernel densities, for each category $c$ with $n$ establishments, we calculate the Euclidean distance between each pair of establishments within category $c$. This results in $\frac{n(n-1)}{2}$ pairwise distances for category $c$. These distances are then kernel-smoothed to estimate the distribution of pairwise distances. The estimator of the density of pairwise distances at distance $d$ (henceforth K-density) is:

$$
\hat{K}_{c}(d)=\frac{1}{n(n-1) h} \sum_{i=1}^{n-1} \sum_{j=i+1}^{n} f\left(\frac{d-d_{i j}}{h}\right)
$$

where $d_{i j}$ is the Euclidean distance between establishment $i$ and $j, h$ is the bandwidth, and $f$ is the kernel function. The bandwidth $h$ is the width of the bins used to describe the true distribution of bilateral distances. Using a correct bandwidth is important to avoid over-smoothing or under-smoothing. We follow Duranton and Overman (2005) by using the optimal bandwidth of Silverman (1986) as this is the default in the R package dbmss (Marcon et al., 2015). We calculate K-densities at $100 \mathrm{~m}$ intervals up to $30 \mathrm{~km}$. The maximum of $30 \mathrm{~km}$ is selected because Duranton and Overman (2005) use the median pairwise distance as their maximum and the median pairwise distance with our observations is around $32 \mathrm{~km}$.

Constructing counterfactuals is the second step. All consumer services establishments are randomly relabeled still using $n$ establishments for category $c$. K-densities are then calculated as in the first step and 1000 simulations are run to create the set of counterfactuals. This process controls for the distribution of the consumer services industry as a whole. Therefore, localization of category $c$ means localization relative to other consumer services and not absolute spatial concentration.

The third step is to evaluate statistical significance with global confidence bands. $\bar{K}_{c}(d)$ is the upper global confidence band while $\underline{K}_{c}(d)$ is the lower global confidence band. $95 \%$ 
of the simulations between $0-30 \mathrm{~km}$ lie below the upper band while $95 \%$ lie above the lower band. A category is considered localized if $\hat{K}_{c}(d)>\bar{K}_{c}(d)$ for at least one $d \in[0,30000]$. The classification for dispersion is less straightforward because by construction K-densities sum to one so that categories highly localized at close distances will by default most likely be dispersed at larger distances. We follow Duranton and Overman (2005) by defining a category as dispersed if $\hat{K}_{c}(d)>\underline{K}_{c}(d)$ for at least one $d \in[0,30000]$ and the category is not localized. Therefore, the index of localization for category $c$ at distance $d$ is:

$$
\Gamma_{c}(d)=\max \left(\hat{K}_{c}(d)-\bar{K}_{c}(d), 0\right)
$$

while the index of dispersion is:

$$
\Psi c(d)= \begin{cases}\max \left(\underline{\mathrm{K}}_{c}(d)-\hat{K}_{c}(d), 0\right) & \text { if } \sum_{d=0}^{30,000} \Gamma_{c}(d)=0 \\ 0 & \text { otherwise }\end{cases}
$$

The indexes for localization and dispersion across the entire range are

$$
\Gamma_{c}=\sum_{d=0}^{30,000} \Gamma_{c}(d) \text { and } \Psi_{c}=\sum_{d=0}^{30,000} \Psi_{c}(d) .
$$

Graphically, establishments in a subcategory are localized when the K-density lies above its upper global confidence band. Establishments in a subcategory are dispersed when the K-density lies below its lower global confidence band and never lies above its upper global confidence band. We estimate K-densities and upper/lower confidence bands for all subcategories in the food, restaurants, and shopping primary categories in the Yelp data for the Phoenix area.

A comparison of K-densities and the upper/lower confidence bands can identify subcategories where establishments are localized, dispersed, or spatially distributed in the same way as all consumer service establishments in the area. Figure 2.4 illustrates the relationship between the K-density estimates and confidence bands for establishments in four different subcategories: bakeries, Indian restaurants, department stores, and antiques. From Figure 2.4, firms in the bakeries subcategory are neither localized nor dispersed, as the K-density for this subcategory lies entirely in the Phoenix confidence band at all distances. Firms in 
the Indian restaurants subcategory are localized at close distances, less than ten kilometers, as the K-density lies above the upper confidence band from 0-9500m. Establishments in the department stores subcategory are dispersed, as the K-density lies below the confidence bands and never lies above the confidence bands. Firms in the antiques classification are localized even though the K-density falls below the lower global confidence band at larger distances.

To provide intuition into the patterns of location associated with localized and dispersed subcategories, the left panel of Figure 2.5 displays the location of all 53 Indian restaurants in the Phoenix area. Consistent with the K-density plot in Figure 2.5, a number of clusters of Indian restaurants at close distances can clearly be seen in Figure 2.5.

The right panel of Figure 2.5 shows the location of all 266 department stores in the Phoenix area. Consistent with the K-density plot in Figure 2.4, some clusters of department stores at close distances can be seen, but many isolated establishments also exist, reflecting an absence of localization or dispersion at close distances. However, clusters tend not to locate near one another, and the overall distribution of pairwise distances between department stores in Phoenix is large, which is reflected by dispersion at larger distances on the K-density plot for this subcategory. While visual inspection of maps is illustrative, a formal K-density test is required to determine how different types of consumer services locate relative to the consumer services industry as a whole.

\subsection{Results}

We first analyze the spatial distribution of establishments in specific Yelp categories and subcategories in the Phoenix area. These groups of establishments mirror the industries used in previous research on firm location decisions. We then turn to an analysis of the spatial distribution of consumer service establishments by service quality and cost. Previous theoretical research established the role of cost in location decisions (Fischer and Harrington, 1996) but previous empirical analysis generally lacks information on service cost and quality. 
Figure 2.4: K-densities for Four Illustrative Categories
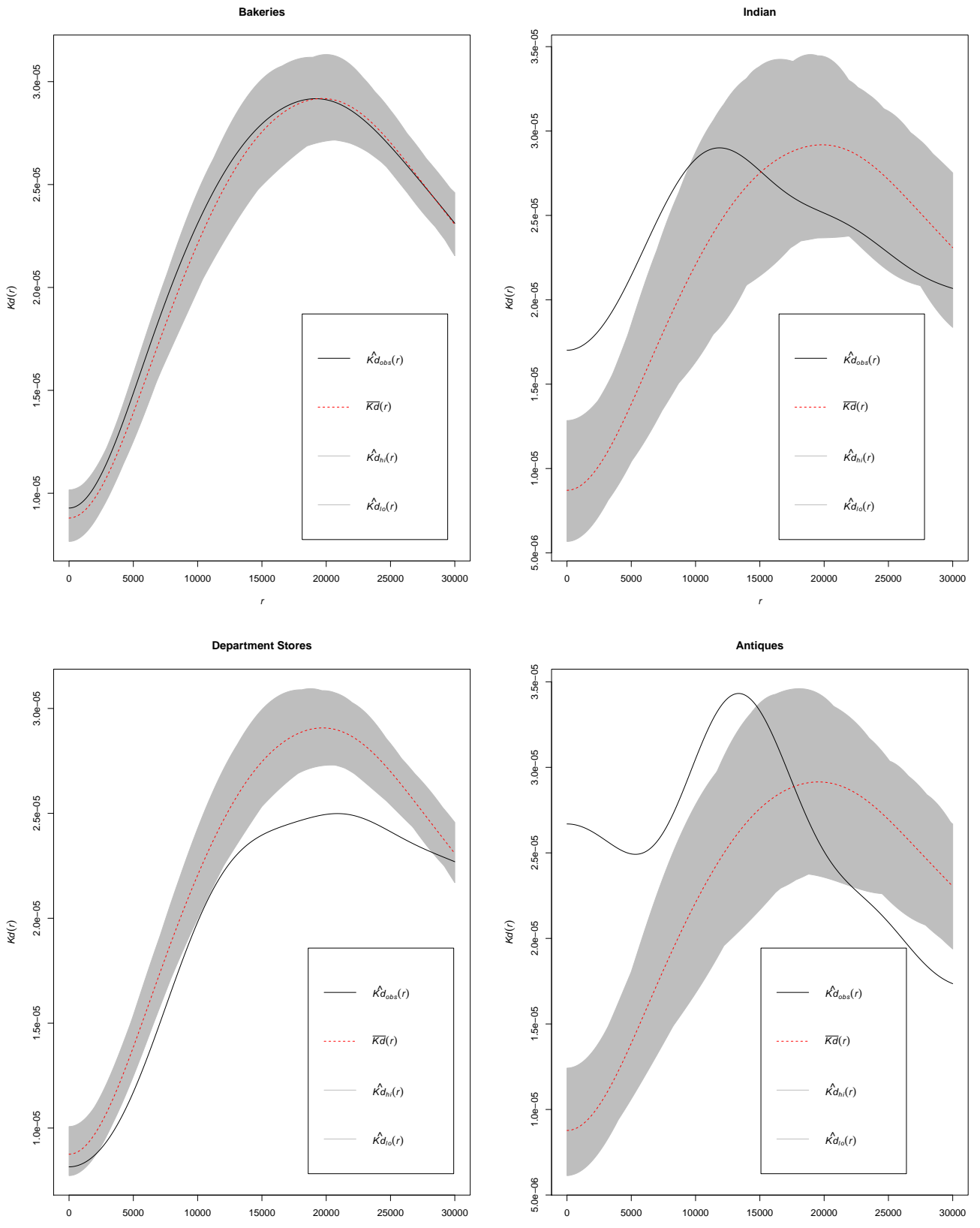
Figure 2.5: Localization and Dispersion

Indian Restaurants

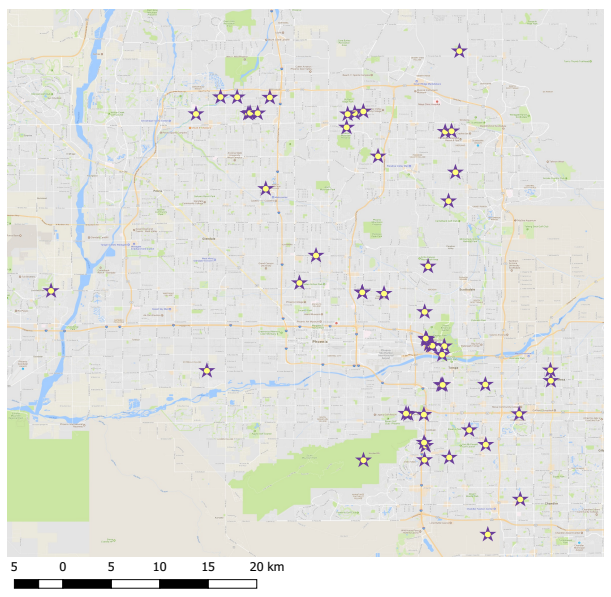

Department Stores

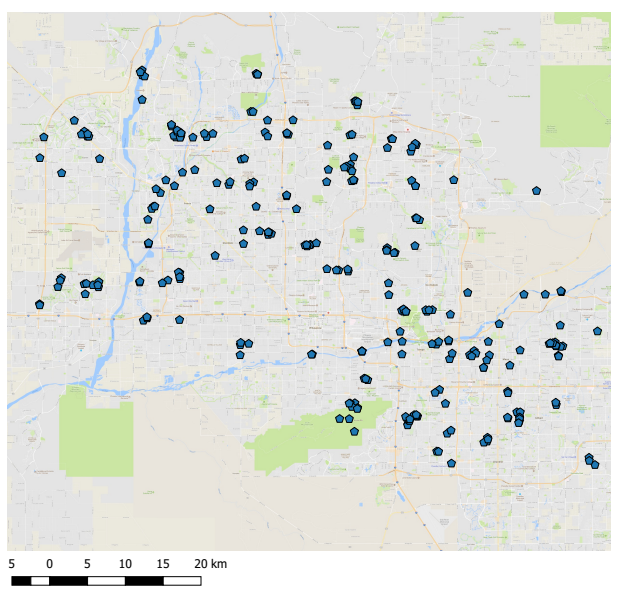

\subsubsection{Results by Establishment Category}

K-density functions and upper/lower confidence bands were estimated for 15 food subcategories, 32 restaurant subcategories, and 43 shopping subcategories using Equation (2.1). Counterfactuals reflect the location of all consumer service establishments in the Yelp data. ${ }^{5}$ Indexes of localization, from Equation (2.2), and dispersion, from Equation (2.3), were also estimated for all subcategories. The results indicate that localization patterns vary across subcategories and distances.

Note that localization could result from limited locations for service providing firms to open. These limitations could come from local zoning laws, local building restrictions, or local geographic features like hills or water. Many measures of localization cannot account for these factors. The K-density approach developed by Duranton and Overman (2005) uses the actual spatial distribution of all firms in the area as a counterfactual, and measures localization and dispersion relative to the existing spatial distribution of consumer service firms. The actual spatial distribution will reflect any local conditions that limit the locations where firms can locate.

The location patterns of food establishments differs the least from the overall location of consumer services. In the food category, 8/15 subcategories are neither localized nor

\footnotetext{
${ }^{5}$ An alternative approach - constructing counterfactuals using only the location of restaurants, food establishments and shopping establishments - produced very similar results.
} 
dispersed, with 4 categories localized and 3 dispersed. Establishments in the restaurants category are more likely to differ spatially from consumer services as a whole; 11 subcategories contain localized establishments, 8 contain dispersed establishments, and 13 contain neither localized nor dispersed establishments. Establishments in the shopping category are the most likely to be localized; 19 subcategories contain localized establishments, 7 contain dispersed establishments, and 17 neither localized nor dispersed establishments.

To understand broad location patterns across distances and subcategories, Figure 2.6 displays the fraction of categories with significant localization or dispersion at each distance from $0-30,000 \mathrm{~m}$. The overall pattern in food, restaurants, and shopping shows the prevalence of localization decreasing with distance, while the share of dispersed categories remains relatively constant. However, patterns of dispersion vary based upon category. Dispersion decreases with distance for food, remains relatively constant with shopping, and is most common around $15,000 \mathrm{~m}$ for restaurants.

Figure 2.6: Share of Localized and Dispersed Categories
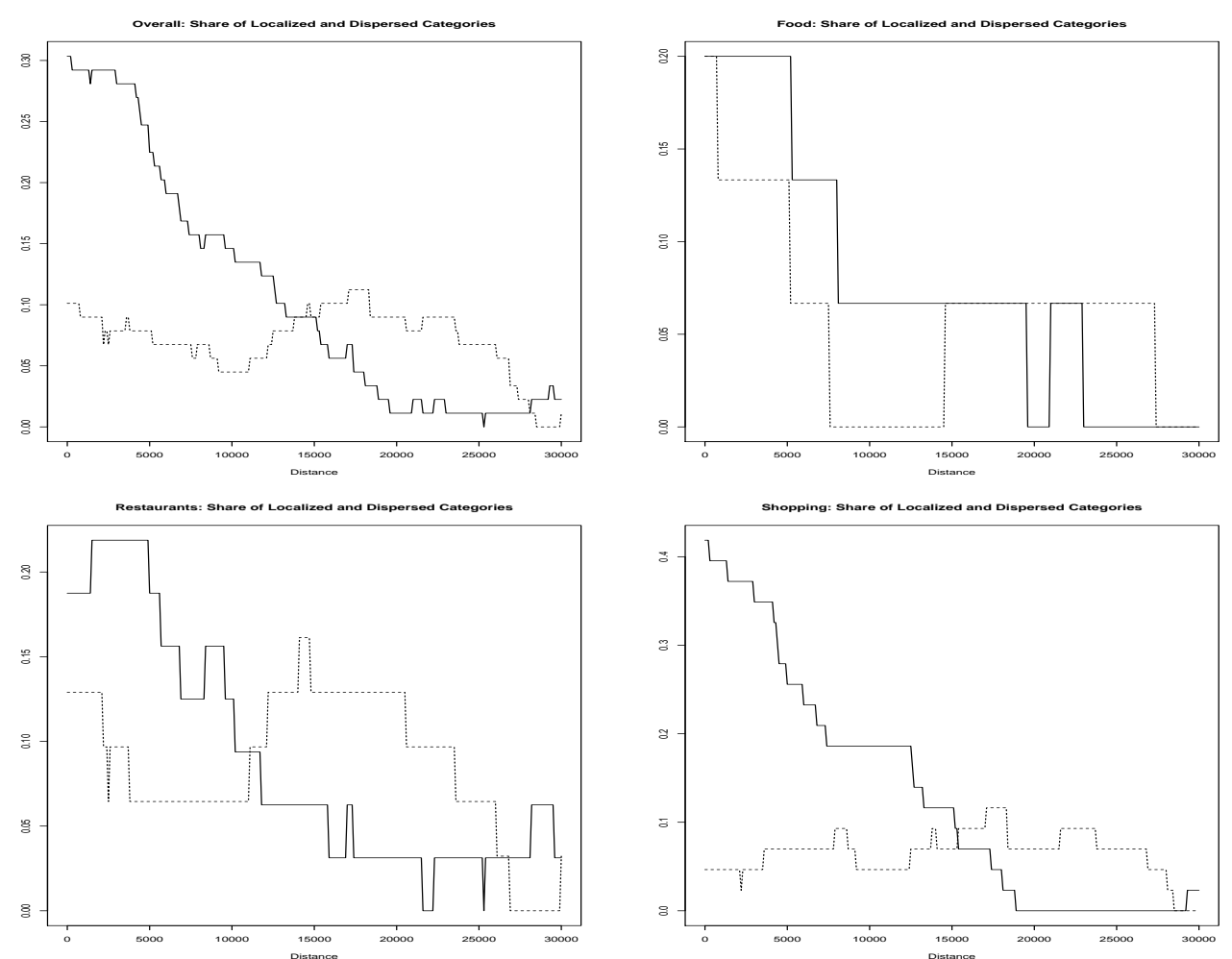
The general pattern of localization decreasing with distance is consistent with the proliferation of shopping centers and polycentrism of Phoenix. Over the last 60 years, establishments have increasingly clustered in shopping centers to profit from more potential customers (Carter, 2009). Shopping centers are densely packed with consumer services at short distances, but two shopping centers are unlikely to locate next to each other. Consistent with this view is Zhou and Clapp's (2015) finding of greater dispersion of department anchor stores among new stores than existing stores. Anchor stores are the foundation of shopping centers so a greater dispersion of anchor stores leads to a greater dispersion across shopping centers. Shopping centers are especially relevant for Phoenix. Leslie and Ó hUallacháin (2006) find considerable co-localization between retail and entertainment establishments, which is unsurprising given the shopping centers and strip malls dotting the sprawling landscape.

Table 2.2 provides specific information about the most localized subcategories of establishments in food, restaurants, and shopping. Yelp subcategories are specific enough to include competing establishments, but broad enough to include establishments with differentiated services. While price competition leads firms to spatially differentiate or disperse, service differentiation can lead similar firms to cluster. Subcategories that exhibit localization should include firms with the ability to differentiate their services.

The most highly localized shopping subcategories include industries already identified in the literature as containing establishments highly differentiated in terms of quality. These include art galleries (Schuetz and Green, 2014) and jewelry and women's clothing (Fischer and Harrington, 1996). Antiques and vintage/consignment clothing would appear to contain establishments that operate along similar lines to art galleries.

Highly localized subcategories in the food category also support the predictions from models of clustering in consumer services. Food trucks exhibit the largest degree of localization in the food category and clearly have very low fixed costs. Recall that the model developed by Humphreys and Zhou (2015) predicts that establishments with low fixed costs will tend to localize. The other three food subcategories with a high degree of localization, beer, wine and spirits, coffee and tea, and specialty foods are establishments that can plausibly differentiate their services in terms of quality or other characteristics. All can specialize in products from different areas of the world (craft beers, European wines, coffees from exotic 
Table 2.2: Most Highly Localized Subcategories

\begin{tabular}{llcc}
\hline Category & Subcategory & Establishments & Localization Index \\
\hline Shopping & Art Galleries & 57 & 0.1271 \\
Shopping & Antiques & 59 & 0.0921 \\
Shopping & Used, Vintage \& Consignment & 96 & 0.0509 \\
Shopping & Jewelry & 225 & 0.0443 \\
Shopping & Women's Clothing & 404 & 0.0212 \\
\hline Food & Food Trucks & 92 & 0.0881 \\
Food & Beer, Wine \& Spirits & 116 & 0.0187 \\
Food & Coffee \& Tea & 551 & 0.0025 \\
Food & Specialty Food & 274 & $<.0001$ \\
\hline Restaurants & American (New) & 431 & 0.0330 \\
Restaurants & Indian & 53 & 0.0262 \\
Restaurants & Vegetarian & 90 & 0.0244 \\
Restaurants & Mexican & 1007 & 0.0080 \\
Restaurants & Cafes & 178 & 0.0063 \\
\hline
\end{tabular}


locations) or in the case of specialty food, cater to customers with different dietary preferences (kosher, halal, gluten-free, etc.). Specialty food establishments, by definition, provide differentiated services, so establishments in this subcategory would be expected to cluster.

The highly localized subcategories in food show similar establishment characteristics. Restaurants have a large number of quality-related features available for differentiation, including service, decor, ambience, regional specialization, menu breadth, and other features. This rich environment for quality differentiation within a restaurant subcategory like American (New) or Mexican provides establishments in these subcategories with ample room to compete on margins other than price.

Table 2.3 provides specific information about the most dispersed subcategories in food, restaurants, and shopping. These subcategories contain establishments with relatively few margins on which to differentiate. In the shopping category, department stores carry a wide variety of products like clothing, electronics, furniture, toys, books, sundries, and home goods. Their comprehensive nature provides little flexibility in terms of offerings or quality, and also makes price competition more intense, which leads them to spatially differentiate through dispersion. Drugstores also have little room to diversify, as consumers expect these establishments to carry a standard array of over the counter medications, greeting cards, and seasonal products. Cosmetic stores also carry a standard selection of makeup, lipsticks, creams, lotions, and other beauty products. Mattresses and mobile telephony stores provide commodity products differentiated primarily by brand. In all these subcategories, similarities in the consumer services offered would amplify price competition, leading them to locate farther from one another.

In the food category, ice cream and frozen yogurt shops sell homogenous products with little room for variation in quality. Grocery stores and convenience stores face the same problems as department stores and drug stores, in that they must offer a similar array of products and services as their competitors with little room to differentiate.

In the restaurant category, fast food restaurants and pizza shops are highly dispersed. These establishments have little ability to differentiate on quality. Fast food restaurants offer homogenous, low cost, quick meals. Pizza shops frequently offer delivery, which would also tend to disperse locations. Sushi Bars offer a uniform menu of raw fish prepared in a limited 
Table 2.3: Most Highly Dispersed Subcategories

\begin{tabular}{llcc}
\hline Category & Subcategory & Establishments & Dispersion Index \\
\hline Shopping & Department Stores & 266 & 0.0247 \\
Shopping & Drugstores & 327 & 0.0212 \\
Shopping & Cosmetics \& Beauty Supply & 306 & 0.0035 \\
Shopping & Mattresses & 101 & 0.0016 \\
Shopping & Mobile Phones & 187 & 0.0015 \\
\hline Food & Ice Cream \& Frozen Yogurt & 292 & 0.0085 \\
Food & Grocery & 509 & 0.0014 \\
Food & Convenience Stores & 320 & $<.0001$ \\
\hline Restaurants & Fast Food & 1181 & 0.0245 \\
Restaurants & Pizza & 812 & 0.0109 \\
Restaurants & Sushi Bars & 166 & 0.0059 \\
Restaurants & Chinese & 409 & 0.0047 \\
Restaurants & Tex-Mex & 127 & 0.0013 \\
\hline
\end{tabular}


number of ways; many have the same seating format.

\subsubsection{Results by Cost and Quality}

While localization or dispersion by establishment category or subcategory is a reasonable way of analyzing the spatial distribution of consumer services, other factors are likely to affect their location patterns. For example, localization decisions could also depend on the cost of the service provided. High end shopping establishments may cluster together in expensive shopping centers. To explore other potential factors relating to consumer services locations, we consider how consumer services are located by price, category-price, and rating.

The Yelp data contains information about service characteristics that is not present in many other establishment level data sources: dollar sign data that provides information about the cost of consumer services provided and star ratings that provide information about the quality of the services provided based on customer reviews of the businesses. Recall that Fischer and Harrington (1996) characterize differentiation in terms of the variability of consumer willingness to pay. The dollar sign ratings provided by Yelp can be thought of as a proxy for variability in consumer willingness to pay. One dollar sign restaurants have an average cost per person of under $\$ 10$. Two dollar sign restaurants have an average cost per person of between $\$ 11$ and $\$ 30$ per person. These restaurants likely provide options for customers to pay less that $\$ 11$, for example by ordering only a cheap entree, salad or appetizer, but also provide the opportunity for customers to spend more on a meal. In this sense, two dollar sign restaurants provide a wider range of willingness to pay for meals than a one dollar sign restaurant, which matches the differentiation measure used by Fischer and Harrington (1996). Therefore, two dollar sign restaurants could be expected to localize more than one dollar sign restaurants.

Table 2.4 shows location patterns by dollar sign rating for the shopping, food, and restaurants categories. As expected, one dollar sign shopping and restaurants show no pattern of localization. One dollar sign restaurants are more dispersed than the average consumer service firm, and one dollar sign shopping establishments have the same spatial distribution as the overall spatial distribution of consumer service firms in the area. However, two dollar 
sign shopping and two dollar sign restaurant establishments are localized. This likely reflects more differentiation in the services provided by these more costly establishments.

Table 2.4: Location Patterns by Category and Cost

\begin{tabular}{lccc}
\hline Category & Establishments & Localization Index & Dispersion Index \\
\hline \$ Shopping & 671 & 0 & 0 \\
$\$ \$$ Shopping & 2511 & 0.0003 & 0 \\
\hline Food & 1384 & 0.0007 & 0 \\
$\$ \$$ Food & 1111 & 0 & 0 \\
\hline Restaurants & 3431 & 0 & 0.0003 \\
$\$ \$$ Restaurants & 2471 & $<.0001$ & 0 \\
\hline
\end{tabular}

From Table 2.4, one dollar sign food establishments are localized, but two dollar sign food establishments are not. Table 2.2 shows the most localized subcategories in the food category: food trucks, beer, wine, \& spirits, coffee \& tea, and specialty foods. Why might low cost establishments in the food category cluster? Food trucks typically produce a single type of food or dish; even low cost specialty foods can be highly differentiated. Picone et al. (2009) find that offsite alcohol shops were less localized than onsite providers, but provide no information about the degree of localization relative to the overall spatial distribution of consumer service firms in cities. Picone et al. (2009) report that offsite alcohol shops are more localized than elementary schools, which could indicate general localization.

Table 2.5 provides more detailed information about the spatial distribution of consumer service providers, showing localization and dispersion indexes for selected subcategories by dollar sign rating. One dollar sign coffee \& tea establishments are localized, but two dollar sign establishments are not. This suggests that low cost coffee \& tea shops can generate enough differentiation to overcome costs associated with price competition and localize. This could reflect variation in factors like ambience or variety of specialty drinks offered.

The rest of the spatial patterns by establishment cost generally support a relationship between service differentiation and localization. One dollar sign establishments in fashion and American "traditional" restaurants do not localize but two dollar sign establishments 
Table 2.5: Location Patterns by Subcategory and Cost

\begin{tabular}{|c|c|c|c|}
\hline Subcategory (category) & Establishments & Localization Index & Dispersion Index \\
\hline Coffee \& Tea (food) & 551 & 0.0025 & 0 \\
\hline$\$$ Coffee \& Tea & 339 & 0.0091 & 0 \\
\hline$\$ \$$ Coffee \& Tea & 193 & 0 & 0 \\
\hline Grocery (food) & 509 & 0 & 0.0014 \\
\hline$\$$ Grocery & 196 & 0 & 0 \\
\hline$\$ \$$ Grocery & 286 & 0 & 0.0090 \\
\hline Fashion (shopping) & 1007 & 0.0080 & 0 \\
\hline$\$$ Fashion & 190 & 0 & 0 \\
\hline$\$ \$$ Fashion & 510 & 0.0027 & 0 \\
\hline Drugstores (shopping) & 327 & 0 & 0.0212 \\
\hline \$ Drugstores & 74 & 0 & 0 \\
\hline$\$ \$$ Drugstores & 229 & 0 & 0.0145 \\
\hline Mexican (restaurants) & 1007 & 0.0080 & 0 \\
\hline$\$$ Mexican & 698 & 0.0029 & 0 \\
\hline$\$ \$$ Mexican & 267 & 0.0013 & 0 \\
\hline American Traditional (restaurants) & 693 & 0 & 0 \\
\hline$\$$ American Traditional & 241 & 0 & $<.0001$ \\
\hline$\$ \$$ American Traditional & 422 & 0.0003 & 0 \\
\hline
\end{tabular}


localize. Two dollar sign establishments exhibit more variation in consumer willingness to pay, which reflects diversification in the model developed by Fischer and Harrington (1996).

In subcategories with substantial dispersion, grocery stores and drug stores, the tendency to disperse increases with costs. Again, these establishments generally provide a homogenous set of consumer products which would make price competition more intense, leading them to locate farther from each other to reduce price competition. Two dollar sign grocery stores and drug stores may have higher markup over marginal cost for consumer staples than one dollar sign establishments, which would lead them to locate even farther apart.

Finally, the Yelp data contain information on the quality of the service provided, as reflected in customer ratings. Increasing the quality of service can be thought of as a way for establishments to generate differentiation in the minds of consumers. At low quality establishments, all customers are treated (equally) badly. High quality establishments may be able to create an impression that they cater to individual customer preferences in some way, making them distinct from other establishments. Also, clustering of high quality establishments may create a "halo" effect where customer perceptions of a high quality of service spill over when customers visit other nearby establishments.

Table 2.6: Location Patterns by Quality Rating

\begin{tabular}{lccc}
\hline Category & Establishments & Localization Index & Dispersion Index \\
\hline Low Quality Food & 174 & 0 & 0 \\
Medium Quality Food & 1074 & 0 & $<.0001$ \\
High Quality Food & 1413 & 0.0050 & 0 \\
\hline Low Quality Restaurants & 556 & 0 & 0 \\
Medium Quality Restaurants & 3300 & 0 & 0.0086 \\
High Quality Restaurants & 2407 & 0.0198 & 0 \\
\hline Low Quality Shopping & 337 & 0 & 0.0210 \\
Medium Quality Shopping & 1885 & 0 & 0.0201 \\
High Quality Shopping & 2215 & 0.0276 & 0 \\
\hline
\end{tabular}

Table 2.6 displays the location patterns for low, medium, and high quality establishments 
in the food, restaurant, and shopping categories. Low quality is defined as establishments with an average rating of 1, 1.5, or 2 stars; medium quality as establishments with an average rating of 2.5, 3, or 3.5 stars; high quality establishments have average ratings of 4, 4.5, or 5 stars. Each establishment included in this location analysis contains at least 3 customer reviews; many have hundreds of reviews. High quality establishments for food, restaurants, and shopping are all localized, but medium and low quality establishments tend to be dispersed. Again, this pattern suggests that the quality of service offered is an important component of service differentiation.

\subsection{Conclusions}

Previous research primarily used the spatial econometrics tools developed in the last decade to understand the spatial distribution of manufacturing and business-services firms. Research using modern methods of spatial distribution analysis developed by Duranton and Overman (2005) to analyze consumer services are rare. We use Yelp data from over 29,000 consumer service establishments to contribute to this growing literature by describing the location patterns of consumer services establishments in the greater Phoenix area.

Localization is generally more prevalent than dispersion in this setting, and service differentiation explains much of the observed clustering of establishments. However, concentration varies across distances, categories of consumer services, cost and quality. The variation in densities at different distances underscores the importance of using a point pattern analysis to describe densities over the entire distribution of distances rather than traditional approaches that rely on a single level of aggregation.

Most previous research does not analyze the spatial distribution of consumer service firms based on cost or quality of the service provided. Our results show substantial clustering among high cost and high quality consumer service establishments. This clustering is consistent with the predictions of the model developed by Fischer and Harrington (1996), who define service differentiation based on variability in consumer willingness to pay. The observed differences in localization by cost and quality highlight the importance of considering more than just industry classification as has previously been the focus in the literature. 
The widespread clustering across many consumer service providers also has important implications for the development of cities as centers of consumption (Glaeser and Gottlieb, 2006) rather than centers of production. Consumers value the enhanced variety of consumption opportunities in cities, relative to the consumption opportunities in less dense areas. Our results show that within cities, service providing firms tend to cluster, providing urban residents with a rich variety of consumption opportunities in spatially concentrated areas. The observed urban clustering of high cost, high quality shopping and dining opportunities provides new insight into the advantages that cities provide their high income residents, relative to smaller cities and rural areas.

The results in this paper motivate additional research. There are several questions left unexplored. For example, how has consumer services localization changed over time? Does the distribution of consumer services in other cities follow the same trends as in the Phoenix area? What factors explain the localization or dispersion of particular categories of consumer services? Answering these types of questions will shed more light on the changing urban landscapes associated with the rise of the consumer city. 


\section{Chapter 3}

\section{Frustrated Customers: The Effect of Unexpected Emotional Cues on Yelp Reviews}

\subsection{Introduction}

Modern cities offer a variety of consumer amenities such as restaurants, nightlife, and shopping centers. With the rise of the consumer city, urban residents actively frequent the densely concentrated centers of consumer venues (Glaeser et al., 2001; Glaeser and Gottlieb, 2006). In evaluating their experiences, consumers leave reviews on online platforms, such as Yelp. Given the platform's popularity, Yelp-rated establishments shape local economic activity (Glaeser et al., 2017) and neighborhood change over time (Glaeser et al., 2018a). Establishments with quality reviews attract more customers. A one star increase in Yelp restaurant reviews causes a 9\% increase in revenue (Luca, 2016), and a half star increase causes restaurants to sell out reservations $49 \%$ more often (Anderson and Magruder, 2012). Given their impact and prevalence, analyzing Yelp reviews can reveal important characteristics of consumer behavior.

Two central theories of consumer behavior are loss aversion and reference dependence (Kahneman and Tversky, 1979). With loss aversion, the pain of losses feels greater than the joy of gains. With reference dependence, the domain of gains and losses is dependent 
upon a reference point. Although important to understanding consumer behavior, there are relatively few empirical tests of loss averse and reference-dependent behavior in real-world settings.

Sporting events are one real-world setting suitable for exploring loss aversion and reference dependence $^{1}$. The reference point depends upon pregame expectations, whether the team is expected to win or lose. Gains and losses are determined by whether the team does better or worse than expected. A growing number of papers use this framework to explore criminal and consumer behavior after unexpected sporting event outcomes. ${ }^{2}$

Card and Dahl (2011) examine the impact of unexpected NFL losses on domestic violence. Consistent with loss aversion and reference dependence, there is no impact for unexpected wins or expected close games. Exploring crime more broadly, Rees and Schnepel (2009) find increased assault, vandalism, DUI, and disorderly conduct violations with unexpected wins and losses for college football games. With celebratory drinking in mind, Lindo et al. (2018) show that unexpected college football wins increase reports of rape. Outside of football, unexpected losses in Brazilian soccer games lead to an increase in vehicle robberies and thefts (Sarmiento-Barbieril et al., 2018) while both unexpected wins and losses impact violent crime following soccer matches in Uruguay (Munyo and Rossi, 2013).

Although these papers exploit the exogeneity of unexpected game outcomes to draw causal inferences, the focus is on criminal behavior rather than consumer behavior. Most closely related to this paper, Ge (2018) finds that after unexpected Knicks basketball wins, taxi-cab tipping increases. However, the presence of social norms leads to no difference in tipping behavior following an unexpected loss.

This paper contributes to this literature in two ways. First, while prior research primarily focuses on criminal behavior, I focus on consumer behavior. Unexpected game outcomes will not necessarily impact consumer behavior in the same way as criminal behavior. Although I am not the first in this literature to examine consumer behavior, the setting of Yelp reviews differs from the tipping behavior explored in Ge (2018). Given strong social norms, tipping

\footnotetext{
${ }^{1}$ Taxi drivers offer another suitable real-world setting (Crawford and Meng, 2011; Farber, 2008, 2015).

${ }^{2}$ Other papers using sports settings but not relying upon unexpected outcomes for identification include Pope and Schweitzer (2011) with loss aversion among professional golfers and Allen et al. (2017) with reference-dependent preferences among marathon runners.
} 
behavior is not a setting where the downside of unexpected losses is likely to be detected. However, there are no such social norms for leaving Yelp reviews. Thus, unlike with tipping behavior, Yelp reviews provide a setting in which both the upside of unexpected wins and the downside of unexpected losses can have an impact.

The second contribution of the paper is increasing understanding of the temporal impact of emotional cues. Card and Dahl (2011) and Ge (2018) find effects concentrated in the hours after games, but can the impact of emotions be observed after a longer period of time? Do people experience fleeting emotions that alter behavior only during a short period of time, or do unexpected game outcomes affect emotions over a longer period of time? By considering the day after unexpected game outcomes, I show that fan emotions are not transient. Negative emotional cues affect behavior the day after games.

To make these contributions, I use Yelp data from over 29,000 businesses in the greater Phoenix, Arizona area to explore the impact of unexpected Phoenix Suns game outcomes on Yelp reviews. Considering nearly one million reviews over five years, the results reveal that unexpected losses lead to lower ratings for Yelp reviews. Unexpected wins, however, do not increase ratings. In addition to reflecting loss aversion, reviewer behavior is consistent with reference-dependent preferences. Wins and losses in games predicted to be close do not impact reviewer behavior. A number of robustness checks rule-out alternative explanations for the results and demonstrate that the findings are not fragile.

The remainder of the paper proceeds as follows. Section 3.2 frames the contributions of the paper within the context of the emotional cues literature. Section 3.3 describes the Yelp and sports data utilized in the empirical approach presented in Section 3.4. Section 3.5 displays the results while Section 3.6 concludes by discussing the implications of the findings and avenues for additional research.

\subsection{Context}

Sporting events evoke emotion. Interview-based evidence in psychology suggests that outcomes not only alter mood but also perceptions of unrelated events. Schwarz et al. (1987) consider two games played by Germany in the 1982 World Cup. They find that 
winning is associated with more positive assessments of the country's economy and national prestige. Similarly, Schweitzer et al. (1992) interview college students after a televised college football game. Students rooting for the losing team judged a war with Iraq as more likely and destructive than students rooting for the winning team. Importantly, in both studies, outcomes from sporting events shape viewers' perceptions of unrelated events. Thus, I explore whether NBA losses lead consumers to leave worse Yelp reviews and whether wins result in better reviews.

The psychology literature suggests that emotions associated with sporting events may be strong enough to elicit different reviewing behavior after wins and losses. However, consumers may be loss averse. The pain of unexpected losses may be greater than any joys associated with unexpected wins. Additionally, consumers' emotions following games may be reference dependent. A loss to the best team in the league may not feel like a loss while a win over the worst team in the league may not feel like much of a win.

In reference-dependent models, a reference point divides outcomes into gains or losses based upon where the outcome falls relative to the reference point. As modeled in Kôszegi and Rabin (2006), the reference point is shaped by the consumer's rational expectations based upon past outcomes. However, in real-world settings, determining a consumer's rational expectations based upon past outcomes is difficult. Thus, it is difficult to determine relevant real-world reference points. With the difficulty of defining reference points in the real-world, experiments have been one prominent way of exploring reference-dependent preferences (Abeler et al., 2011; Ericson and Fuster, 2011; Gill and Prowse, 2012).

One non-experimental setting well-suited for studying reference dependence is sporting events. With sports, both the outcome and the reference point are clearly defined. Teams win or lose games by a precise number of points. For example, the Phoenix Suns could win a close game by 3 points or experience a blowout loss of 15 points. In addition to clearly defined outcomes, reference points for sporting events are clearly defined. Sports betting data serves as a reasonable proxy for consumers' rational expectations based upon past outcomes. Teams are expected to win or lose by a precise number of points. With both expectations and outcomes clearly defined, sporting events are a setting well-suited for testing reference dependence. 
One application of reference dependence in sports comes from studying game attendance. Coates et al. (2014) develop and test a model of consumer choice in attending sporting events. With reference-dependent preferences and loss aversion, fans prefer events with more certain outcomes.

Reference-dependent preferences and loss aversion in sports have often been explored within the context of crime. Rees and Schnepel (2009) explore upset wins and losses across over 1500 college football games. After controlling for regional fixed effects and day of week, holiday, month, and year fixed effects, they compare non-upset outcomes to unexpected wins and losses. Basing upsets upon team's rankings, they find that upset losses result in more assaults, vandalism, and DUIs compared to non-upset losses. They find similar effects for upset wins, although upset wins with their celebratory drinking also increase liquor law violations.

Following Rees and Schnepel (2009), Card and Dahl (2011) consider upset wins and losses in professional football. Rather than defining upsets based upon rankings, they exploit betting lines. With the efficiency of betting markets, deviations from predicted outcomes are treated as exogenous. Using data from 763 city and county police agencies and NFL team data from over 1000 games, they find that upset losses lead to a 10\% increase in domestic violence by men. Consistent with loss aversion, they find no effect for upset wins. Consistent with reference-dependent preferences, there is no effect for losses in games that were expected to be close. Exploiting information on game characteristics, they find the largest effects for games against rivals, games where the team is still in playoff contention, and games with high levels of sacks, turnovers, and penalties.

Most recently, following Card and Dahl (2011), Lindo et al. (2018) evaluate the impact of college football games on sexual assault. Their findings suggest that football games across the 128 schools in Division 1 cause 724 additional rapes per year. While simply having football games leads to more reported rapes, they find that upset wins increase the number of reported rapes. Celebratory drinking following unexpected wins is a plausible link explaining the increase in reported rapes.

Outside of the setting of football games, Munyo and Rossi (2013) and Sarmiento-Barbieril et al. (2018) explore the impact of unexpected soccer game outcomes. Munyo and Rossi 
(2013) find that robberies increase in the hour following unexpected losses for two popular Uruguayan soccer teams. Unlike with Card and Dahl (2011), unexpected wins reduce violent crime. With micro-level spatial data, Sarmiento-Barbieril et al. (2018) consider the spatial and temporal impact of emotional cues on vehicle-related crimes. They find that after unexpected home losses for three popular soccer teams in Brazil, there is an increase in vehicle thefts within two miles of the stadium.

Although Rees and Schnepel (2009), Card and Dahl (2011), Munyo and Rossi (2013), Lindo et al. (2018), and Sarmiento-Barbieril et al. (2018) consider unexpected sports outcomes, they focus on crime rather than consumer behavior. Unexpected game outcomes will not necessarily impact consumer behaviors in the same way as criminal behaviors. For example, emotional cues may not influence everyday consumer behaviors as much as they influence 'crimes of passion'. Thus, it is important to extend the literature to study how unexpected game outcomes impact consumers.

One recent paper does analyze how unexpected game outcomes impact consumer behavior. Ge (2018) explores how unexpected outcomes from New York Knicks' basketball games impact tipping behavior. Based upon data from over 8 million taxi rides, people leaving the arena following an upset win leave 10\% higher tips. Contrary to other studies, Ge (2018) finds no evidence for loss averse behavior. Unexpected losses do not lead to lower tips, likely due to strong social norms in tipping. Following Ge (2018) by focusing on consumers, this paper explores the impact of unexpected NBA outcomes on consumers' perceptions of their experiences at restaurants, shops, bars, etc.

\subsection{Data}

\subsubsection{Yelp Data}

To analyze the effect of unexpected sports outcomes on consumer reviews, I compiled two different data sets. First, I obtained Yelp data from the Yelp dataset challenge. ${ }^{3}$ These

\footnotetext{
${ }^{3}$ Over the last several years, Yelp has made its data for a few cities publicly available through the Yelp dataset challenge. Contestants submit papers using the dataset and representatives from Yelp evaluate the entries based upon the quality of the research and its relevance for Yelp.
} 
data contain the precise latitude and longitude coordinates for nearly 30,000 Yelp-rated establishments in the greater Phoenix, Arizona area. Figure 3.1 shows the location of each Yelp-rated establishment. In addition to location, each establishment also contains several important descriptors.

One important descriptor is category. Yelp establishments are grouped into nearly 1000 categories, sub-categories, and sub-sub-categories. Table 3.1 displays the primary categories, number of establishments, and a representative sample of sub-categories. While restaurants are the most common type of establishment rated on Yelp, the Yelp data contain a wide variety of consumer services.

Each establishment also contains information on user-generated reviews. Customers provide reviews at whole star intervals between 1 star and 5 stars. A review of 1 star reflects a poor experience while 5 stars are awarded for an excellent experience. As reflected in one review given for a popular sports bar the day after a Suns loss, reviewers reflect upon their overall experience when writing reviews:

"This was the first time I've come for food before a Suns game...Our server was nice although I'm not a huge fan of the 'slumpy' dress code with the lazily drawn on makeup to mimic Alice Cooper. I get it but it just didn't look put together. I digress because the food is what matters. My buffalo grilled chicken wrap was very boring. I wished they would add more buffalo sauce because all I was eating was chicken and tortilla. Even the chicken could've used some basic taste like salt and pepper." (2-star review left on 1-20-2017, the day following a loss)

With the unconstrained way in which Yelp elicits reviews, there are potential concerns with using Yelp review data. Luca (2015) frames the potential issues by comparison to traditional surveys such as the Census and National Longitudinal Survey of Youth. While traditional surveys contain national, representative sampling, Yelp users voluntarily provide reviews and no effort is made to create a representative sample of the population.

One potential concern is self-selection. Reviewers with extreme negative experiences, such as finding glass in their food, or extreme positive experiences, such as finding a new favorite hair salon, may be more likely to leave a review than a moderately satisfied diner. Evidence for self-selection with Amazon reviews is documented by Hu et al. (2009), who find a J-shaped distribution for product reviews. However, Dai et al. (2018) document that Yelp 
reviews are unimodal and not J-shaped.

One explanation for why Yelp is not biased by extreme reviews is its incentive system for reviewers. Yelp awards a variety of online badges to reviewers and welcomes the highest quality reviewers into its "Elite Squad". Additionally, individual reviews can by rated as "cool", "funny", or "useful" by other Yelp users. Since behavioral incentive schemes such as badges influence people's participation in providing user generated content (Anderson et al., 2013), Yelp is able to effectively incentivize moderately satisfied customers to leave a review. Since Yelp includes reviews from moderately satisfied customers, low and high reviews following unexpected losses and wins will not be obscured by concentrations of low and high reviews from reviewers with extremely negative or positive experiences.

A second concern with using Yelp review data is fraud. As shown by Luca (2016) and Anderson and Magruder (2012), small differences in Yelp ratings substantially affect business outcomes. Thus, business owners have an incentive to create favorable fake reviews. However, both Luca (2016) and Anderson and Magruder (2012) find no evidence of fake reviews, even in cases where a fraudulent review would generate the highest benefit by boosting an establishment over a half-star threshold.

One explanation for the lack of fake Yelp reviews is that Yelp has an incentive to combat fraud as Yelp's popularity is based upon the reliability of its reviews. As described in Luca and Zervas (2016), Yelp flags and eliminates suspected fake reviews. Additionally, Yelp periodically engages in sting operations by prominently displaying a banner to warn potential consumers on the Yelp pages of businesses with known fake reviews. Fraudulent reviews are not a concern for identifying the impact of unexpected wins and losses on Yelp ratings.

Figure 3.2 shows the average number of reviews per day in the Phoenix area from the start of 2011 through summer 2016. The figure reveals the increasing popularity of Yelp over the period. While the data do contain reviews prior to 2011, I focus on the five NBA seasons since 2011 to avoid small numbers of reviews per day in the Yelp data prior to 2011.

Table 3.2 contains descriptive statistics for the nearly 1 million Yelp reviews. ${ }^{4}$ On average

\footnotetext{
${ }^{4}$ I also perform the analysis with only reviews left during the NBA season (November through April). Although the sample size is reduced to 453,358 reviews, the results are similar and are available upon request.
} 
reviewers leave roughly 3.8 stars. Yelp-rated establishments average nearly 200 reviews, although there is considerable variation in the popularity of establishments.

\subsubsection{Sports Data}

In addition to Yelp data, I also collected data for the Phoenix Suns NBA team across five seasons from the sports betting website covers.com. Table 3.3 displays the descriptive statistics for the 394 Suns games over the five seasons. Having losing records in three of the seasons, the Suns winning percentage over the five seasons was $42.6 \%$. An average betting line $^{5}$ of 2.136 indicates that for an average game the Suns were expected to lose by around 2 points. The minimum of -13.5 indicates that the most the Suns were expected to win by was 13.5 points while the maximum of 18.5 indicates that the most the Suns were expected to lose by was 18.5 points.

Following Ge $(2018)^{6}$ I define games expected to be close as games expected to be decided by one-possession (e.g. by a three-point shot or less). Thus, games are classified into three categories based upon the pre-game point spread: (1) predicted close games (point spread between -3.5 and 3.5); predicted losses (point spread of 3.5 or greater); predicted wins (point spread of -3.5 or less). In 104 games (26\% of games) the Suns were expected to win while in 185 games (47\% of games) the Suns were expected to lose. The remaining 105 games were expected to be close. In 48 games (12\% of games) the Suns were expected to lose but won. In 37 games ( $9 \%$ of games) the Suns were expected to win but lost.

Sports betting data are used to classify expected game outcomes because points spreads are a generally accurate predictor of game outcomes (Lopez and Matthews, 2015). Although there are market anomalies, ${ }^{7}$ the sports betting market is efficient (Sauer, 1998). Real money is on the line. Participants in betting markets have an incentive to make profitable bets.

\footnotetext{
${ }^{5} \mathrm{~A}$ betting line or point spread defines by how much a team must win in order for the bet to win. For example, with a betting line of -7 , a bet on the Suns will only win if the Suns beat their opponent by more than 7 points.

${ }^{6}$ In addition to following the classification in Ge (2018), I also performed the analysis with an alternative definition for unexpected wins and losses. With this classification, an unexpected win is any win where the point spread is positive while an unexpected loss is any loss where the point spread is negative. The results are similar and available upon request.

${ }^{7}$ For example, in the NBA there is a racial bias against teams with more black players (Igan et al., 2015) and a sentiment bias in favor of popular teams (Feddersen et al., 2018).
} 
Accurate predictions are rewarded while poor predictions are punished.

Figure 3.3 plots the relationship between the Suns' point spread and the realized point difference (away point total minus Suns point total). The vertical lines separate the point spreads into three regions: predicted win, predicted close, and predicted loss. The upward sloping best-fit line ${ }^{8}$ shows that as the point spread prediction moves from win to close to loss, the realized point difference increases (the away team wins by a greater margin). Given the accuracy of point spread predictions, losses in games predicted to be wins are unexpected losses. Similarly, wins in games predicted to be losses are unexpected wins. Thus, unexpected wins and losses can be used as an exogenous shock to explore a causal relationship between emotional cues and Yelp reviewer behavior.

Although point spreads are a generally accurate predictor of game outcomes, one concern is that point spreads are not a good proxy for the pre-game expectations of an average person. Many fans may not be aware of the pre-game point spreads. Thus, fans may have different pre-game expectations than expectations derived from sports betting markets. However, Pawlowski et al. (2018) use survey-based evidence to show that pre-game expectations derived from point spreads are strongly correlated to fans' subjective pre-game expectations. Points spreads are a good proxy for pre-game expectations, and therefore serve as a reasonable reference point for exploring the impact of unexpected game outcomes on Yelp reviews.

\subsection{Empirical Approach}

Using the Yelp data and the information on Suns games, I evaluate the effect of unexpected game outcomes on reviews by estimating an equation of the following form:

$$
\text { stars }_{i j k t}=\alpha+\beta_{0} \text { UnexpectedWin }_{i t}+\beta_{1} \text { UnexpectedLoss }_{i t}+\delta \text { controls }_{j}+\mu_{t}+\sigma_{k}+\varepsilon_{i j k t}
$$

where $\operatorname{star}_{i j k t}$ is the number of stars between one and five for review $i$ of establishment $j$ within category $k$ on day $t$. controls $s_{j}$ includes the number of reviews and overall rating of the establishment. $\mu_{t}$ includes the time fixed effects for day of week, month, and year. The category fixed effect $\sigma_{k}$ controls for unobserved differences in ratings across different

\footnotetext{
${ }^{8}$ The slope of the best-fit line is .90 with $R^{2}=.22$.
} 
categories of establishments. Lastly, UnexpectedWin $n_{i t}$ and UnexpectedLoss $s_{i t}$ are the outcome variables of interest. UnexpectedWin $i t$ takes the value of 1 for all reviews on the day following an unexpected win and the value of 0 otherwise. UnexpectedLoss $s_{i t}$ takes the value of 1 for all reviews on the day following an unexpected loss and the value of 0 otherwise.

The goal of the empirical approach is to estimate the effect of unexpected game outcomes on ratings. To ensure that the emotional cue of unexpected game outcomes comes before the review is given, it is important to consider NBA game times. The majority of NBA games take place at night. Across the five seasons considered, the average game start time for the Suns was around 6:30pm mountain time while the median was 7:00pm. With games typically finishing past 9:00pm, the majority of Yelp reviews left on game days are left prior to the end of Suns games. Thus, for games with an unexpected outcome, most reviews on game day are left prior to any emotional cues from an unexpected win or loss. ${ }^{9}$ However, for games with an unexpected outcome, all Yelp reviews given the day after the game come after the emotional cues associated with unexpected wins and losses.

By focusing on the day after unexpected game outcomes, I explore how reviewer behavior changes after an emotional cue. $\beta_{0}$ and $\beta_{1}$ reflect the impact of unexpected wins and unexpected losses on Yelp reviews for establishment $i$ the day after either an unexpected win or unexpected loss.

Besides the timing of Suns games, another potential threat to determining the impact of emotional cues on Yelp reviews is with identifying Yelp reviewers who experience emotional cues from unexpected Suns' game outcomes. Do people in the Phoenix area care about the Phoenix Suns? Importantly, the Suns are the only NBA team in the Phoenix area. Additionally, Giratikanon et al. (2014) show that the Suns are the most popular team in the Phoenix area. Using Facebook likes for different NBA teams in each zip code, Giratikanon et al. (2014) document NBA fan bases across the United States. ${ }^{10}$ Their findings, displayed in Figure 3.4, reveal two different patterns for fan bases.

\footnotetext{
${ }^{9}$ Consistent with the timing of games, there is no impact of unexpected game outcomes for reviews left on game days.

${ }^{10}$ Janhuba (2018) is a recent paper assessing fan base locations with Facebook likes. After unexpected college football home wins, reported life satisfaction is higher in areas with a concentration of Facebook likes for the winning team.
} 
First, dominant teams, such as the Los Angeles Lakers, have fan bases throughout much of the United States. Second, a team's fan base is most concentrated in the city where the team plays. The Phoenix area is no exception; the Suns are the most popular team in the area. Importantly, the Facebook likes data in Giratikanon et al. (2014) show that the Suns are three to four times more popular than the second most popular team for zip codes in the Phoenix area. Although not all Yelp reviewers in the Phoenix area are fans of the Suns, Phoenix is the geographic area where unexpected Suns game outcomes are most likely to impact Yelp reviewer behavior.

The control variables and fixed effects are included in the model to account for systematic differences in reviews across establishments and time. Including a day of week fixed effect is important because reviews vary systematically within each week. Consistent with the common expression, 'Thank God It's Friday' (TGIF), ratings are highest on Fridays. Consistent with 'Monday Blues' associated with the start of the workweek, ratings are lowest on Mondays. Reviews also vary within each year. For example, the month of January is associated with the lowest ratings of any month. Yelp ratings also vary across years, with higher ratings in more recent years. Including day of week, month, and year fixed effects controls for systematic differences in ratings over time. ${ }^{11}$

Since the Yelp data contain a wide variety of consumer services, I control for the type of establishment. $\sigma_{k}$ takes the value of 1 if the establishment falls within a particular category and 0 otherwise. For example, with beauty \& spas, a review left at a hair salon takes the value of 1 while a review for a restaurant takes the value 0 . It is important to control for the type of establishment because Yelp reviews vary systematically by establishment type. For example, restaurants receive lower ratings compared to other establishment types.

In addition to ratings varying across time and categories, ratings also vary across establishments. Some establishments receive more reviews and higher ratings. Thus, controls $s_{j}$ includes the number of reviews and overall rating of the establishment. Including number

\footnotetext{
${ }^{11}$ Another factor that may systematically vary across time with ratings is rainfall. A rainy day may negatively impact reviewers' moods and be reflected in lower ratings. I collect data from the National Oceanic and Atmospheric Administration (NOAA) on daily rainfall amounts in the Phoenix area. However, including a dummy variable that takes the value of 1 on days with any amount of rain and a value of 0 otherwise has no impact on the explanatory power of the models and is never statistically significant. Results with rainfall included are similar to the results presented in the paper and are available upon request.
} 
of reviews is important because more popular establishments generally have higher ratings. Controlling for the overall rating of the establishment means that a review for a particular day is considered relative to how the establishment is normally reviewed. Thus, any effect of unexpected game outcomes on star $_{i j k t}$ reflects reviews for establishment $i$ after a game deviating from the average reviews of establishment $i$.

Given the discrete nature of the dependent variable, the linear regression assumption of a continuous dependent variable is violated. Thus, in addition to the above specification, I also use a logit model. I define a new, binary dependent variable indicating an above average or below average review. Given an average review in the data of 3.8 stars, I define a four or five star review as a positive review and a one, two, or three star review as a negative review. With the logit model, the dependent variable takes the value of one if the review is positive and zero if the review is negative.

\subsection{Results}

\subsubsection{Loss Aversion}

Table 3.4 presents the impact of unexpected wins and losses on Yelp reviews across all establishment categories. Model 1 includes all Suns games, Model 2 focuses on home games, and Model 3 away games. Each model includes establishment characteristics, time fixed effects, and category fixed effects. The results in Model 1 show that unexpected losses cause worse Yelp reviews while there is no effect for unexpected wins. ${ }^{12}$ This finding is indicative of loss aversion. The pain of unexpected losses is greater than any joys associated with unexpected wins. Carrying a negative mood from the previous day, Yelp users give worse reviews.

Unlike with the tipping behavior in Ge (2018), social norms do not prevent consumers from leaving worse reviews following an unexpected loss. Model 2 and Model 3 reveal that

\footnotetext{
${ }^{12}$ Since Rees and Schnepel (2009), Card and Dahl (2011), and Lindo et al. (2018) find that NFL game outcomes impact behavior, one concern is that the effect from unexpected losses is driven by NFL game outcomes and not by NBA game outcomes. However, the NFL and NBA seasons only overlap in November and December. Importantly, only three Phoenix Suns unexpected loss games were played on the same day as games played by the NFL team located in the Phoenix area (the Arizona Cardinals). I re-do the analysis with these three games dropped. The results are similar and available upon request.
} 
the effect is driven by unexpected losses at home. This home court effect is similar to the results in Janhuba (2018) where unexpected outcomes for home college football games, but not away games, impact reported life satisfaction. Watching the game at the stadium or experiencing the social environment nearby the stadium create a shared fan experience that shapes the psychological effects of emotional cues. The logit models in Table 3.5 confirm the findings in Table 3.4. Unexpected losses cause lower Yelp ratings while unexpected wins have no effect.

In Table 3.4, an unexpected loss leads to a .022 decrease in the star ratings of Yelp reviews. With the mean for reviews at 3.785, a .022 decrease from the mean would result in a Yelp review of 3.763 , or a $.6 \%$ decrease from the mean. Interpreting the marginal effects reported in Table 5, an unexpected loss leads to a .9 percentage point decrease in the likelihood of leaving a positive review compared to a negative review.

Although these results are statistically significant, the magnitude of the effect is small. However, the small decrease in ratings for establishments as a whole is expected since this result reflects changes in behavior for all Yelp reviewers in the Phoenix area. On days following an unexpected loss, only a subset of reviewers will have watched the Suns game. Many reviewers would be unaffected by the unexpected loss. Thus, the results from the empirical analysis produce intention-to-treat (ITT) estimates, likely reflecting a lower-bound estimate of the impact of unexpected losses on Yelp reviews. In a subsequent robustness check I explore the impact of unexpected game outcomes across two types of establishments: those with reviewers likely to experience emotional cues from sporting events and those with reviewers who likely do not follow the Suns.

\subsubsection{Reference-Dependent Preferences}

The results from Tables 3.4 and 3.5 show that consumers leave worse reviews the day after unexpected losses. However, these findings on their own do not necessarily reflect reference-dependent preferences. The results may simply reflect fan frustration following any loss. Thus, to clearly identify the results from Tables 3.4 and 3.5 as reflecting reference dependence, I re-do the analysis with games predicted to be close. Of the 105 games predicted 
to be close, there were 32 home losses, 20 away losses, 28 home wins, and 25 away wins. Table 3.6 displays the results. Model 1 contains the OLS results while Model 2 shows the logit results. Each variable reflects the impact of different game outcomes for games predicted to be close. For example, "Predicted Close, Loss (Home)" takes the value of 1 for each day immediately following the 32 home losses and a value of 0 otherwise. Across both models, there is no evidence that losses lead to worse reviews. Additionally, there is no evidence that wins lead to better reviews.

A loss only results in worse reviews if the loss in unexpected. In games that are expected to be close, a loss does not affect reviewer behavior. This suggests that the negative emotions following an unexpected loss are greater than any negative emotions following a loss in a game predicted to be close. In other words, preferences are reference-dependent. The utility decrease from a loss depends upon the reference of pre-game expectations.

The results from Table 3.6 also address an alternative explanation for why Yelp reviews are worse following unexpected losses. Worse reviews could result from crowded establishments providing worse service during Suns games. But if this is the case, reviews would be worse after all games, unlike the results in Table 3.6. Many Yelp-rated establishments are unlikely to be busier because of Suns games. However, sports bars likely are. Therefore, I replicate Table 3.6 but with a focus only on sports bars. The results, which are available upon request, show that there is no relationship between regular Suns games and reviews at sports bars. Worse reviews following unexpected losses do not appear to result from establishments being crowded. The most plausible explanation is that worse reviews following unexpected losses are the result of negative emotional cues.

\subsubsection{Robustness Check - Random Timing}

The results suggest that unexpected Suns' game outcomes affect Yelp reviewer behavior in a manner consistent with loss aversion and reference-dependent preferences. However, perhaps the findings are simply due to random deviations in Yelp reviews over time. Maybe the stars just so happened to align in a manner consistent with loss aversion and referencedependent preferences. Perhaps there would be similar findings by randomly assigning days 
to have unexpected wins and losses.

As a falsification test, I randomly assign unexpected win and loss days across dates spanning each of the 5 seasons. In this test, although each season has the same number of unexpected wins and losses as the actual Suns team, the unexpected wins and losses are assigned to random dates across each season. For example, in the 2015-2016 season the Suns experienced 7 unexpected wins and 9 unexpected losses. Thus, I randomly assigned 7 unique dates to be unexpected wins and 9 unique dates to be unexpected losses between November 1st, 2015 and April 15th, 2016, which corresponds to the length of the season. Each fake unexpected win and loss date is also randomly assigned to be either a home or away game.

Table 3.7 shows the results given these fake dates for unexpected wins and losses. Unlike with the real-world game outcomes, there is no impact of unexpected losses on reviewer behavior. Table 3.7 contains no statistically significant results. However, Table 3.4 with the results from actual game outcomes shows that unexpected losses lead to worse Yelp reviews. If the results in Table 3.4 were due to randomness, then like the falsification test, the models in Table 3.4 would likely yield non-results. Given the non-results of this falsification test, it is unlikely that the findings using actual game outcomes are the result of randomness.

\subsubsection{Robustness Check - Beauty \& Spas and Sports Bars}

Following Suns unexpected losses, Yelp reviews in the Phoenix area are worse. With no effect for unexpected wins or for games expected to be close, reviewer behavior reflects loss aversion and reference-dependent preferences. However, perhaps some unknown factor not included in the analysis just so happens to be affecting all Yelp reviews in the Phoenix area following unexpected losses.

To demonstrate that the results are plausibly linked to unexpected game outcomes rather than some unknown factor, I consider two types of establishments: those with reviewers likely to experience emotional cues from sporting events and those with reviewers who likely do not follow the Suns. Since sports fans gather at sports bars to watch sporting events, sports bars are arguably the type of establishment with customers most likely impacted by the emotional cue of unexpected Suns losses. Although reviews at sports bars comprise only 
$2.5 \%$ of reviews, with nearly a million reviews, there are 22,683 reviews for sports bars. I explore how these reviews are impacted by unexpected game outcomes.

Although sports fans gather at sports bars to watch sporting events, there is no corresponding group of people who purposely gather at a specific type of establishment to avoid watching sporting events. Thus, it is more challenging to determine a specific establishment type with customers least likely to be impacted by emotional cues from unexpected game outcomes. However, by exploring demographic information on basketball game viewership, I consider what establishment types are least likely to serve customers who are Suns fans.

According to the 2013 Nielsen Year in Sports Media report, ${ }^{13}$ females comprise $30 \%$ of NBA TV viewership. Although there are female fans, men make up the majority of those who are most likely to be impacted by emotional cues following unexpected outcomes from sporting events. From Table 3.1, with subcategories such as day spas, hair salons, and nail salons, beauty \& spas is arguably the primary category most focused on serving female customers. With females comprising $30 \%$ of NBA TV viewership, beauty \& spas establishments are less likely to serve customers impacted by emotional cues from unexpected Suns wins and losses. Although reviews at beauty \& spas establishments comprise only $6.1 \%$ of reviews, with nearly a million reviews, there are 55,675 reviews for beauty \& spas establishments. I explore how these reviews are impacted by unexpected game outcomes. ${ }^{14}$

In contrast to beauty \& spas establishments, sports bars are arguably the type of establishment most likely to serve customers who are sports fans cheering for the Suns. Thus, if the negative impact on reviews following unexpected losses is actually caused by unexpected losses, then there should be no effect (or a mitigated effect) with beauty \& spas establishments and a pronounced effect for sports bars.

Table 3.8 displays precisely these results. ${ }^{15}$ In both the OLS model (Model 1) and the

\footnotetext{
${ }^{13}$ The report is available for download at www.nielson.com.

${ }^{14}$ I also consider how the reviews for the subcategories of OBGYNs, bridal, and women's clothing are impacted by unexpected game outcomes. Although these subcategories have relatively low numbers of reviews (1352, 1398, and 3101 respectively), they are arguably more closely linked to female customers than beauty \& spas establishments are. For each of these subcategories, I find no impact of unexpected game outcomes on reviewer behavior.

${ }^{15}$ Since the main analysis indicates that the effect of unexpected losses is not present for away games, I display results for home games only. If ratings for beauty \& spas establishments are impacted by unexpected Suns outcomes, the effect is most likely to be with home games. I also consider both home and away games. Across all games, there is also no effect for beauty \& spas establishments but still an effect for sports bars.
} 
logit model (Model 2), I explore the interaction between category type and unexpected home game outcomes. Across both models, neither unexpected wins nor losses have any impact on reviews for beauty \& spas establishments. However, with sports bars, there is a pronounced effect following unexpected losses. In Model 1, an unexpected loss leads to a .209 decrease in ratings. With the mean for reviews at 3.785, a .209 decrease from the mean would result in a Yelp review of 3.576, or a 5.5\% decrease from the mean. This impact is nearly 10 times larger than the impact across all Yelp reviews. Interpreting the marginal effects from the logit model reported in Model 2, an unexpected loss leads to a 5 percentage point decrease in the likelihood of leaving a positive review compared to a negative review. This impact is over 5 times larger than the impact across all Yelp reviews.

Following unexpected Suns losses, beauty \& spas establishments experience no change in reviewer behavior. However, sports bars experience an up to 10 times larger decrease in the star-ratings of reviews compared to the decrease for Yelp establishments as a whole. The most plausible explanation is that unexpected Suns losses influence reviewer behavior.

\subsubsection{Robustness Check - Alternative Explanations}

The above regressions and robustness checks provide evidence that unexpected losses by the Phoenix Suns basketball team cause Yelp reviews in the Phoenix area to be worse the following day. Arguably the most natural interpretation of the findings is that unexpected losses provide a negative emotional cue that causes people to leave worse Yelp reviews. However, in this section I consider two alternative explanations.

First, perhaps the results are driven by people leaving reviews at lower-quality establishments following unexpected losses. If this explanation is correct, then the observed lower ratings following unexpected losses are not the result of emotional cues but of establishment differences. To determine the plausibility of this explanation, I compare the mean ratings of establishments that received at least one review on the day after an unexpected loss to establishments that did not. The left side of Figure 3.5 shows that there is no difference between the mean ratings of these two types of establishments. In terms of ratings, there is no difference between establishments rated following unexpected losses and establishments 
that are not.

Second, perhaps the results are driven by harsh critiques or generally sad people leaving negative reviews following unexpected losses. If this explanation is correct, then the observed lower ratings following unexpected losses are not the result of emotional cues but of reviewer differences. To determine the plausibility of this explanation, I compare the mean ratings for reviewers who gave at least one review on a day following an unexpected loss to the mean ratings of reviewers who did not. The right side of Figure 3.5 shows that there is no difference between the mean ratings of these two types of reviewers. In terms of ratings given, there is no difference between reviewers leaving reviews after unexpected losses and reviewers who do not.

\subsection{Conclusion}

I use Yelp data for over 29,000 businesses in the greater Phoenix, Arizona area to explore the impact of unexpected Phoenix Suns game outcomes on Yelp reviews. Considering nearly one million reviews over five years, the results reveal that unexpected losses lead to lower ratings for Yelp reviews. However, unexpected wins and outcomes for games that were expected to be close do not impact reviewer behavior. Consumer services that cater to NBA fans (e.g. sports bars) experience pronounced effects. However, consumer services with customers unlikely to be NBA fans (e.g. beauty \& spas) have no change in reviews.

The results in this paper are consistent with loss aversion. The pain of unexpected losses is greater than any joys associated with unexpected wins. Consistent with referencedependent preferences, the negative effects of losing are only present with unexpected losses. The utility decrease from a loss depends upon the reference of pre-game expectations. A broader implication of this paper is that consumers are affected by emotions over a longer time horizon than what has been observed in prior studies. A 'hangover effect' exists; NBA outcomes impact Yelp reviews the next day.

Unexpected negative emotional cues cause worse Yelp reviews, and worse Yelp reviews negatively impact businesses. Worse Yelp reviews lead to lower revenue (Luca, 2016) and selling out reservations less often (Anderson and Magruder, 2012). With no impact for 
unexpected wins and a negative impact for unexpected losses, emotional cues from Suns games have an overall negative impact on Yelp reviews in Phoenix, and therefore, an overall negative impact on businesses. However, policy implications are unclear for two reasons.

First, any negative impact of unexpected losses on businesses is likely small. For establishments as a whole, an unexpected loss leads to a .6\% decrease in Yelp ratings. Importantly, this impact is only for the 37 unexpected losses over the five Suns seasons. Even with sports bars, where unexpected losses lead to a $5.5 \%$ decrease in ratings, this impact for roughly 7 days per year likely has a small overall impact on establishment ratings.

Second, given the negative impact across Phoenix, it is unclear what impact worse reviews have on establishments. For example, if all sports bars have slightly worse reviews because of unexpected losses, it is unclear whether this would lead to a negative impact for any individual sports bar. However, if proximity effects exist, then establishments nearest to the arena could be negatively impacted. Following unexpected losses, reviews of establishments closest to the arena may be lower than reviews of establishments further from the arena. With the agglomeration of consumer services around sports facilities (Humphreys and Zhou, 2015), unexpected losses could cause a disproportionately negative impact around clusters of consumer services near Talking Stick Arena. However, I find no evidence of proximity effects with sports bars or with establishments as a whole. ${ }^{16}$ The impact of unexpected losses on Yelp reviews does not vary based upon distance to the arena.

The results in this paper suggest a number of avenues for additional research. One extension is to identify Yelp reviewers who have attended Suns games. Considering all Yelp reviews in the Phoenix area the day after an unexpected loss as the treatment group likely yields a lower-bound estimate of the effect since many reviewers in the Phoenix area are unaffected by Suns games. More accurately identifying the treatment group would lead to a more accurate estimate of the impact of emotional cues on Yelp reviews. A second extension is to explore whether changes in worker behavior following unexpected losses leads to worse Yelp reviews. Worse reviews after unexpected losses may not only be due to the impact

\footnotetext{
${ }^{16}$ To test for proximity effects, I re-do the analysis but with establishments separated based upon distance (e.g. within 10 miles, 10-20 miles, and more than 20 miles from the arena). Regardless of how I separate the establishments by distance, there is no evidence of proximity effects. The impact of negative emotional cues is consistent across distance.
} 
of emotional cues on customers but also from frustrated workers providing lower quality service. Additional research using Yelp data can lead to a better understanding of city life in the 21st century (Glaeser et al., 2018b) by revealing how customers interact with urban consumer services.

\section{Tables and Figures}


Table 3.1: Yelp Consumer Service Categories

\begin{tabular}{|c|c|c|}
\hline Primary Category & Obs & Sample Subcategories \\
\hline Active Life & 1,234 & $\begin{array}{l}\text { Fitness \& Instruction, Golf, Laser Tag, Parks, Swimming } \\
\text { Pools }\end{array}$ \\
\hline $\begin{array}{l}\text { Arts \& Entertain- } \\
\text { ment }\end{array}$ & 528 & $\begin{array}{l}\text { Art Galleries, Cinema, Museums, Opera \& Ballet, Per- } \\
\text { forming Arts }\end{array}$ \\
\hline Automotive & 2,332 & $\begin{array}{l}\text { Body Shops, Car Dealers, Car Wash, Gas \& Service Sta- } \\
\text { tions, Parking }\end{array}$ \\
\hline Beauty \& Spas & 3,061 & Day Spas, Hair Salons, Massage, Nail Salons, Tanning \\
\hline Education & 378 & $\begin{array}{l}\text { Adult Education, Elementary Schools, Middle Schools \& } \\
\text { High Schools, Specialty Schools, Test Preparation }\end{array}$ \\
\hline $\begin{array}{l}\text { Event Planning \& } \\
\text { Services }\end{array}$ & 982 & $\begin{array}{l}\text { Caterers, Party Supplies, Photographers, Wedding Plan- } \\
\text { ning, Valet Services }\end{array}$ \\
\hline Financial Services & 528 & $\begin{array}{l}\text { Banks \& Credit Unions, Financial Advising, Insurance, } \\
\text { Investing, Tax Services }\end{array}$ \\
\hline Food & 2,661 & Bakeries, Breweries, Coffee \& Tea, Desserts, Grocery \\
\hline Health \& Medical & 3,104 & $\begin{array}{l}\text { Counseling \& Mental Health, Dentists, Doctors, Family } \\
\text { Practice, Hospitals }\end{array}$ \\
\hline Home Services & 3,164 & $\begin{array}{l}\text { Carpeting, Electricians, Home Cleaning, Plumbing, Tree } \\
\text { Services }\end{array}$ \\
\hline Hotels \& Travel & 753 & $\begin{array}{l}\text { Airports, Car Rental, Hotels, Tours, Transportation, } \\
\text { Child Care \& Day Care, Community Service/Non-Profit, }\end{array}$ \\
\hline Local Services & 1,907 & $\begin{array}{l}\text { IT Services \& Computer Repair, Pest Control, Self Stor- } \\
\text { age }\end{array}$ \\
\hline Nightlife & 993 & Bars, Comedy Clubs, Dance Clubs, Karaoke, Pool Halls \\
\hline Pets & 746 & $\begin{array}{l}\text { Animal Shelters, Pet Adoption, Pet Services, Pet Stores, } \\
\text { Veterinarians, }\end{array}$ \\
\hline $\begin{array}{l}\text { Professional Ser- } \\
\text { vices }\end{array}$ & 554 & $\begin{array}{l}\text { Accountants, Architects, Lawyers, Marketing, Web De- } \\
\text { sign }\end{array}$ \\
\hline Real Estate & 830 & $\begin{array}{l}\text { Apartments, Mobile Home Dealers, Mortgage Brokers, } \\
\text { Property Management, Real Estate Agents }\end{array}$ \\
\hline Restaurants & 6,259 & $\begin{array}{l}\text { American (Traditional), Fast Food, Chinese, Italian, } \\
\text { Seafood }\end{array}$ \\
\hline Shopping & 4,437 & $\begin{array}{l}\text { Arts \& Crafts, Department Stores, Electronics, Fashion, } \\
\text { Sporting Goods }\end{array}$ \\
\hline
\end{tabular}


Table 3.2: Descriptive Statistics for Reviews

\begin{tabular}{lcccc}
\hline \hline Statistic & Mean & St. Dev. & Min & Max \\
\hline Stars for Reviews & 3.785 & 1.453 & 1 & 5 \\
Stars for Establishments & 3.791 & 0.743 & 1 & 5 \\
Review Count & 188.567 & 262.248 & 3 & 1,938 \\
$\mathrm{~N}$ & 907,339 & & & \\
\hline \hline
\end{tabular}

Table 3.3: Descriptive Statistics for Suns Games

\begin{tabular}{lcccc}
\hline \hline Statistic & Mean & St. Dev. & Min & Max \\
\hline Win & 0.426 & 0.495 & 0 & 1 \\
Home & 0.500 & 0.501 & 0 & 1 \\
Phoenix Betting Line & 2.136 & 6.857 & -13.5 & 18.5 \\
Predicted to Lose & 0.470 & 0.500 & 0 & 1 \\
Predicted Close & 0.266 & 0.443 & 0 & 1 \\
Predicted to Win & 0.264 & 0.441 & 0 & 1 \\
Unexpected Loss & 0.094 & 0.292 & 0 & 1 \\
Unexpected Win & 0.122 & 0.328 & 0 & 1 \\
N & 394 & & & \\
\hline \hline
\end{tabular}


Table 3.4: Effects of Unexpected Wins and Losses on Reviews

\section{Stars}

(1)

$(2)$

(3)

\begin{tabular}{lc}
\hline Unexpected Win & -0.004 \\
& $(0.009)$ \\
Unexpected Loss & $-0.022^{* *}$ \\
& $(0.010)$
\end{tabular}

Unexpected Home Win

$-0.013$

Unexpected Home Loss

$-0.021^{* *}$

(0.011)

Unexpected Away Win

0.002

Unexpected Away Loss

Unexpected Away Loss

$-0.027$

$(0.030)$

\begin{tabular}{lccc}
\hline Observations & 907,460 & 907,460 & 907,460 \\
$\mathrm{R}^{2}$ & 0.247 & 0.247 & 0.247 \\
Establishment Characteristics & $\mathrm{Y}$ & $\mathrm{Y}$ & $\mathrm{Y}$ \\
Time FEs & $\mathrm{Y}$ & $\mathrm{Y}$ & $\mathrm{Y}$ \\
Category FEs & $\mathrm{Y}$ & $\mathrm{Y}$ & $\mathrm{Y}$ \\
\hline \hline
\end{tabular}

Note:

$$
{ }^{*} \mathrm{p}<0.1 ;{ }^{* *} \mathrm{p}<0.05 ;{ }^{* * *} \mathrm{p}<0.01
$$

Constant included but not reported

Standard Errors in parentheses 
Table 3.5: Effects of Unexpected Wins and Losses on Reviews (Logit Model)

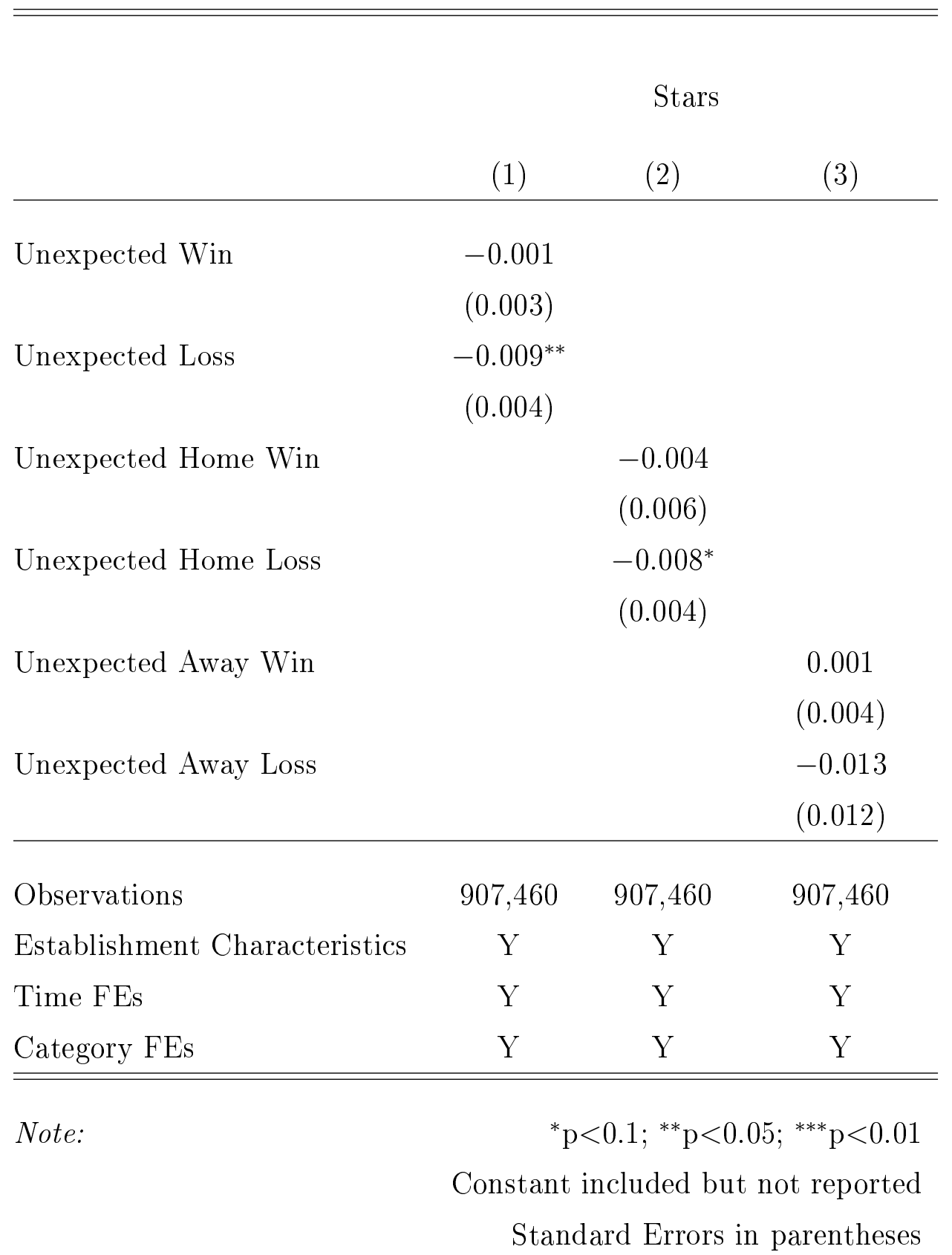


Table 3.6: The Effects of Wins and Losses on Reviews in Games Expected to be Close

\begin{tabular}{lcc}
\hline \hline & \multicolumn{2}{c}{ Stars } \\
& $(1)$ & $(2)$ \\
\hline Predicted Close, Loss (Home) & 0.006 & 0.002 \\
& $(0.011)$ & $(0.004)$ \\
Predicted Close, Loss (Away) & 0.002 & 0.001 \\
& $(0.013)$ & $(0.005)$ \\
Predicted Close, Win (Home) & -0.013 & -0.004 \\
& $(0.012)$ & $(0.005)$ \\
Predicted Close, Win (Away) & $-0.021^{*}$ & $-0.010^{*}$ \\
& $(0.012)$ & $(0.005)$ \\
\hline Observations & 907,460 & $\mathrm{Y}$ \\
$\mathrm{R}^{2}$ & 0.247 & $\mathrm{Y}$ \\
Establishment Characteristics & $\mathrm{Y}$ & - \\
Time FEs & $\mathrm{Y}$ & $\mathrm{Y}$ \\
Category FEs & & \\
\hline \hline
\end{tabular}

Note:

${ }^{*} \mathrm{p}<0.1 ;{ }^{* *} \mathrm{p}<0.05 ;{ }^{* * *} \mathrm{p}<0.01$

Constant included but not reported

Standard Errors in parentheses 
Table 3.7: Robustness Check - Random Timing

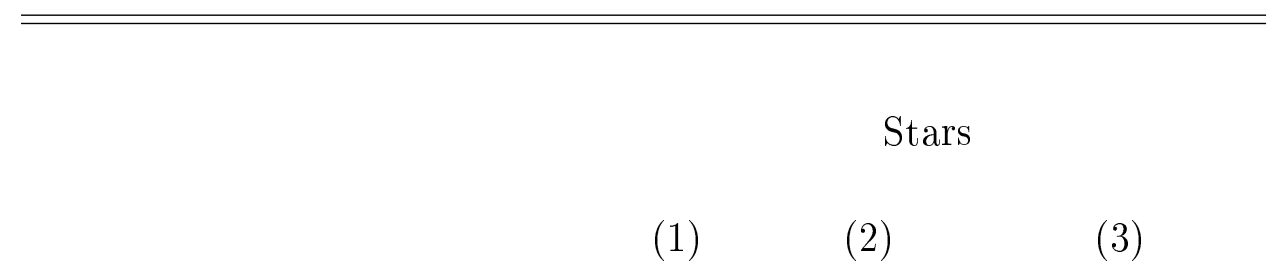

Fake Unexpected Win

$-0.014$

Fake Unexpected Loss

$-0.014$

$(0.010)$

Fake Unexpected Home Win

$-0.032$

Fake Unexpected Home Loss

$-0.004$

$(0.015)$

Fake Unexpected Away Win

0.011

(0.018)

Fake Unexpected Away Loss

0.014

$(0.026)$

\begin{tabular}{lccc} 
Observations & 907,460 & 907,460 & 907,460 \\
$\mathrm{R}^{2}$ & 0.247 & 0.247 & 0.247 \\
Establishment Characteristics & $\mathrm{Y}$ & $\mathrm{Y}$ & $\mathrm{Y}$ \\
Time FEs & $\mathrm{Y}$ & $\mathrm{Y}$ & $\mathrm{Y}$ \\
Category FEs & $\mathrm{Y}$ & $\mathrm{Y}$ & $\mathrm{Y}$ \\
\hline \hline
\end{tabular}

Note:

${ }^{*} \mathrm{p}<0.1 ;{ }^{* *} \mathrm{p}<0.05 ;{ }^{* * *} \mathrm{p}<0.01$

Constant included but not reported

Standard Errors in parentheses 
Table 3.8: Robustness Check - Beauty \& Spas and Sports Bars

\section{Stars}

(1)

$(2)$

\begin{tabular}{lcc}
\hline Unexpected Win Beauty \& Spas (Home) & -0.039 & -0.020 \\
& $(0.058)$ & $(0.025)$ \\
Unexpected Loss Beauty \& Spas (Home) & -0.001 & -0.006 \\
& $(0.040)$ & $(0.018)$ \\
Unexpected Win Sports Bar (Home) & -0.020 & -0.011 \\
& $(0.105)$ & $(0.036)$ \\
Unexpected Loss Sports Bar (Home) & $-0.209^{* * *}$ & $-0.050^{* *}$ \\
& $(0.063)$ & $(0.024)$ \\
\hline Observations & 907,460 & 907,460 \\
$\mathrm{R}^{2}$ & 0.247 & - \\
Establishment Characteristics & $\mathrm{Y}$ & $\mathrm{Y}$ \\
Time FEs & $\mathrm{Y}$ & $\mathrm{Y}$ \\
Category FEs & $\mathrm{Y}$ & ${ }^{*} \mathrm{p}<0.1 ;{ }^{* *} \mathrm{p}<0.05 ;{ }^{* * *} \mathrm{p}<0.01$ \\
\hline \hline & & Standard Errors in parentheses
\end{tabular}


Figure 3.1: Spatial Distribution of Consumer Services Establishments in Phoenix

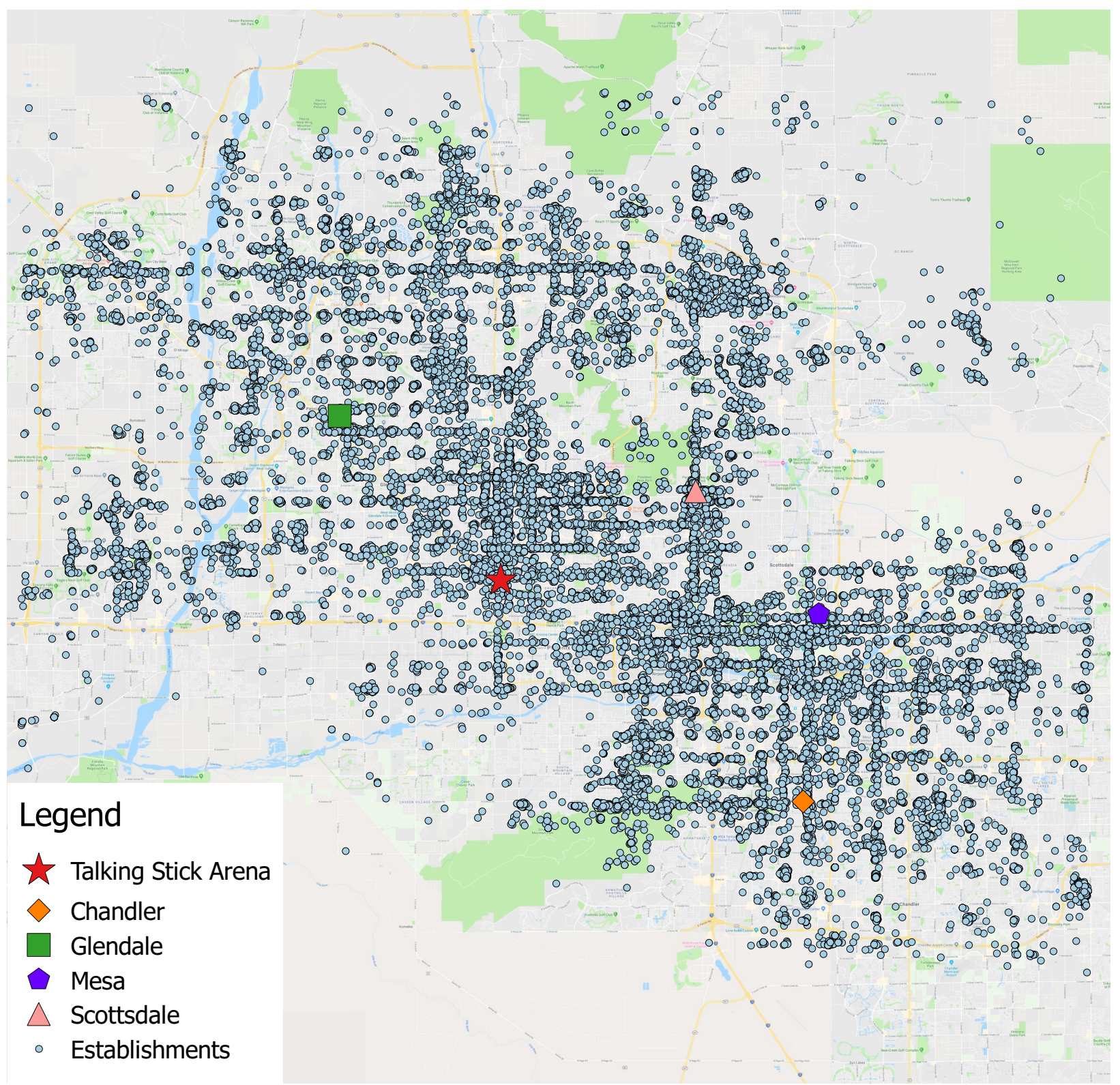

\section{$\begin{array}{llllll}2.5 & 0 & 2.5 & 5 & 7.5 & 10 \text { miles }\end{array}$}


Figure 3.2: Reviews by Day

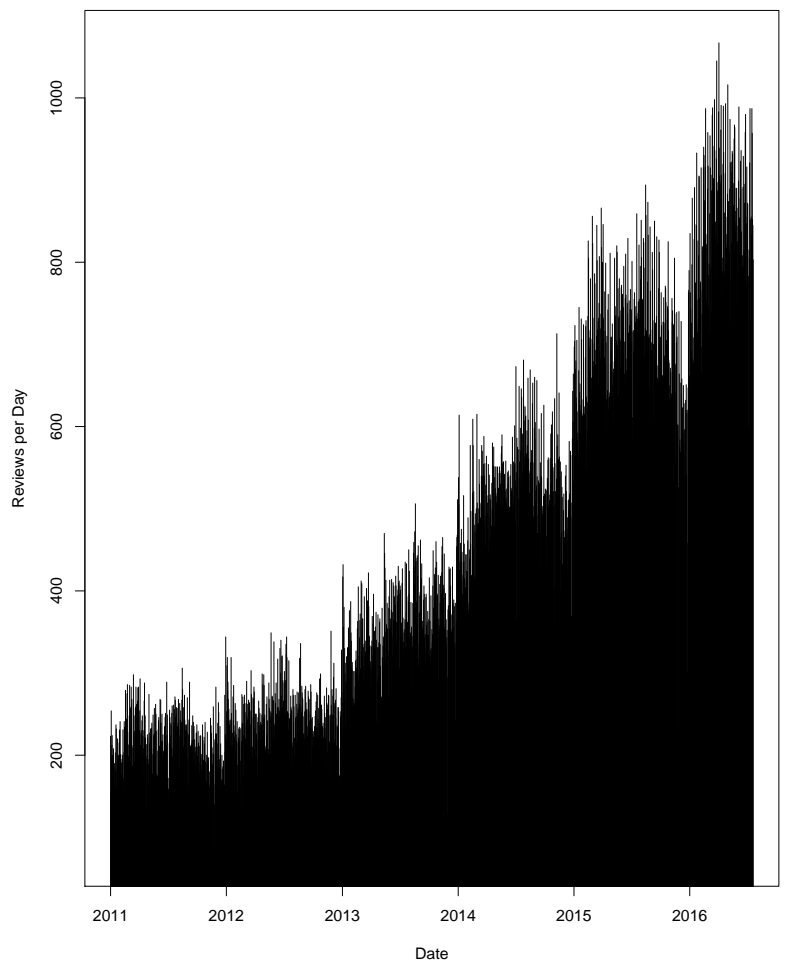

Figure 3.3: Point Spreads vs. Realized Point Differences

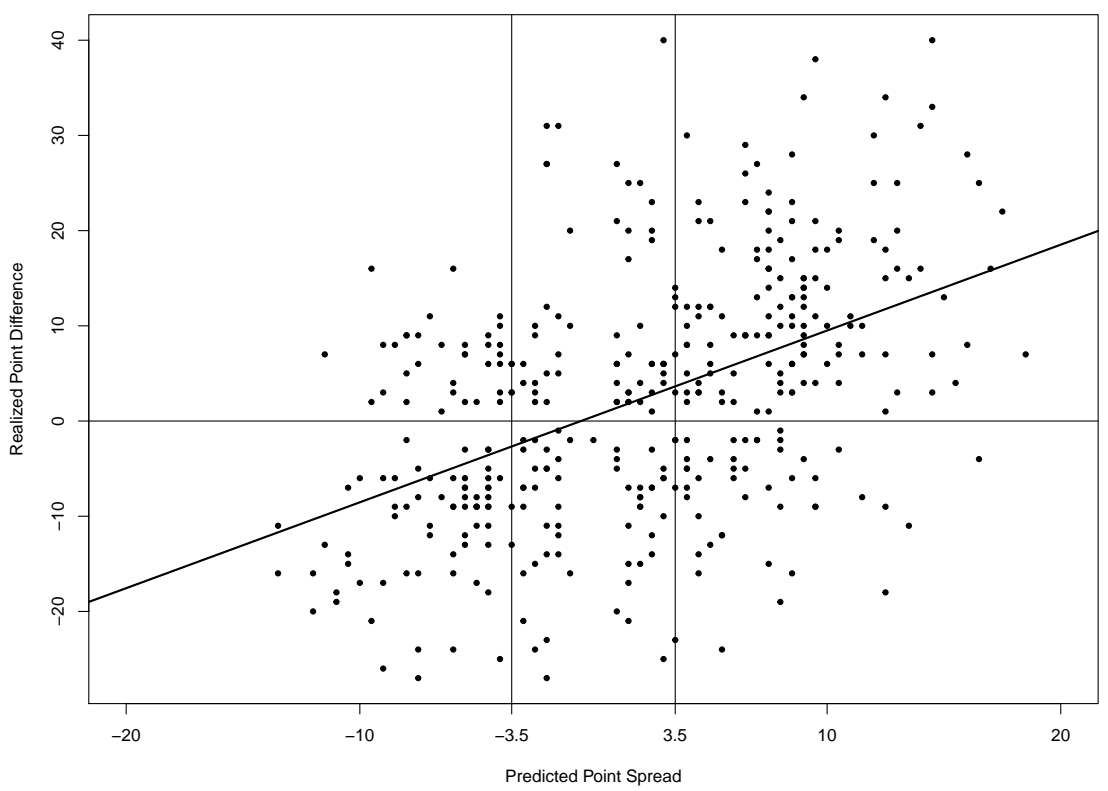


Figure 3.4: NBA Fan Bases Across the United States

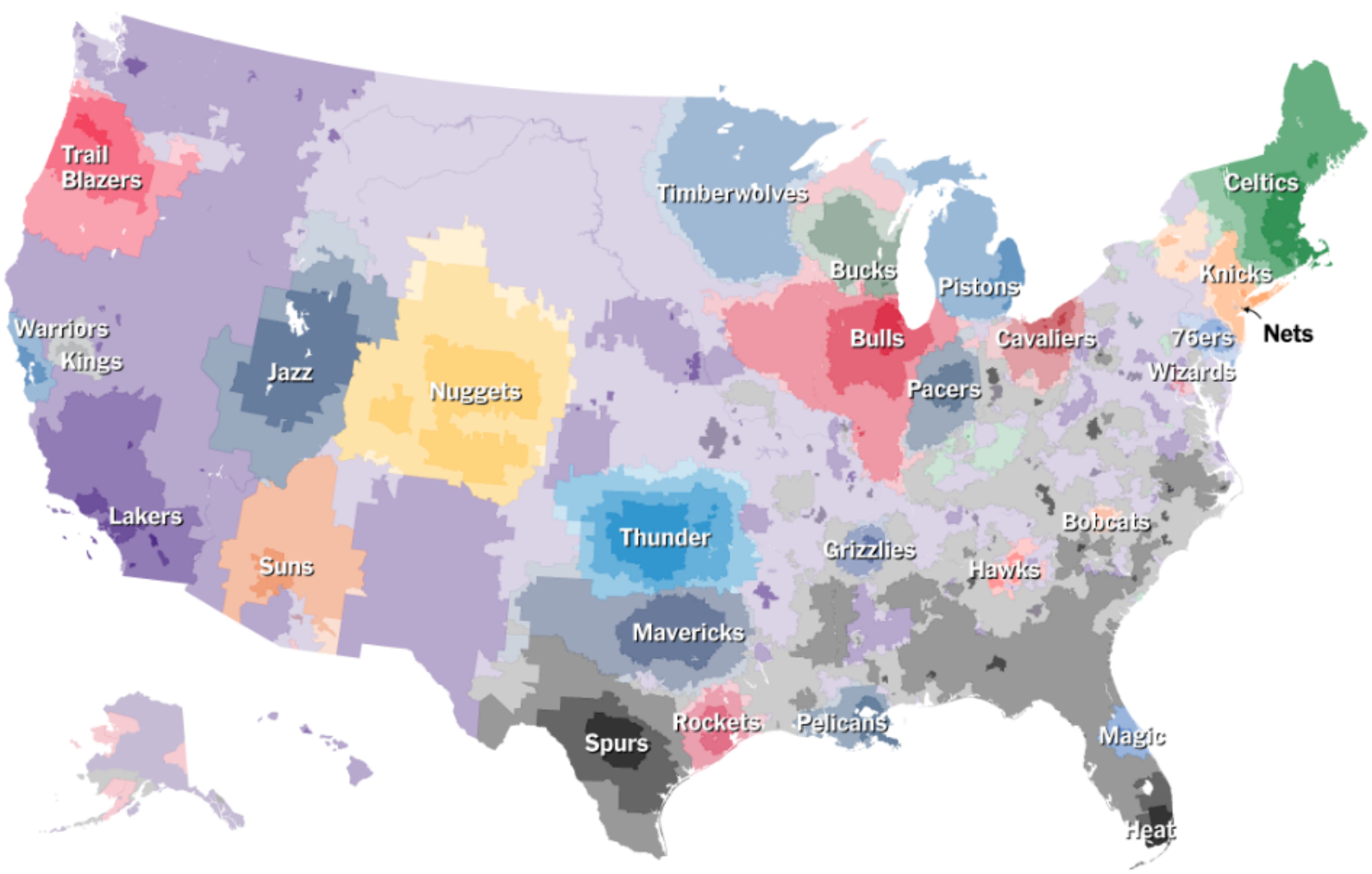

Source: Giratikanon et al. (2014)

Figure 3.5: Differences in Means
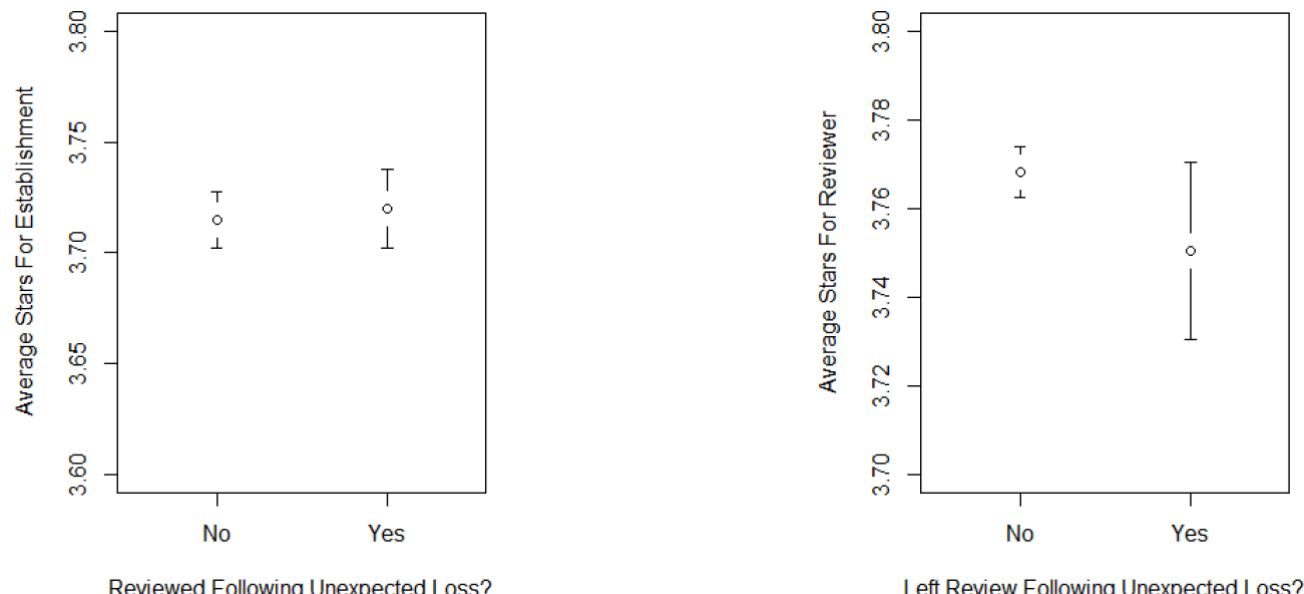

Note: Differences in means evaluated with Welch's two-sample t-test. 95\% confidence intervals are displayed. 


\section{Bibliography}

Abeler, J., Falk, A., Goette, L., and Huffman, D. (2011). Reference points and effort provision. American Economic Review, 101(2):470-92.

Allen, E. J., Dechow, P. M., Pope, D. G., and Wu, G. (2017). Reference-dependent preferences: Evidence from marathon runners. Management Science, 63(6):1657-1672.

Anas, A. (2007). A unified theory of consumption, travel and trip chaining. Journal of Urban Economics, 62(2):162-186.

Anderson, A., Huttenlocher, D., Kleinberg, J., and Leskovec, J. (2013). Steering user behavior with badges. In Proceedings of the 22nd international conference on World Wide Web, pages $95-106$. ACM.

Anderson, M. and Magruder, J. (2012). Learning from the crowd: Regression discontinuity estimates of the effects of an online review database. The Economic Journal, 122(563):957989.

Auty, S. (1992). Consumer choice and segmentation in the restaurant industry. Service Industries Journal, 12(3):324-339.

Barff, R. A. (1987). Industrial clustering and the organization of production: a point pattern analysis of manufacturing in Cincinnati, Ohio. Annals of the Association of American Geographers, 77(1):89-103.

Barlet, M., Briant, A., and Crusson, L. (2013). Location patterns of service industries in France: A distance-based approach. Regional Science and Urban Economics, 43(2):338351.

Beckers, P. and Boschman, S. (2017). Residential choices of foreign highly skilled workers in the Netherlands and the role of neighbourhood and urban regional characteristics. Urban Studies.

Behrens, K. and Bougna, T. (2015). An anatomy of the geographical concentration of Canadian manufacturing industries. Regional Science and Urban Economics, 51:47-69. 
Billings, S. B. and Johnson, E. B. (2016). Agglomeration within an urban area. Journal of Urban Economics, 91:13-25.

Biscaia, R. and Mota, I. (2013). Models of spatial competition: A critical review. Papers in Regional Science, 92(4):851-871.

Brekke, K. R., Siciliani, L., and Straume, O. R. (2010). Price and quality in spatial competition. Regional Science and Urban Economics, 40(6):471-480.

Card, D. and Dahl, G. B. (2011). Family violence and football: The effect of unexpected emotional cues on violent behavior. The Quarterly Journal of Economics, 126(1):103-143.

Carter, C. (2009). Review articles: What we know about shopping centers. Journal of Real Estate Literature, 17(2):163-180.

Coates, D., Humphreys, B. R., and Zhou, L. (2014). Reference-dependent preferences, loss aversion, and live game attendance. Economic Inquiry, 52(3):959-973.

Crawford, V. P. and Meng, J. (2011). New York City cab drivers' labor supply revisited: Reference-dependent preferences with rational-expectations targets for hours and income. American Economic Review, 101(5):1912-32.

Dai, W., Jin, G. Z., Lee, J., and Luca, M. (2018). Aggregation of consumer ratings: An application to yelp.com. National Bureau of Economic Research Working Paper No. 18567.

Dixit, A. K. and Stiglitz, J. E. (1977). Monopolistic competition and optimum product diversity. The American Economic Review, 67(3):297-308.

Duranton, G. and Overman, H. G. (2005). Testing for localization using micro-geographic data. The Review of Economic Studies, 72(4):1077-1106.

Duranton, G. and Overman, H. G. (2008). Exploring the detailed location patterns of UK manufacturing industries using microgeographic data. Journal of Regional Science, 48(1):213-243. 
Economides, N. (1993). Quality variations in the circular model of variety-differentiated products. Regional Science and Urban Economics, 23(2):235-257.

Ellison, G. and Glaeser, E. L. (1997). Geographic concentration in US manufacturing industries: a dartboard approach. Journal of Political Economy, 105(5):889-927.

Ellison, G., Glaeser, E. L., and Kerr, W. R. (2010). What causes industry agglomeration? evidence from coagglomeration patterns. The American Economic Review, 100(3):11951213.

Ericson, K. M. and Fuster, A. (2011). Expectations as endowments: Evidence on referencedependent preferences from exchange and valuation experiments. The Quarterly Journal of Economics, 126(4):1879-1907.

Farber, H. S. (2008). Reference-dependent preferences and labor supply: The case of New York City taxi drivers. American Economic Review, 98(3):1069-82.

Farber, H. S. (2015). Why you can't find a taxi in the rain and other labor supply lessons from cab drivers. The Quarterly Journal of Economics, 130(4):1975-2026.

Feddersen, A., Humphreys, B. R., and Soebbing, B. P. (2018). Sentiment bias in national basketball association betting. Journal of Sports Economics, 19(4):455-472.

Firgo, M. and Kügler, A. (2018). Cooperative pricing in spatially differentiated markets. Regional Science and Urban Economics, 73:51-67.

Fischer, J. H. and Harrington, J. E. (1996). Product variety and firm agglomeration. The RAND Journal of Economics, pages 281-309.

Gao, G. G., Greenwood, B. N., Agarwal, R., and McCullough, J. S. (2015). Vocal minority and silent majority: How do online ratings reflect population perceptions of quality? MIS Quarterly, 39(3):565-589.

Gaynor, M. and Town, R. J. (2011). Competition in health care markets. Technical report, National Bureau of Economic Research. 
Ge, Q. (2018). Sports sentiment and tipping behavior. Journal of Economic Behavior \& Organization, 145:95-113.

Gill, D. and Prowse, V. (2012). A structural analysis of disappointment aversion in a real effort competition. American Economic Review, 102(1):469-503.

Giratikanon, T., Katz, J., Leonhardt, D., and Quealy, K. (2014). Which team do you cheer for? An N.B.A. fan map. The New York Times.

Glaeser, E. L. and Gottlieb, J. D. (2006). Urban resurgence and the consumer city. Urban Studies, 43(8):1275-1299.

Glaeser, E. L., Kim, H., and Luca, M. (2017). Nowcasting the local economy: Using yelp data to measure economic activity. Working Paper 24010, National Bureau of Economic Research.

Glaeser, E. L., Kim, H., and Luca, M. (2018a). Nowcasting gentrification: Using Yelp data to quantify neighborhood change. AEA Papers and Proceedings, 108:77-82.

Glaeser, E. L., Kolko, J., and Saiz, A. (2001). Consumer city. Journal of Economic Geography, 1(1):27-50.

Glaeser, E. L., Kominers, S. D., Luca, M., and Naik, N. (2018b). Big data and big cities: The promises and limitations of improved measures of urban life. Economic Inquiry, $56(1): 114-137$.

Gravelle, H. (1999). Capitation contracts: access and quality. Journal of Health Economics, $18(3): 315-340$.

Gravelle, H., Scott, A., Sivey, P., and Yong, J. (2016). Competition, prices and quality in the market for physician consultations. The Journal of Industrial Economics, 64(1):135-169.

Hu, N., Zhang, J., and Pavlou, P. A. (2009). Overcoming the j-shaped distribution of product reviews. Communications of the ACM, 52(10):144-147. 
Humphreys, B. R. and Zhou, L. (2015). Sports facilities, agglomeration, and public subsidies. Regional Science and Urban Economics, 54:60-73.

Igan, D., Pinheiro, M., and Smith, J. (2015). A study of a market anomaly: "White men can't jump", but would you bet on it? Journal of Economic Behavior 8 Organization, $113: 13-25$.

Janhuba, R. (2018). Do victories and losses matter? Effects of football on life satisfaction. Journal of Economic Psychology.

Jin, G. Z. and Leslie, P. (2009). Reputational incentives for restaurant hygiene. American Economic Journal: Microeconomics, 1(1):237-267.

Kahneman, D. and Tversky, A. (1979). Prospect theory: An analysis of decision under risk. Econometrica, 47(2):263-291.

Konishi, H. (2005). Concentration of competing retail stores. Journal of Urban Economics, $58(3): 488-512$.

Köszegi, B. and Rabin, M. (2006). A model of reference-dependent preferences. The Quarterly Journal of Economics, 121(4):1133-1165.

Kuang, C. (2017). Does quality matter in local consumption amenities? An empirical investigation with yelp. Journal of Urban Economics, 34:1-18.

Leslie, T. F. and Ó hUallacháin, B. (2006). Polycentric Phoenix. Economic Geography, $82(2): 167-192$.

Li, X. and Hitt, L. M. (2010). Price effects in online product reviews: An analytical model and empirical analysis. MIS quarterly, 34(4):809-831.

Liao, H. and Chuang, A. (2004). A multilevel investigation of factors influencing employee service performance and customer outcomes. Academy of Management Journal, 47(1):4158. 
Lindo, J. M., Siminski, P., and Swensen, I. D. (2018). College party culture and sexual assault. American Economic Journal: Applied Economics, 10(1):236-65.

Lopez, M. J. and Matthews, G. J. (2015). Building an NCAA men's basketball predictive model and quantifying its success. Journal of Quantitative Analysis in Sports, 11(1):5-12.

Luca, M. (2015). User-generated content and social media. In Handbook of Media Economics, pages 563-592. Elsevier.

Luca, M. (2016). Reviews, reputation, and revenue: The case of yelp.com. Harvard Business School, Working Paper 12-016.

Luca, M. and Zervas, G. (2016). Fake it till you make it: Reputation, competition, and yelp review fraud. Management Science, 62(12):3412-3427.

Marcon, E. and Puech, F. (2003). Evaluating the geographic concentration of industries using distance-based methods. Journal of Economic Geography, 3(4):409-428.

Marcon, E. and Puech, F. (2009). Measures of the geographic concentration of industries: improving distance-based methods. Journal of Economic Geography, 10(5):745-762.

Marcon, E., Traissac, S., Puech, F., Lang, G., et al. (2015). Tools to characterize point patterns: dbmss for R. Journal of Statistical Software, 67(3):1-15.

Matsa, D. A. (2011). Competition and product quality in the supermarket industry. The Quarterly Journal of Economics, 126(3):1539-1591.

Mazzeo, M. J. (2003). Competition and service quality in the US airline industry. Review of Industrial Organization, 22(4):275-296.

Munyo, I. and Rossi, M. A. (2013). Frustration, euphoria, and violent crime. Journal of Economic Behavior \& Organization, 89:136-142.

Nakajima, K., Saito, Y. U., and Uesugi, I. (2012). Measuring economic localization: Evidence from Japanese firm-level data. Journal of the Japanese and International Economies, $26(2): 201-220$. 
Netz, J. S. and Taylor, B. A. (2002). Maximum or minimum differentiation? location patterns of retail outlets. Review of Economics and Statistics, 84(1):162-175.

Ó hUallacháin, B. and Leslie, T. F. (2007). Producer services in the urban core and suburbs of Phoenix, Arizona. Urban Studies, 44(8):1581-1601.

Ó hUallacháin, B. and Leslie, T. F. (2009). Postindustrial manufacturing in a sunbelt metropolis: Where are factories located in Phoenix? Urban Geography, 30(8):898-926.

Ó hUallacháin, B. and Leslie, T. F. (2013). Spatial pattern and order in Sunbelt retailing: shopping in Phoenix in the twenty-first century. The Professional Geographer, 65(3):396420.

Ott, M., Cardie, C., and Hancock, J. (2012). Estimating the prevalence of deception in online review communities. In Proceedings of the 21st international conference on World Wide Web, pages 201-210. ACM.

Pantelidis, I. S. (2010). Electronic meal experience: A content analysis of online restaurant comments. Cornell Hospitality Quarterly, 51(4):483-491.

Parsa, H., Self, J. T., Njite, D., and King, T. (2005). Why restaurants fail. Cornell Hotel and Restaurant Administration Quarterly, 46(3):304-322.

Pawlowski, T., Nalbantis, G., and Coates, D. (2018). Perceived game uncertainty, suspense and the demand for sport. Economic Inquiry, 56(1):173-192.

Pennerstorfer, D. (2017). Can competition keep the restrooms clean? Price, quality and spatial competition. Regional Science and Urban Economics, 64:117-136.

Picone, G. A., Ridley, D. B., and Zandbergen, P. A. (2009). Distance decreases with differentiation: Strategic agglomeration by retailers. International Journal of Industrial Organization, 27(3):463-473.

Pope, D. G. and Schweitzer, M. E. (2011). Is Tiger Woods loss averse? Persistent bias in the face of experience, competition, and high stakes. American Economic Review, 101(1):129-57. 
Rees, D. I. and Schnepel, K. T. (2009). College football games and crime. Journal of Sports Economics, 10(1):68-87.

Rosenthal, S. S. and Strange, W. C. (2001). The determinants of agglomeration. Journal of Urban Economics, 50(2):191-229.

Salop, S. C. (1979). Monopolistic competition with outside goods. The Bell Journal of Economics, 64(1):141-156.

Sarmiento-Barbieril, I., Ge, Q., and Schneider, R. (2018). Emotional cues and crime: Spatial and temporal evidence from Brazilian soccer games. Unublished Manuscript.

Sauer, R. D. (1998). The economics of wagering markets. Journal of Economic Literature, 36(4):2021-2064.

Schuetz, J. and Green, R. K. (2014). Is the art market more bourgeois than bohemian? Journal of Regional Science, 54(2):273-303.

Schwarz, N., Strack, F., Kommer, D., and Wagner, D. (1987). Soccer, rooms, and the quality of your life: Mood effects on judgments of satisfaction with life in general and with specific domains. European Journal of Social Psychology, 17(1):69-79.

Schweitzer, K., Zillmann, D., Weaver, J. B., and Luttrell, E. S. (1992). Profile: Perception of threatening events in the emotional aftermath of a televised college football game. Journal of Broadcasting 8 Electronic Media, 36(1):75-82.

Silverman, B. W. (1986). Density estimation for statistics and data analysis, volume 26. CRC press.

Smart Growth America (2014). Measuring sprawl 2014. http://www.smartgrowthamerica. org/documents/measuring-sprawl-2014.pdf. Accessed May 5, 2017.

Smith, S. L. (1985). Location patterns of urban restaurants. Annals of Tourism Research, 12(4):581-602. 
Sveum, M. and Sykuta, M. (2017). The effect of franchising on establishment performance in the US restaurant industry. Cornell Hospitality Quarterly, pages 1-12.

Takahashi, T. (2013). Agglomeration in a city with choosy consumers under imperfect information. Journal of Urban Economics, 76:28-42.

The Daily Meal (2015). How do chain restaurants keep food so consistent across all locations. https://ww.thedailymeal.com/eat/ how-do-chain-restaurants-keep-food-so-consistent-across-all-locations. Accessed September 14, 2017.

The Onion (2016). New study finds most of earth's landmass will be phoenix suburb by 2050 . http://ww.theonion.com/article/ new-study-finds-most-earths-landmass-will-be-phoen-54107. Accessed May 5, 2017.

Walk Score (2016). Walk score- cities \& neighborhoods. https://www.walkscore.com/ cities-and-neighborhoods/. Accessed May 5, 2017.

Zheng, L. (2016). What city amenities matter in attracting smart people? Papers in Regional Science, 95(2):309-327.

Zhou, T. and Clapp, J. M. (2015). The location of new anchor stores within metropolitan areas. Regional Science and Urban Economics, 50:87-107. 